\title{
Essays on Sustainability and Poverty
}

\author{
Tianshu Li \\ Shenyang, China
}

Master of Economics, University of Tokyo, 2010

M.A. Economics, University of Virginia, 2012

A Dissertation presented to the Graduate Faculty of the University of Virginia in Candidacy for the Degree of Doctor of Philosophy

Department of Economics

University of Virginia

May, 2016 


\title{
UNIVERSITY OF VIRGINIA
}

\author{
Abstract \\ Department of Economics \\ Doctor of Philosophy \\ by Tianshu Li
}

The three chapters of my dissertation mainly study two related issues. Chapter 1 focuses on the sustainability problem concerning inter-generational welfare disparity, and Chapters 2 and 3 focus on the poverty problem concerning cross-sectional welfare disparity.

In Chapter 1, "Protecting the Breadbasket with Trees? The Effect of the Great Plains Shelterbelt Project on Agricultural Production", I empirically estimate the short- and long-term effects of planting windbreak trees on agricultural revenue by analyzing the Great Plains Shelterbelt Project implemented in 1935-1942 in the US. In order to address the endogeneity problem in the location choice of tree planting, I use a 100-mile-wide belt-shaped shelterbelt zone designated by the program as the instrument. My estimates show that a $10 \%$ increase in shelterbelt coverage in a county leads to a $7-10 \%$ increase in agricultural revenue. This increase is attributable to animal products rather than crops, and farmers in the treated counties were more likely to switch from cropland to pasture, especially for cattle ranching. In addition, I find heterogeneous effects by levels of soil erosion caused by the 1930s Dust Bowl. The regions with lower levels of soil erosion benefit from shelterbelts, whereas highly eroded regions do not.

In Chapter 2, "Poverty Targeting and Income Distribution: Evidence from China's National Designated Poor Counties", we study the impact of poverty targeting on household income using three natural experiments through adjustments in China's National Designated Poor Counties program between 1988 and 2008, in combination with agricultural promotion policies. With difference-in-difference analyses, we consistently find that when government publicity promoted agriculture, agricultural income of households in newly designated counties increased, while non-agricultural income declined. In addition, we examine the redistributive effects of the policy: an increase in agricultural income benefited the rich rather than the poor while a decline in non-agricultural income (mainly wage income) affected both the rich and the poor. More interestingly, once the designation ceased, people received less income from both agricultural and non-agricultural sources. Overall, this regional targeting policy led to an inter-sectoral 
distortion favoring agricultural production and provided no evidence that its policy package benefited the poorest households in the poor county.

In Chapter 3, "The Unintended Consequences of Employment-Based Safety Net Programs", we examine the consequences of increasing rural employment opportunities for the human capital accumulation of children in rural areas as employment guarantee program are widely used as an anti-poverty lever in the developing world. We evaluate the impact of India's flagship Mahatma Gandhi National Rural Employment Guarantee Scheme (MGNREGA) on school enrollment. We exploit the timing of roll-out of MGNREGA across Indian districts and find that introduction of MGNREGA results in lower relative enrollment in treated districts. Using nationally representative employment data, we find consistent evidence indicating an increase in child labor highlighting the unintentional perverse effects of the employment guarantee schemes. 


\section{Acknowledgements}

Pursuing a Ph.D. degree in economics has been an enlightening, inspiring, and challenging experience. As one of my most important accomplishment, it would not have been possible without the guidance, encouragement, and support from my advisors, family, and friends.

The exposure to economics that I received from Yasuyuki Sawada, Motoshige Itoh, and R. Anton Brown at the University of Tokyo has opened my door to this engaging field. Moreover, it is my advisors at the University of Virginia that have enlightened me with the thoughts, tools, and consciousness as an economist. Leora Friedberg provides me tirelessly advise and always had an open door when I needed help. Sheetal Sekhri entrusted me with many opportunities and has been a nurturing teacher to my academic career. Peter Debaere has helped me broaden my scope in viewing economic problems and provides fruitful collaboration and devoted mentorship. Jay Shimshack gives me altruistic help supporting my research and career, and I always cherish his insightful opinion and judgment. I also sincerely appreciate Molly Lipscomb, Sarah Turner, Heidi Schramm, Sisir Debnath, Sangui Wang, Kelsey Jack, Dennis Yang, Wallace Huffman, David Hennessy, Kathy Baylis, Ken Leonard, Albert Park, Xiaohuan Lan, as well as other professors and scholars who shared their wisdom over these years. In addition, I would like to thank the Research Center for Rural Economy in China for providing access to data. I am also grateful for financial support from the Center for International Studies, the Steer Family Endowed Fund, and the Department of Economics at the University of Virginia.

I am fortunate to have been through this process together with all my friends at the University of Virginia, including Xiuchang Yang, Ce Shi, Li Zhang, Scott Laughery, Tianying He, Xiaping Tang, Jimiao Du, Xian Zhou, Shuhui Chen, Xiaoyuan Wang, as well as many others that I met in Charlottesville. Their company has made the burden on the road seem much lighter.

I also appreciate a lifetime of encouragement and unabated support from my parents. Ultimately, it is my wife, Zhengzheng, who has stood by me throughout this process. Her love, comfort, and trust has kept me motivated and committed to my work and life. I dedicate this dissertation to her. 


\section{Contents}

Abstract $\quad$ i

Acknowledgements

List of Figures vi

List of Tables $\quad$ vii

1 Protecting the Breadbasket with Trees? The Effect of the Great Plains $\begin{array}{lr}\text { Shelterbelt Project on Agricultural Production } & 1\end{array}$

1.1 Introduction . . . . . . . . . . . . . . . . . . . 1

1.2 Contextual Information . . . . . . . . . . . . . . . 4

1.2.1 Background of the Program . . . . . . . . . . . . . . . . 4

1.2.2 Trade-offs of the Shelterbelts . . . . . . . . . . . . . 5

1.3 Conceptual Framework . . . . . . . . . . . . . . . . . . . . 6

1.4 Data . . . . . . . . . . . . . . . . . . . 7

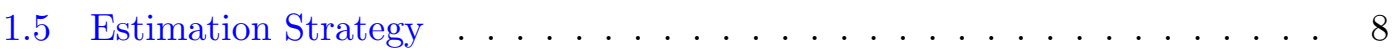

1.5.1 Endogeneity Concerns and the Instrumental Variable . . . . . . . 8

1.5.2 Validity of the Instrumental Variable . . . . . . . . . . . . . . 9

1.5.3 Estimation Procedure . . . . . . . . . . . . . . . . . . 10

1.6 Results . . . . . . . . . . . . . . . . . . . . . . . . 11

1.6.1 Main Results . . . . . . . . . . . . . . . . . . 11

1.6.2 Additional Results about Mechanisms . . . . . . . . . . . . . . 12

1.6.3 Results by Different Erosion Categories . . . . . . . . . . . . . . . 13

1.7 Robustness Checks . . . . . . . . . . . . . . . . . . . . . 14

1.7.1 The East and the West of the Shelterbelt Zone . . . . . . . . . . . 14

1.7.2 Alternative Channel: Labor and Capital Input . . . . . . . . . . . 15

1.7.3 Alternative Channel: Irrigation . . . . . . . . . . . . . . . 15

1.7.4 Alternative Channel: the Great Plains Conservation Program and Other Programs . . . . . . . . . . . . . . . 16

1.8 Conclusion . . . . . . . . . . . . . . . . . . . 17 
2 Poverty Targeting and Income Distribution: Evidence from China's National Designated Poor Counties (co-authored with Sangui Wang) $\quad 39$

2.1 Introduction . . . . . . . . . . . . . . . . . . . . . . . . . 39

2.2 Contextual Information . . . . . . . . . . . . . . . . . 42

2.2.1 Background of the Targeting Program . . . . . . . . . . . . 42

2.2.2 Criteria for the Designation of the Poor Counties . . . . . . . . . . 43

2.3 Model . . . . . . . . . . . . . . . . . . . . . . . . . . . . 44

2.4 Data . . . . . . . . . . . . . . . . . . . . . . 47

2.5 Estimation Strategy . . . . . . . . . . . . . . . . . . . . . . . . . . . . . . . . . . 48

2.5.1 Three Experiments and the Selection Problem . . . . . . . . . 48

2.5.2 Estimation Procedure . . . . . . . . . . . . . . . . 49

2.6 Results . . . . . . . . . . . . . . . . . . 50

2.6.1 Inter-sectoral Effect under the Experiments . . . . . . . . . . . 50

2.6.2 Within County Distributional Effect . . . . . . . . . . . . . 52

2.6.3 Overall Effect and the Effect of Political Background . . . . . . . . 53

2.7 Robustness Checks . . . . . . . . . . . . . . . . . . . 54

2.8 Conclusion . . . . . . . . . . . . . . . . . 56

3 The Unintended Consequences of Employment-Based Safety Net Programs

(co-authored with Sheetal Sekhri) $\quad \mathbf{7 4}$

3.1 Introduction . . . . . . . . . . . . . . . . . . . . . . 74

3.2 Contextual Information . . . . . . . . . . . . . . . 78

3.2.1 Background-National Rural Employment Guarantee Act . . . . . 78

3.2 .2 Roll-out of the MGNREGA Program . . . . . . . . . . . . . . . 79

3.3 Conceptual Framework . . . . . . . . . . . . . . . . . . . . . . 80

3.4 Data . . . . . . . . . . . . . . . . . . . 81

3.5 Estimation Strategy . . . . . . . . . . . . . . . . . . . . . . . . . . . . . . . . 82

3.5.1 Roll-out and Selection . . . . . . . . . . . . . . 83

3.5.2 Estimation Procedure . . . . . . . . . . . . . . . . . 84

3.6 Results . . . . . . . . . . . . . . . . . . 85

3.6.1 Overall Enrollment . . . . . . . . . . . . . . . . 85

3.6.2 Effects on Enrollment by Type of Schools . . . . . . . . . . . . . . . . 86

3.6.3 Schooling Outcomes . . . . . . . . . . . . . . . . . . 86

3.6 .4 Mechanisms . . . . . . . . . . . . . . . . . . 87

3.7 Robustness Checks and Sensitivity Analysis . . . . . . . . . . . . . . 88

3.8 Alternative Channels . . . . . . . . . . . . . . . . . . . . . . . . . . 89

3.8 .1 Other Programs . . . . . . . . . . . . . . . . . . 89

3.8.2 Growth and Demand for Private Schools . . . . . . . . . . . . . . 90

3.8.3 Migration and Population Changes . . . . . . . . . . . . . . 90

3.9 Caveats . . . . . . . . . . . . . . . . . . . . . . . . 91

3.10 Conclusion . . . . . . . . . . . . . . . . . . . . . . 91 


\section{List of Figures}

1.1 100-mile-wide Belt and Counties in Treatment and Control Groups . . . . 22

1.2 The Effect of Windbreaks on Wind Velocity . . . . . . . . . . . . . . . 23

1.3 An Example of Shelterbelt Planting . . . . . . . . . . . . . . . . . . 24

1.4 The Pre-treatment Trends for Agricultural Revenue per Acre . . . . . . . 25

1.5 The Location of the Ogallala Aquifer and the 100-mile-wide Belt . . . . . 26

1.6 Designated Counties under the Great Plains Conservation Program . . . . 27

2.1 Treated and Selected Control Counties in Experiment I . . . . . . . . . . 59

2.2 Treated and Selected Control Counties in Experiment II . . . . . . . . . . 60

2.3 Treated and Selected Control Counties in Experiment III . . . . . . . . . 61

3.1 Districts in Different Phases of NREGA . . . . . . . . . . . . . . 98

3.2 Total Enrollment by Phases . . . . . . . . . . . . . . . . . . . . . . . . . . . . 99

3.3 Total Number of Schools by Phases . . . . . . . . . . . . . . . . . . . . . . . . . . . . 99

3.4 Year Wise Impact . . . . . . . . . . . . . . . . . . . . . 100

3.5 Phase Wise Expansion in Different Types of Schools . . . . . . . . . . . 101 


\section{List of Tables}

1.1 Comparison of Treated and Control Counties in 1930 (weighted by farmland area) . . . . . . . . . . . . . . . . . . . 28

1.2 OLS and 2SLS Regression Results on Farm Revenue per Acre . . . . . . . 29

1.3 Effect of Shelterbelt-planting on Other Related Outcome Variables (2SLS) 30

1.4 Effect of Shelterbelt-planting on Major Crops and Livestock (2SLS) . . . 31

1.5 2SLS Regression Results on Farm Revenue by Soil-erosion Level . . . . . 32

1.6 East versus West on Farm Revenue per Acre: $\log$ (Total revenue per acre) 33

1.7 Effect of Shelterbelt-planting on Labor and Capital (2SLS) . . . . . . . . 34

1.8 Effect of Shelterbelt-planting and the Great Plains Conservation Program 35

1.9 Comparison of Treated and Control Counties in 1930 by Different Cutoff . 36

1.10 Effect of Shelterbelt-planting Comparing Counties along the Eastern Boundary of the Belt . . . . . . . . . . . . . . . 37

1.11 Effect of Shelterbelt-planting Comparing Counties along the Western Boundary of the Belt . . . . . . . . . . . . . . . . . 38

2.1 Summary Statistics by Treated and Control Groups . . . . . . . . . . . . 62

2.2 Seemingly Unrelated Regressions for NDP Counties on Agricultural and Self-employed Industrial Income . . . . . . . . . . . . . . . . 63

2.3 Seemingly Unrelated Regressions for NDP Counties on Agricultural and Non-agricultural Income . . . . . . . . . . . . . . . . . . . . . . 64

2.4 Quantile Regression Results for the Treatment in 1993: Newly Designated vs Never Designated . . . . . . . . . . . . . . . . . . 65

2.5 Quantile Regression Results for the Treatment in 2001: Newly Designated vs Never Designated . . . . . . . . . . . . . . . . 66 66

2.6 Quantile Regression Results for the Treatment in 2001: Ceased Designation vs Always Designated . . . . . . . . . . . . . . . . 6 67

2.7 Quantile Regression Results on Household Gross Income . . . . . . . . . . 68

2.8 OLS Regressions for Households with Political Background for the Treatment Groups of National Designated Poor Counties . . . . . . . . . . . . . 69

2.9 Seemingly Unrelated Regressions for Placebo Test I on Agricultural and Self-employed Industrial Income . . . . . . . . . . . . . . . . . 70

2.10 Seemingly Unrelated Regressions for Placebo Test I on Agricultural and Non-agricultural Income . . . . . . . . . . . . . . . . . 71

2.11 Seemingly Unrelated Regressions for Placebo Test II on Agricultural and Self-employed Industrial Income . . . . . . . . . . . . . . . . 72 
2.12 Seemingly Unrelated Regressions for Placebo Test II on Agricultural and Non-agricultural Income . . . . . . . . . . . . . . . . . . . . 73

3.1 Summary Statistics Outcome variables (All phases, all years) . . . . . . 102

3.2 Summary Statistics- Outcome Variables by NREGA Phases . . . . . . . . 103

3.3 Comparison of District Level Characteristics across NREGA Phases . . . 104

3.4 The Impact of Introduction of NREGA on Enrollment (2005-08) . . . . . 105

3.5 Heterogneous Impact of the Introduction of NREGA on Enrollment (2005-

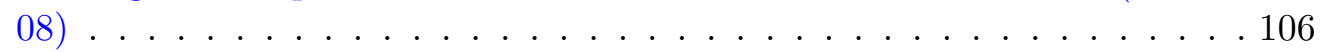

3.6 The Impact of the Introduction of NREGA on Performance Outcomes

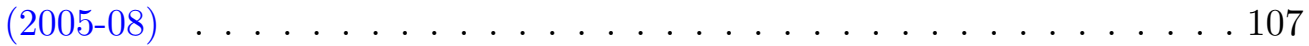

3.7 Linear Probability Regression Results on Child Labor (Age: 5 - 15) . . . 108

3.8 The Impact of the Introduction of NREGA on Enrollment (2005-08) Controlling Pre-trends from 2003 to 2005 . . . . . . . . . . . . . . . . . 109

3.9 Placebo Test for Child Labor Using Pre-period Data (Age: 5 - 15) . . . . 110

3.10 The Impact of Introduction of NREGA on Enrollment (2005-08) Excluding States for Which 2003-2005 Data Is Unavailable . . . . . . . . . . 111

3.11 Heterogeneous Impact of the Introduction of NREGA on Enrollment (2005-08) Excluding States for Which 2003-2005 Data Is Unavailable . . . 112

3.12 The Impact of the Introduction of NREGA on Additional Performance Outcomes $(2005-08) \ldots \ldots . \ldots \ldots 113$ 
Dedicated to Princess Sophie for her birthday and the 2nd anniversary of our marriage... 


\section{Chapter 1}

\section{Protecting the Breadbasket with Trees? The Effect of the Great Plains Shelterbelt Project on Agricultural Production}

\subsection{Introduction}

Wind erosion degrades the environment and is detrimental for agricultural production. It widely affects many arid and semi-arid areas and is a global policy concern (Toy, Foster, and Renard, 2002). One of the most famous examples, the 1930s American Dust Bowl, is estimated to have persistently decreased annual agricultural revenue and farmland value by $20-30 \%$ from the 1940s to the 1990s in highly eroded Great Plains areas in the US (Hornbeck, 2012). Historically, several countries including the United States and the Soviet Union used forestation as a strategy to counter the adverse effect of wind erosion. One such endeavor on a large scale, the Great Plains Shelterbelt Project was initiated by President Franklin D. Roosevelt in 1934. A total of 220 million trees were planted in the American Midwest at a cost of nearly $\$ 20$ million of federal and local investment from 1935 to 1942 (Droze, 1977). ${ }^{1}$ Similar projects are being undertaken today in many developing countries experiencing wind erosion, such as the Three North Shelterbelts

\footnotetext{
${ }^{1}$ Perry (1942) recorded that the gross federal expenditure was $\$ 13,882,419$, and estimated other local and individual donation and cooperation cost at about $\$ 5$ million.
} 
planned to cover the whole northern half of China and the Great Green Wall along the southern edge of the Sahara.

Agroforestry based benefits of shelterbelts include reducing wind velocity and windrelated damage, maintaining moisture in the soil, protecting livestock, and improving air quality and irrigation efficiency; on the other hand, potential harmful effects from shelterbelts include occupying arable land as well as sapping and shading effects that take away water and sunlight from the crops nearby even if properly maintained (Natural Resources Conservation Service, 2011). Thus, we do not know in practice whether shelterbelts are worth the investment. Existing scientific literature has only focused on determining the technological effects of shelterbelts from small scale field experiments, leaving a paucity of empirical evidence on the actual effects of shelterbelts on agricultural production. My paper sheds light on the efficacy of new programs promoting tree planting by assessing the short- and long-run economic consequences of one such program in the US, the Great Plains Shelterbelt Project.

In order to prevent the breadbasket of the US from detrimental effects of severe dust storms, President Roosevelt initiated this project in 1934 by planting windbreaks to protect farms in the Plains states. The United States Forest Service (USFS) proposed a shelterbelt zone forming a 100-mile-wide belt that stretched 1,150 miles from the Canadian border into northern Texas as shown in Figure 1.1 (Droze, 1977). This northto-south belt was determined by pushing as far westward as possible, considering the feasibility of climate and soil conditions. Figure 1.1 shows that a majority of the shelterbelts were planted within the proposed belt.

The location choice of tree planting is endogenous. For example, they may be planted where the opportunity cost of planting is low. To tackle this endogeneity problem, I use the historical variation arising from the 100-mile-wide Belt designated as a feasible shelterbelt zone in the Great Plains Shelterbelt Project as an instrumental variable to predict the actual region where shelterbelts were planted. The identifying assumption is that the proportion of a county included in the Belt was exogenous conditional on relevant climate and soil conditions.

The main data set I use is the US Census of Agriculture and Population from 1910 to 1992. This county-level panel on agricultural production allows me to evaluate the short- and long-term effects of the shelterbelts. In addition, I digitized the proportion of each county affected by the Great Plains Shelterbelt Project from the maps provided in USFS (1935) and Droze (1977) using Geographic Information Systems (GIS) tools. 
The information on soil erosion in the 1930s Dust Bowl is from Hornbeck (2012), and the information on the Ogallala Aquifer from Hornbeck and Keskin (2014).

My first-stage regression shows that counties within the 100-mile-wide Belt are nearly twice as likely to be covered by shelterbelts (or 14.9 percentage points higher in coverage) as the neighboring counties outside the Belt. The second-stage results show that a $10 \%$ increase in shelterbelt coverage in a county leads to a $7-10 \%$ increase in agricultural revenue in the long run. This increase is attributable to cattle ranching rather than crops, and farmers in the treated counties are more likely to switch from cropland to pasture. Therefore, the shelterbelts help to generate more agricultural surplus, although they are not literally protecting the bread in the basket, but animal products. In addition, I find heterogeneous effects by levels of soil erosion caused by the 1930s Dust Bowl. The regions with lower levels of soil erosion benefit from shelterbelts, whereas highly eroded regions do not. My estimates are robust when examining different subsamples and alternative channels that can potentially confound the main results, including other inputs, irrigation, and other related government programs.

To the best of knowledge, this paper is the first empirical evaluation of the long-term effects of a large-scale forestation program. One closely related literature is the evaluation of payments for ecosystem service (PES) programs, including Uchida, Rozelle, and Xu (2005, 2009), Xu et al (2006), and Jack (2013), etc. Different from the PES literature where the participation of ecosystem service programs is compensated, my paper focuses on evaluating the private benefit directly generated by the ecosystem service. Meanwhile, forests and trees have also drawn a lot of interest as outcome variables in the economics literature. Foster and Rosenzweig (2003) finds that an increase in the demand for forest products leads to more forestation. There is also a literature on deforestation and illegal logging, such as Deng et al (2011), Burgess et al (2012), and Baylis, Fullerton, and Shah (2015). In addition, two papers on agriculture in the Great Plains area are highly relevant to my research: Hornbeck (2012) evaluates the impact of soil erosion caused by the 1930s Dust Bowl and finds that it has persistent detrimental effects on agricultural production; and Hornbeck and Keskin (2014) examines the effects of the availability of groundwater irrigation from the Ogallala Aquifer.

The remainder of this article is organized as follows. In Section 1.2, I provide detailed information about the program and discuss all effects of shelterbelts from the scientific literature. Section 1.3 outlines a simple conceptual framework that captures the economic mechanism in planting shelterbelts. Section 1.4 provides an introduction of data used. Section 1.5 discusses the endogeneity problems in identifying the effects of 
planting shelterbelts and explains my empirical strategy to resolve these problems. Section 1.6 shows my results assessing the impact of sheltetbelts on various agricultural outcomes. Section 1.7 examines the robustness of my results by analyzing subsamples and by checking alternative channels. Section 1.8 provides an approximate cost-benefit analysis and offers concluding remarks.

\subsection{Contextual Information}

\subsubsection{Background of the Program}

In response to the most severe drought and wind erosion in the history of the Great Plaines area in 1932, the Great Plains Shelterbelt Project, or officially the Prairie States Forestry Project, was initiated by President Franklin D. Roosevelt in July 1934, aiming to substantially reduce the wind erosion in the region. After careful field survey and experiment, the United States Forest Service (USFS) published a formal report in 1935, which contains comprehensive details to guide the whole project (Droze, 1977). ${ }^{2}$ One of the most important issues settled in this report was the proposed region where the shelterbelts would be planted. The shelterbelt zone could not be placed too far to the west as the seedlings would die due to the lack of water. Neither could it go too far to the east as trees were less necessary. As a result, USFS (1935) advocates a 100-milewide belt stretching 1,150 miles from the Canadian border into northern Texas, totaling 114,700 square miles as shown in Figure 1.1. The western limit of the Belt was generally within the sufficient precipitation boundary (the blue line in Figure 1.1) accounting for varying evaporation from the north to the south. In addition, It was also acknowledged that some $56 \%$ of the proposed land area had desirable soil condition for shelterbelt planting while $5 \%$ was entirely unfit. Hence, the proposed Belt did not actually form continuous parallel strips of windbreaks, but "each planting must be adapted to the condition of each farm" (USFS, 1935).

Due to financial and legal difficulties, the project simply worked under cooperative agreements with land owners although the USFS initially wanted the federal government to directly acquire ownership of the land (Zon, 1935; Ballantyne, 1949). Participating farmers needed to prepare their land for planting in return for a shelterbelt, fences, and rodent control. Taking the opportunity cost of the land that the farmers sacrificed for

\footnotetext{
${ }^{2}$ This report is called Possibilities of Shelterbelt Planting in the Plains Region prepared by the Lake States Forest Experiment Station, United States Forest Service.
} 
tree planting into calculation, the project financed the participants roughly half of the entire costs for planting shelterbelts around their farms (Droze, 1977). Each contract was signed with the owner of individual farms, although it was made clear to the public that "the best results are obtained by grouping belts on a number of adjoining farms" (USFS, 1935).

The actual shelterbelt planting started from 1935, peaked in 1938, and eventually ceased in 1942 as funds were cut off after the United States entered World War II (Droze, 1977). Because USFS (1935) estimated that it would take about five years for newly-planted shelterbelts to grow high enough "to achieve some degree of effectiveness", one would expect the effect of the project appear after 1940. By 1942, 30,233 shelterbelts containing 220 million trees had been planted within the actual covered area shown in Figure 1.1 (Droze, 1977). One can see that most of the shelterbelts were planted within the 100mile-wide Belt with some exceptions. ${ }^{3}$ My estimation indicates that counties within the 100-mile-wide Belt are nearly twice as likely to be covered by shelterbelts (or 14.9 percentage points higher in coverage) as the neighboring counties outside the belt..

Another concern that may arise is the low survival rates of trees in the semi-arid Plains area. However, the USFS achieved a survival rate as high as $73 \%$ with over half the trees rated good or excellent while less than 5\% disappeared in 1954. Even until the 1970s, about $75 \%$ still remains in Oklahoma (Droze, 1977). Therefore, we can conclude that a majority of the shelterbelts still exist and are functioning after decades of the establishment.

\subsubsection{Trade-offs of the Shelterbelts}

Natural Resources Conservation Service (2011) lists the purpose for growing windbreaks as reducing soil erosion and wind related damage (such as windfall in orchards), protecting properties and livestock, and improving air quality and irrigation efficiency. Figure 1.2 illustrates how shelterbelts can reduce wind velocity. The protected zone extends 20 times height of the trees so the benefits are basically localized within each treated county. An example of shelterbelt planting and protected areas are shown in Figure 1.3. One can see that the effects of shelterbelt are actually quite localized. Moreover, in the literature of animal science, field experiment shows that providing shade to cattle improves their dry matter intake (DMI) by $6 \%$ and average daily gain (ADG) by $9 \%$ (Barajas, Garces,

\footnotetext{
${ }^{3}$ Some shelterbelts were planted in the Sand Hills country of the Nebraska Panhandle. In addition, Congress passed the Norris-Doxey Cooperative Farm Forestry Act which widened the shelterbelt zone to 200 miles on May 18, 1937, but couldn't provide additional funding (Wessel, 1969).
} 
and Zinn, 2013). Shade of the shelterbelts also help suppress heat stress, a problem that can reduce cow's milk production and increase their risk of lameness in dairy industry (Allen et al, 2013).(?)

On the other hand, potential harm can also be generated from shelterbelts. First of all, shelterbelts must unavoidably occupy some arable land. In practice, two major reasons for the destruction of shelterbelts are: freeing land for crop production and eliminating obstacles to sprinkle irrigation systems. Other problems may occur if the shelterbelts do not receive proper maintenance. For example, sapping and shading from the shelterbelts can take away water and sunlight from the crops nearby if the trees are not pruned and thinned periodically (Droze, 1977; NRCS, 2011). Therefore, one can see that most harm generated by shelterbelts mainly affects crops, but not livestock.

\subsection{Conceptual Framework}

Here, I present a simple model to show the mechanisms supporting my empirical analyses on responses to the shelterbelts. The effects described in the previous subsection suggest that shelterbelts cause differential shocks to the production of crops and animal products. Suppose a farm can allocate its land to produce two types of goods with different technologies, $X_{1}=F_{1}\left(\theta, A_{1}\right)$ and $X_{2}=F_{2}\left(1-\theta, A_{2}\right)$, where $\theta$ is the share of land allocated to produce Good 1 and $A_{i}$ measures the productivity producing Good $i$ for $\mathrm{i}=1$ or 2 . A farmer's objective function is to allocate land so as to maximize the total profit generated by the two goods:

$$
\operatorname{Max}_{\{\theta\}} \Pi\left(X_{1}, X_{2}\right)=\pi_{1}\left(\theta, A_{1}\right)+\pi_{2}\left(1-\theta, A_{2}\right),
$$

Assume the profit maximization problem leads to an interior solution so the farmer is always producing positive quantities of Goods 1 and $2{ }^{4}$ The first order condition of $\theta$ solves $\pi_{1}^{\prime}\left(\theta, A_{1}\right)-\pi_{2}^{\prime}\left(1-\theta, A_{2}\right)=0$. Let the initial equilibrium level of $\theta$ be $\bar{\theta}$ such that $\pi_{1}^{\prime}\left(\bar{\theta}, A_{1}\right)=\pi_{2}^{\prime}\left(1-\bar{\theta}, A_{2}\right)$.

\footnotetext{
${ }^{4}$ Possible corner solutions are that the farmer produces only Good 1 or only Good 2. With a technological shock favoring the production of Good 2, some farmers initially producing only Good 1 may be induced to move to an interior solution producing both of the goods; farmers initially producing only Good 2 will continue to stick to their corner solution. These two occasions will not change the qualitative outcomes of the model. Hence, to simplify the discussion, I only focus on the interior solution.
} 
Suppose there is a technology that improves the productivity of Good 2 (i.e. $A_{2}$ increases to $\left.\hat{A}_{2}\right) .{ }^{5}$ However, farmers need to pay a one-time fixed cost in order to adopt this technology. Because this is a period of hardship after a natural disaster, farmers facing liquidity constraints are less likely to adopt the technology without help from the government. The government decides to provide a subsidy to the farmers who want to adopt the technology as long as their farms are located within a designated zone, which is determined exogenously conditional on explicit criteria. Therefore, the farms within the designated zone are more likely to adopt this technology.

Once a farm adopts the technology, $A_{2}$ goes to $\hat{A}_{2}$, but assume that the adjustment of land allocation $(\theta)$ is also costly and cannot be done immediately after the adoption. Consequently, $\pi_{2}\left(1-\bar{\theta}, A_{2}\right)$ increases instantaneously to $\pi_{2}\left(1-\bar{\theta}, \hat{A_{2}}\right)$, but there is also a dead weight loss in total profit under this occasion because $\theta=\bar{\theta}$ is not the optimal level after adopting the new technology. Eventually, the farmer is able to adjust the land allocation to its new equilibrium level $\hat{\theta}$. This will lead to a further increase in total profit due to the efficiency gain comes from eliminating the dead weight loss when $\theta=\bar{\theta}$. After the adjustment of $\theta$ among the farmers whose farms are located within the designated zone, we are more likely to see an increase in $\pi_{2}$ as it goes to $\pi_{2}\left(1-\hat{\theta}, \hat{A}_{2}\right)$, as well as an increase in total profit.

\subsection{Data}

The main data set that I use is a county-level panel from the USDA Census of Agriculture and Population, which is collected decennially from 1910 to 1940 and approximately every five years from 1945 to 1992. Although most of the shelterbelts were planted in the late 1930s, most trees needed 5 years to "achieve some degree of effectiveness" (USFS, 1935). Thus, I have 3 waves of data until 1930 before the treatment occurred and 14 waves after although I do not expect to see any positive effect in $1940 .^{6}$

This data set contains detailed information on agriculture production and revenue. As for the information on the treatment, I constructed the data on the 100-mile-wide Belt and the actual planted regions of shelterbelts under the Great Plains Shelterbelt Project according to the maps provided by USFS (1935) and Droze (1977). I digitized the maps

\footnotetext{
${ }^{5}$ From the scientific literature, shelterbelts are likely to be improve the productivity of animal products but their effects on crops are ambiguous.

${ }^{6}$ Specifically, the years included are 1910, 1920, 1930, 1940, 1945, 1950, 1954, 1959, 1964, 1969, 1978, 1982,1987 , and 1992. There is another wave taken in 1974, but the main outcome variable, total farm revenue per acre, is not available.
} 
from the Forest Service's documentation and calculated the proportion of each county within the Belt as well as the shelterbelt planted region, as shown in Figure 1.1. The 100-mile-wide Belt ran from the Canadian border into northern Texas with occasional bends that shifted it to the east or west due to local geographic conditions. In addition, I utilize the county-level soil erosion data constructed by Hornbeck (2012) according to the Soil Conservation Service. The information on the Ogallala Aquifer is from Hornbeck and Keskin (2014) based on the United States Geological Survey, and the precipitation and temperature data come from the database at the University of Delaware.

Table 1.1 shows the summary statistics of the more and less (or not) treated counties in 1930, the baseline year. In this comparison, the more treated group consists of 117 counties whose area is covered by the 100-mile-wide Belt by over 50\%; the less (or not) treated group includes 117 counties with less than $50 \%$ covered by the Belt and the neighboring counties to the east and west of the Belt. ${ }^{7}$ From the table, the two groups were generally similar to each other in most variables. There is a mere 4 percentage point difference in the fraction of rural population although it is statistically significant at $95 \%$. In terms of land allocation for crops, the more treated counties planted slightly more cotton and less barley/oats/rye than the less treated counties. Despite statistical significance, the scale of these differences is not large either, leaving the only striking difference in shelterbelt coverage as shown in the first row. All the observations above are not sensitive to the arbitrary cutoff at $50 \%$. I show that the qualitative features do not change in Table 1.9 as I adjust the cutoff for more treated counties to be over $60 \%$ covered by the Belt and the cutoff for less (or not) treated counties to be less than $40 \%$ covered by the Belt. In my regression analyses, I will control for all these pre-treatment characteristics listed in Table 1.1 in order to account for differential initial conditions. The main outcome variable is the overall farmland productivity calculated from per acre total revenue. The pre-treatment status of the outcome variable is shown in Figure 1.4 with its discussion detailed in 1.5 .

\subsection{Estimation Strategy}

\subsubsection{Endogeneity Concerns and the Instrumental Variable}

I am interested in the effect of shelterbelt planting on agricultural production. It is difficult to empirically assess this effect because the decision concerning where to plant

\footnotetext{
${ }^{7}$ The same numbers of counties in the two groups are a coincidence.
} 
the trees is endogenous: Trees survive in natural conditions that are also favorable for other crops. Hence, simply comparing the areas with and without trees may lead to an upward bias. On the other hand, if farmers do not want to sacrifice their best land to grow trees, this could lead to a downward bias.

I use the geographical neighbors of counties covered by the 100-mile-wide Belt chosen by the Great Plains Shelterbelt Project as the control group. In the Plains area, geographically neighboring counties almost always have fairly similar natural conditions. Therefore, the concerns about the upward and downward biases mentioned above are mitigated. Moreover, I include county-fixed effect to purge out such differences. However, another concern that may potentially lead to downward bias still exists: Considering that this project was initiated in response to the crisis caused by the Dust Bowl, so the farmers who suffered more from the Dust Bowl were more likely to cooperate in planting shelterbelts. Therefore, an Ordinary Least Squares (OLS) estimation using the actual planted region of shelterbelts is expected to be downward-biased.

I adopt an Instrumental Variable (IV) method to address the endogeneity concerns above. The instrument that I use is the proportion of a county's area within the 100mile-wide Belt determined by the Great Plains Shelterbelt Project. In other words, I instrument the actual take-up of the treatment (the proportion of a county's area within the actual planted region of shelterbelts) with the eligibility measure (the proportion of a county's area within the proposed 100-mile-wide shelterbelt zone).

\subsubsection{Validity of the Instrumental Variable}

From Figure 1.1, a majority of the shelterbelts were planted within the 100-mile-wide Belt. Moreover, my estimates show that counties within the Belt are on average 14.9 percentage points higher in shelterbelt coverage and is statistically significant at $1 \%$ level. Thus, there is little doubt about the high correlation between the proportion covered by the Belt and the proportion actually covered by shelterbelts.

In order to establish that the exclusion restrictions are met, I focus on the determinants of selection. When policy makers determined the location of the 100-mile-wide Belt, they took three factors into account: adequate rainfall under local temperature, soil quality, and longitude. The first two factors ensured the trees' survival within the Belt while the third factor, longitude, was important in determining how far west they could go (Droze, 1977). These criteria are easily controlled with annual rainfall and temperature data as well as a county fixed effect. 
Conditional on these criteria, the proportion within the Belt is potentially a good instrument with one remaining concern that there are time varying characteristics of counties that matter for selection. ${ }^{8}$ I also account for this by controlling for differential trends for the proportion within and outside the shelterbelt zone. In Figure 1.3, I show that conditional on these control variables, the farmland productivity measured as per acre total revenue, establishes parallel pre-treatment trends.

\subsubsection{Estimation Procedure}

As stated in Section 1.4, the shelterbelts were planted from 1935 to 1942 with the peak year in 1938. However, the USFS (1935) says that it generally would take at least five years for the trees to become effective windbreaks. Hence, although I use $1910-30$ as pre-treatment years and 1940 - 92 as post-treatment years for the project, I do not expect to see much of the treatment effect right after the shelterbelts were planted in 1940. From 1940 to 1992 (i.e. $t>1930$ ), the first stage of my 2SLS regression is a cross-sectional regression for each year since 1940 and is estimated as follows:

$$
\text { PropShltrBlt }_{c}=\text { cont } .+\alpha \text { PropBelt }_{c}+\gamma \text { Erosion }_{c}+\delta \text { Control }_{c}+e_{c}
$$

where PropShltrBlt $t_{c}$ is the proportion of shelterbelt coverage in county $c$ under the project; PropBelt Pr the proportion of county $c$ within the 100-mile-wide Belt; Erosion $_{c}$ is the proportions of high- and medium-eroded regions in county $c$ in the 1930s (with the proportion of low-eroded regions as the baseline category); Control $_{c}$ is a whole set of control variables on pre-treatment characteristics in $1910-1930$, and $e_{c}$ is an idiosyncratic error term.

To estimate the time varying effect of PropShltrBlt $c$ on the annual county-level agricultural revenue, I need to interact all time invariant variables, PropShltrBlt , PropBelt $_{c}$, Erosion $_{c}$, and Control $_{c}$, with corresponding dummies for post years, 1(year $\left.=t\right)$. Hence, the baseline empirical model for my second stage estimation is

$$
Y_{c t}=\Sigma_{t \geq 1940} \beta_{t}\left\{\text { PropShltrBlt }_{c} * 1(\text { year }=t)\right\}+\theta \text { Control }_{c t}+F_{c}+T_{t}+\epsilon_{c t},
$$

\footnotetext{
${ }^{8}$ Figure 1.3 shows that the raw pre-treatment trends of total agricultural revenue for the treated and control groups. The treated group seems to have suffered more from the Great Depression in the 1920s. No official document that I know mentions that the policy makers in charge of the Great Plains Shelterbelt Project chose the area suffered more during the 1920 s, but it is clearly the fact from data.
} 
where $Y_{c t}$ is the outcome variable in county $c$ in year $t$; PropShltrBlt $t_{c}$ is instrumented

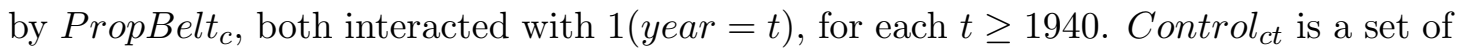
control variables including a treatment-specific pre-trend, and Erosion and $_{\text {Control }}$ defined in the first stage, both interacted with corresponding dummies for post years. $F_{c}$ is a set of county-fixed effects, $T_{t}$ a set of year-fixed effects, and $\epsilon_{c t}$ an idiosyncratic error term. Hence, the effects after the shelterbelts planted, $\beta_{t}$ for all $t \geq 1930$, are coefficients of interest.

In addition, I am also interested in the differential effects at various soil erosion levels. I take the sum of the proportions of high-eroded and medium-eroded regions during the Dust Bowl and categorized it into four quantiles: (1) Less than $16.83 \%$ (59 counties), (2) $16.83-58.18 \%$ (58 counties), (3) 58.18 - 99.9\% (58 counties), and (4) over 99.9\% (59 counties). The empirical model with the interaction terms is

$Y_{c t}=\Sigma_{t \geq 1940} \Sigma_{q=1,2,3,4}\left\{\beta_{q t}\right.$ PropShltrBlt ${ }_{c} *$ ErosionQuantiles $_{q c} * 1($ year $\left.=t)\right\}$ $+\theta_{t}$ Control $_{c t}+F_{c}+T_{t}+\epsilon_{c t}$,

where ErosionQuantiles $_{q c}$ is the indicator of erosion quantile $q$ for county $c$, for all $q=1,2,3$, or 4 . The coefficients of interest are $\beta_{q t}$, for all $q$ and $t>1930$.

To further investigate the mechanism behind the impact on agricultural revenue, I run similar regressions on other outcome variables including the revenue from crops and from livestock, the land allocation of cropland and pasture, yields of several major crops, the inventory of major livestock, the population, the value of farming equipments, and farmland area in each county.

\subsection{Results}

\subsubsection{Main Results}

The main results are shown in Table 1.2. The OLS regression in Column (1) shows the effects of shelterbelt coverage in a county on agricultural productivity in each time period. These coefficients are potentially downward biased because farmers in the counties that were affected more during the Dust Bowl should be more likely to cooperate in shelterbelt planting, as explained in Section 1.5. Even so, we can still see that the treated counties only exhibit negative and statistically significant effect from 1945 to the 1950s and recover in later decades when comparing with those in the control group. 
As stated in the previous section, I use an instrumental variable method to deal with endogeneity problem. The first stage of 2SLS regressions as shown in Column (5) indicates that the counties covered by the 100-mile-wide Belt are 14.9 percentage points higher in shelterbelt coverage than (or nearly twice as likely as) those not covered. This coefficent is statistically significant at $99 \%$, which gives me more confidence about the instrument.

Columns (2) - (4) indicate the baseline Two-stage Least Squares results with different control variables. In Column (2), I control for year- and county-fixed effects, treatmentspecific pre-trends, the outcome variable and other control variables listed in Table 1.1 in all pre-treatment years interacted with each post-decade dummy. The coefficients are positive and mean that a $10 \%$ increase in shelterbelt coverage leads to approximately a $9-12 \%$ increase in farmland productivity since the 1960s. ${ }^{9}$ Column (3) in addition controls for the soil erosion levels from the 1930s Dust Bowl, and the results do not change much from Column (2). This offers more confidence that my results are not driven by the recovery from the Dust Bowl. To address the concern about irrigation and the availability of water, I also control for the proportion of each county that is above the Ogallala Aquifer and show robust results in Column (4). I will discuss more about this point in Section 6.2 as an alternative channel.

Overall, these results suggest positive long-run effects of the shelterbelt on agricultural revenue. Next, I consider possible mechanisms driving these effects.

\subsubsection{Additional Results about Mechanisms}

In order to shed light on the mechanism behind the overall positive effect on agricultural productivity, I break down the total agricultural revenue into revenues from crops and animal products in Table 1.3, and further look into individual crops and livestock in Table 1.4. Note that the results from these outcome variables are not entirely comparable to the main results in Table 1.2 because a little less data are available. ${ }^{10}$

Columns (1) and (2) report the decomposition of the effects of shelterbelt coverage on total revenue per acre from crops and animal products, respectively. It is apparent that animal products are the main contributor to the positive effect of the project.

\footnotetext{
${ }^{9}$ The reason for the muted effect in the 1950 s is potentially due to the lag in costly adjustment of agricultural production, which will be detailed in the next subsection.

${ }^{10}$ The area of cropland and pasture was not reported before 1930, and I also have to interpolate to get data on pasture area in 1969 .
} 
Specifically, the effects in Column (2) are statistically significant from the 1950s on, with the scale of coefficients growing over time although imprecisely measured after 1978. On the other hand, Column (1) shows that the revenue from crops is not growing with higher shelterbelt coverage, potentially due to the negative effect from the sapping and shading effects of trees. However, I do not have data to explore this in detail. Column (3) indicates the effects of shelterbelt coverage on the fraction of cropland relative to the total area of cropland and pasture. The results show that the farmers in treated counties have switched from cropland to pasture since the 1950s with the fraction of pasture around 35 percentage points higher in treated counties since 1978, while Column (4) exhibits no statistically significant effect on overall farmland area in the treated counties.

Moreover, in Table 1.4, I look at the effects of shelterbelt-planting on several major crops and livestock. Columns (1)-(3) show the effects on the yields of wheat, corn, and hay, respectively. Overall, there is no positive and statistically significant effect for wheat and corn in Columns (1) and (2). In Column (3), the yield of hay shows an increase of around $6 \%$ from $10 \%$ shelterbelt coverage but it is only significant at a $10 \%$ level. In addition, I use the log of the numbers of cattle, pigs, and chickens in each county as the outcome variables in Columns (4)-(6). The number of cattle in the treated counties in Column (4) is about $10 \%$ higher than in the control counties since the 1960 s with a $10 \%$ higher coverage of shelterbelts. On the other hand, the numbers of pigs and chickens do not exhibit a robust and statistically significant increase in Columns (5) and (6).

To sum up, I can conclude that cattle are likely to be the main contributor to the positive effect on animal product from shelterbelt-planting. Compared with the main results in Table 1.2, the increase in per acre total revenue since the 1960s occurred after cropland started to be replaced by pasture since the 1950s as shown in Table 1.3. At the same time, the number of cattle started to be significantly higher in treated counties since the $1960 \mathrm{~s}$ as shown in Table 1.4. Similarly, hay production may rise in order to help feed the cattle. Therefore, from my findings, the shelterbelts do not automatically increase agricultural revenue. The farmers need to adjust their agricultural production by replacing cropland with pasture and raise more cattle in order to adapt to the environment with more trees.

\subsubsection{Results by Different Erosion Categories}

I also examine the responsiveness to shelterbelts depending on the prior soil erosion level. The 2SLS regression results are shown in Table 1.5 by four quantiles of soil erosion 
caused by the 1930s Dust Bowl. From Columns (1)-(4), the statistically significant effects appear in the two lower quantiles, especially in Column (2), where $16.83-58.18 \%$ of land is high- or medium-eroded. Although the coefficients are also positive in the two higher quantiles in Columns (3) and (4), they are not statistically significant. In conclusion, the positive effect from growing shelterbelts is mainly contributed by the area experiencing less severe soil erosion. Growing shelterbelts may not be as helpful if a region has already suffered from severe soil erosion.

\subsection{Robustness Checks}

\subsubsection{The East and the West of the Shelterbelt Zone}

One may be concerned that some geographic feature to the east or the west of the shelterbelt zone is causing the effects so the results in the previous section are only driven by one side of the shelterbelt zone. In particular, considering that the prevailing winds in the Great Plains area generally bring dry air masses from the west to the east, the counties to the west can be more likely to suffer from drought (Leathers, 2011).

To address this concern about the robustness of my main results, I divide the treatment and control groups into the eastern half and the western half in the 100-mile-wide Belt and show the regression results in Table 1.6. Column (1) copies the baseline results in Table 1.2 for comparison purposes. Column (2) compares the more treated counties in the eastern half of the Belt with control counties to the east. The treated counties show a statistically significant $8-14 \%$ increase with a $10 \%$ increase in shelterbelt coverage, although the first stage effect is only statistically significant at $10 \%$. This results help me rule out the possibility that prevailing winds from the west may be driving my main results. If my results were indeed driven by prevailing winds, then the more treated counties in the eastern half the Belt in this column, which are located more westwards than the less treated counties to the east of the Belt, should have suffered more from the dry air masses from the west. However, Column (2) proves that this is not what happens.

On the other hand, when comparing the counties in the western half with control counties to the west in Columns (3), the coefficients exhibit larger effects than in Column (2) and are mostly significant at 5-10\% levels. Overall, these two columns mean the results are robust and are not solely driven by the counties on one side of the shelterbelt 
zone. In addition, I show that the main results are robust when comparing the counties along the eastern and western boundaries of the shelterbelt zone in Tables1.10 and 1.11, respectively.

\subsubsection{Alternative Channel: Labor and Capital Input}

Table 1.7 shows some additional checks related to labor and capital inputs. ${ }^{11}$ From Columns (1) and (2), the shelterbelts do not cause significantly different growth in total population or rural population. Hence, the baseline results in Table 1.2 showing a persistent increase in agricultural revenue in treated counties are not likely to be either caused by migration or an increase in labor inputs. Meanwhile, the muted results in Column (3) indicate that the value of farming equipment per acre in the treated counties is not significantly higher than the control counties so the increase in agricultural revenue is not driven by more investment in equipment either.

\subsubsection{Alternative Channel: Irrigation}

The availability of water can be a factor that potentially confound the main results. On the one hand, planting shelterbelts can be more feasible in the area where more water is available, which may lead to an overestimation of the actual effect of shelterbelts elsewhere. On the other hand, irrigation directly ensures sufficient water in the soil so the shelterbelts' benefit of containing moisture in the soil can be compromised.

Surface water has been used for irrigation for over a hundred years in this area so the effect of its availability can be absorbed by a county-fixed effect. However, one potential concern is from the availability of groundwater because large-scale groundwater use in agriculture was enabled by the adoption of new irrigation technology since the 1950s, which is after the shelterbelts were planted. Meanwhile, another difficulty is that the adoption of irrigation technology is an endogenous decision for farmers, so I need to find an arguably exogenous proxy for irrigation to do the analysis. Hornbeck and Keskin (2014) provide suitable variation. The Ogallala Aquifer is the most important water source for irrigation in the Great Plains area, and Hornbeck and Keskin (2014) shows that irrigated farmland area has been significantly higher in the counties above the aquifer since the 1950s. The geographic coverage of the Ogallala Aquifer from the

\footnotetext{
${ }^{11}$ Population data are only available decennially. Data on the value of equipment is missing in the 1950 s, 1964, and the 1980 s
} 
US Geological Survey is shown in Figure 1.5. In Table 1.1, I show that the coverage of the Ogallala Aquifer is not statistically different for the treated and control counties. Moreover, my main results are robust after controlling for the proportion above the aquifer as shown in Table 1.2. Therefore, the adoption of groundwater irrigation technology during the period is not likely to be the channel driving my main results.

\subsubsection{Alternative Channel: the Great Plains Conservation Program and Other Programs}

Multiple conservation programs were implemented by the Soil Conservation Service (currently the Natural Resources Conservation Service) and other agencies under the United States Department of Agriculture, including the Soil Bank Program (1956-1973) and the Agricultural Conservation Program (1936-1996). ${ }^{12}$ Considering the mechanism and the geographic coverage of the programs, an important one that requires special attention is the Great Plains Conservation Program (currently replaced by the Environmental Quality Incentive Program).

Under the Great Plains Conservation Program (GPCP), the Soil Conservation Service provided cost sharing and technical assistance for various conservation practices including reseeding of grassland, erosion-control dam and windbreaks (Soil Conservation Service, 1982). This program was approved in 1956 with its first contract signed in 1957, and 519 counties were designated by 1982 as shown in Figure 1.6 (Helms, 1981; Soil Conservation Service, 1982). Hence, my main conclusion can be threatened if the increases in pasture land and the number of cattle since the 1950s shown in Tables 3 and 4 are driven by this program. I test this possibility formally by using spatial and temporal variation of the GPCP.

From Figure 1.6, the designation of GPCP covers almost of all the counties in my sample. For the counties with over $50 \%$ covered by the shelterbelt zone, the proportion with the GPCP designation is $91.45 \%$; for those with less than $50 \%$ covered, the proportion is

\footnotetext{
${ }^{12}$ The Soil Bank initiated by the Agricultural Act of 1956 were designed to reduce production of basic crops, maintaining farm income, and conserving soil. It includes two components: the Acreage Reserve Program implemented 1956-1958 for the immediate reduction of basic crops and the Conservation Reserve Program for an enduring reduction in cropland acreage. The signing of new contracts for the later component ceased in 1960 although payments continued until 1973. A contemporary version of the program is simply called the Conservation Reserve Program which started in 1985 (Helms, 1985). The Agricultural Conservation Program administered by the Farm Service Agency offered cost-sharing and technical support to farmers who adopt approved land conservation practices (such as practices to increase the efficiency of fertilizer and pesticide use). This program was replaced by the Environmental Quality Incentive Program under the terms of the 1996 Farm Bill (National Center for Environmental Economics, 2015).
} 
79.49\%. This difference between the two groups is statistically significant. To alleviate the concern that this difference is not driving my main results, I test the robustness for all my main outcome variables controlling for the GPCP designation status interacted with dummies for all years after 1957 in Table 1.8. To separate the effects before and after the implementation of the GPCP, I show coefficients for the proportion protected by shelterbelts in 1954 and those in later years in different rows. One can see from Columns (3) and (4) that the revenue from animal products increased and the share of cropland dropped in 1954 before the GPCP was initiated. Meanwhile, even after the GPCP was initiated, the effects from 1959 to 1992 in the two columns are still robust after controlling the designation of GPCP. Hence, across all the columns in Table 1.8, the qualitative results are basically consistent with those in the previous tables. The GPCP may be a factor enhancing the effects from shelterbelts but the main driver is still the mechanism as explained in Section 1.6.

\subsection{Conclusion}

My paper empirically estimates the short- and long-term effects of windbreak planting on agricultural revenue under the the Great Plains Shelterbelt Project. In order to address the endogeneity problem in the location choice of tree-planting, I use a 100mile-wide belt-shaped shelterbelt zone designated by the program as the instrument. Counties within the Belt are nearly twice as likely to be covered by shelterbelts as their neighboring counties outside the Belt with a confidence interval over 99\%. Meanwhile, this instrument is also arguably exogenous conditional on covariates. My estimates show that a $10 \%$ increase in shelterbelt coverage in a county leads to a $7-10 \%$ increase in agricultural productivity. This increase is attributable to animal products rather than crops, and farmers in the treated counties are more likely to switch from cropland to pasture, especially cattle raising. In addition, I find heterogeneous effects by levels of soil erosion caused by the 1930s Dust Bowl. The regions with lower levels of soil erosion benefit from shelterbelts, whereas highly eroded regions do not.

From a rough cost-benefit analysis, I find that the $\$ 20$ million of federal and local investment in the program in 1940 leads to on average $\$ 39$ million increase in annual agricultural revenue from 1940 to 1992 (at the 1940 price level and assuming 0.95 discount rate). I do not observe the maintenance cost of the shelterbelts paid by participating farmers after the program ends in 1942 as well as the adjustment cost in production and land allocation so the amount of investment given above marks a lower bound for 
the overall cost. However, an average annual benefit of $\$ 39$ million still indicates the great success of the program. This is not only meaningful for understanding the effect of shelterbelts on the Great Plains, but also for sustaining the financial viability of ongoing large scale project in other arid or semi-arid regions in the world, such as the Three-North Shelter Forest in China and the Great Green Wall in the Sahara. Thus, the findings can also be helpful from public finance point of view. Another issue worth noticing is that the benefit from the shelterbelts only started to appear after the farmers in treated area adjusted their land and production allocation. This means the policy makers should provide more information and support to help the farmers to adapt to an agricultural environment with the protection of shelterbelt. 


\section{Bibliography}

Allen, J.D., S.D. Anderson, R.J. Collier, and J.F. Smith (2013), "Managing Heat Stress and Its Impact on Cow Behavior", Western Dairy Management Conference.

Ballantyne, John N. (1949), "The Prairie States Shelterbelt Project", Master's thesis, Yale University.

Barajas, R., P. Garces, and R. A. Zinn (2013), "Interactions of shade and feeding management on feedlot performance of crossbred steers during seasonal periods of high ambient temperature", The Professional Animal Scientist, Vol. 29, pp. 645-651.

Baylis, Kathy, Don Fullerton, and Payal Shah (2015), 'What Drives Forest Leakage?", Working Paper, University of Illinois at Urbana-Champaign.

Burgess, Robin, Matthew Hansen, Benjamin A. Olken, Peter Potapov, and Stefanie Sieber (2012), "The Political Economy of deforestation in the Tropics", The Quarterly Journal of Economics, Oct 2012, pp. 1707-1754.

Deng, Xiangzheng, Jikun Huang, Emi Uchida, Scott Rozelle, John Gibson (2011), "Pressure cookers or pressure valves: Do roads lead to deforestation in China?", Journal of Environmental Economics and Management, Vol. 61, pp. 79-94.

Droze, Wilmon H. (1977), Trees, Prairies, and People: A History of Tree Planting in the Plains States, Denton, TX: Texas Woman's University.

Foster, Andrew D. and Mark R. Rosenzweig (2003), "Economic Growth and the Rise of Forests", The Quarterly Journal of Economics, Vol. 118, No. 2 (May, 2003), pp. 601-637.

Helms, J. Douglas (1981), "Great Plains Conservation Program, 1956-1981", Great Plains Conservation Program: 25 Years of Accomplishment, SCS National Bulletin Number 300-2-7. November 24, 1981. Retrieved from http://www.nrcs.usda.gov/ wps/portal/nrcs/detail/national/about/history/?cid=nrcs143_021382.

Helms, J. Douglas (1985), Brief History of the USDA Soil Bank Program, NRCS Historical Insights Number 1, Original Issue January 1985. Retrieved from http://www. nrcs . usda.gov/Internet/FSE_DOCUMENTS/stelprdb1045666.pdf.

Hornbeck, Richard (2012), "The Enduring Impact of the American Dust Bowl: Shortand Long-Run Adjustments to Environmental Catastrophe", American Economic Review, Vol. 102, No. 4, pp. 1477-1507. 
Hornbeck, Richard and Pinar Keskin (2014), "The Historically Evolving Impact of the Ogallala Aquifer: Agricultural Adaptation to Groundwater and Drought", American Economic Journal: Applied Economics, Vol. 6, No. 1, pp. 190-219.

Jack, Kelsey (2013), "Private Information and the Allocation of Land Use Subsidies in Malawi", American Economic Journal: Applied Economics, Vol. 5, No. 3, pp. 113-135.

Lake States Forest Experiment Station, United States Forest Service (1935), Possibilities of Shelterbelt Planting in the Plains Region, Washington: United States Government Printing Office.

Lang, James B. (1970), "The Shelterbelt Project in the Southern Great Plains-19341970-A Geographic Appraisal", Master's thesis, University of Oklahoma.

Leathers, Daniel J. (2011), "Encyclopedia of the Great Plains: Climate", University of Nebraska, Lincoln. Retrieved from http://plainshumanities.unl.edu/encyclopedia/ doc/egp.pe.019.

Mader, Terry L., J. M. Dahlquist, G. L. Hahn and J. B. Gaughan (1999), "Shade and wind barrier effects on summertime feedlot cattle performance", Journal of Animal Science, Vol. 77, pp. 2065-2072.

Munns, E.N. and J. H. Stoeckeler (1946), "How Are the Great Plains Shelterbelts", Journal of Forestry, Vol. 237.

National Center for Environmental Economics (2015), Economic Incentives for Pollution Control: 7.4.3. Agricultural Conservation Program. Retrieved from http://yosemite. epa.gov/ee/epa/eed.nsf/fa6512c6e51c4a208525766200639df2/e66918a9e140d8a785257746000af OpenDocument.

Natural Resources Conservation Service (2011), Conservation Practice Standard: Windbeak / Shelterbelt Establishment, Code 380, May 2011. Retrieved from http://www . nrcs.usda.gov/Internet/FSE_DOCUMENTS/stelprdb1046943.pdf.

Perry, E.L. (1942), History of the Prairie States Forestry Project, U.S. Department of Agriculture, Forest Service.

Prairie States Forestry Project (1937), Forestry for the Great Plains, National Archives Record Group 114, Lincoln, Nebraska.

Soil Conservation Service (1982), The Great Plains conservation program, Washington, D.C.: U.S. Dept. of Agriculture. 
Toy, Terrence J., George R. Foster, and Kenneth G. Renard (2002), Soil erosion : processes, prediction, measurement, and control, New York, NY: Wiley.

Uchida, Emi, Scott Rozelle, and Jintao Xu (2009), "Conservation Payments, Liquidity Constraints, and Off-Farm Labor: Impact of the Grain-for-Green Program on Rural Households in China", American Journal of Agricultural Economics, Vol. 91, No. 1, pp. $70-86$.

Uchida, Emi, Jintao Xu, and Scott Rozelle (2005), "Grain for Green: Cost-Effectiveness and Sustainability of China's Conservation Set-Aside", Land Economics, Vol. 81, pp. 247-264.

Wessel, Thomas R. (1969), "Roosevelt and the Great Plains Shelterbelt", Great Plains Journal, Vol. 8, Spring 1969.

Xu, Zhigang, Jintao Xu, Xiangzheng Deng, Jikun Huang, Emi Uchida, and Scott Rozelle (2006), "Grain for Green versus Grain: Conflict between Food Security and Conservation Set-Aside in China", World Development, Vol. 34, No. 1, pp. 130-148.

Zon, Raphael (1935), "Shelterbelts-Futile Dream or Workable Plan", Science, Vol. 81, April 26, 1935. 
Figure 1.1: 100-mile-wide Belt and Counties in Treatment and Control Groups

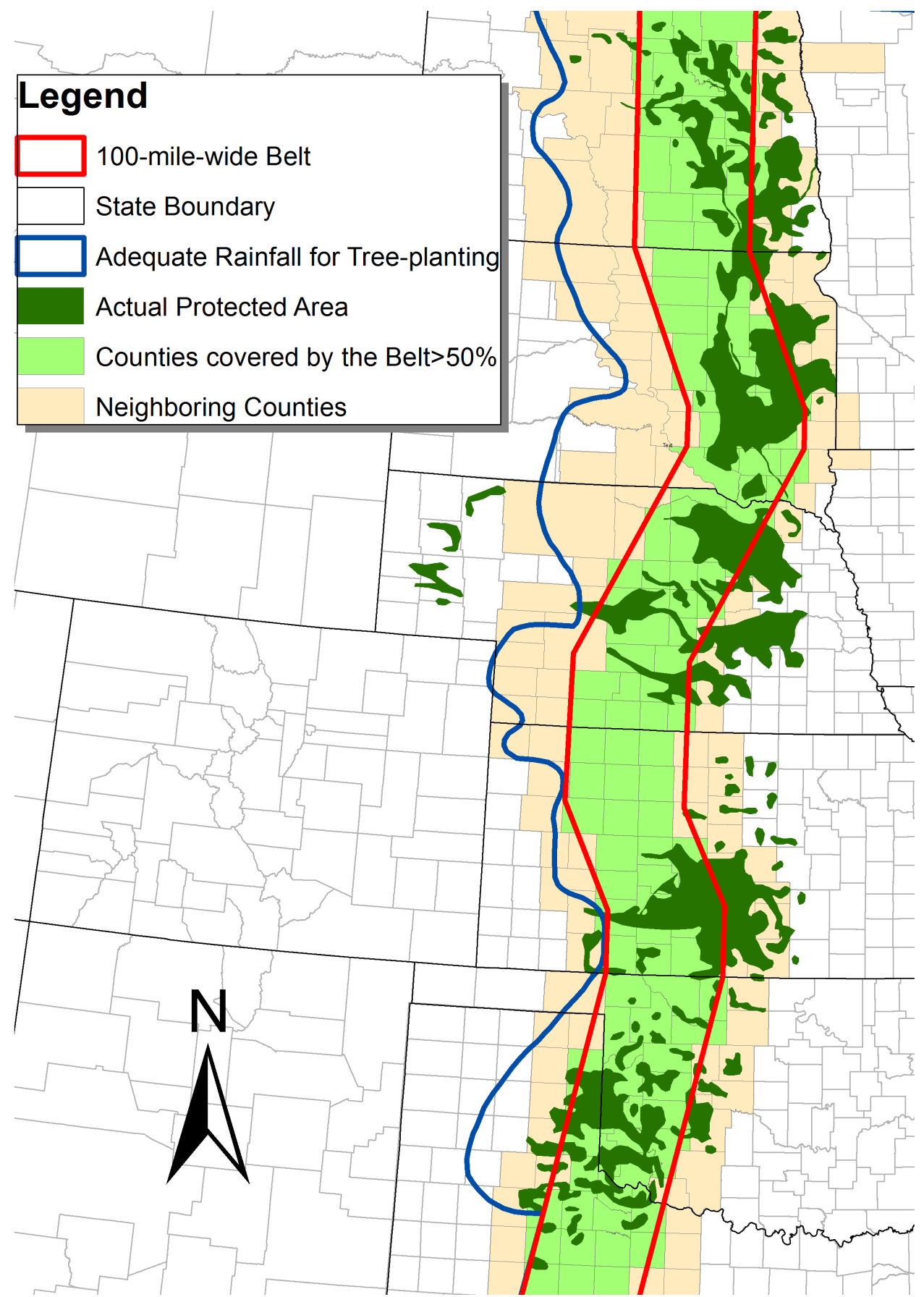

Source: US Forest Service; digitized from "Trees, Prairies, and People: A History of Tree Planting in the Plains States" by Wilmon Henry Droze (1977) 
Figure 1.2: The Effect of Windbreaks on Wind Velocity
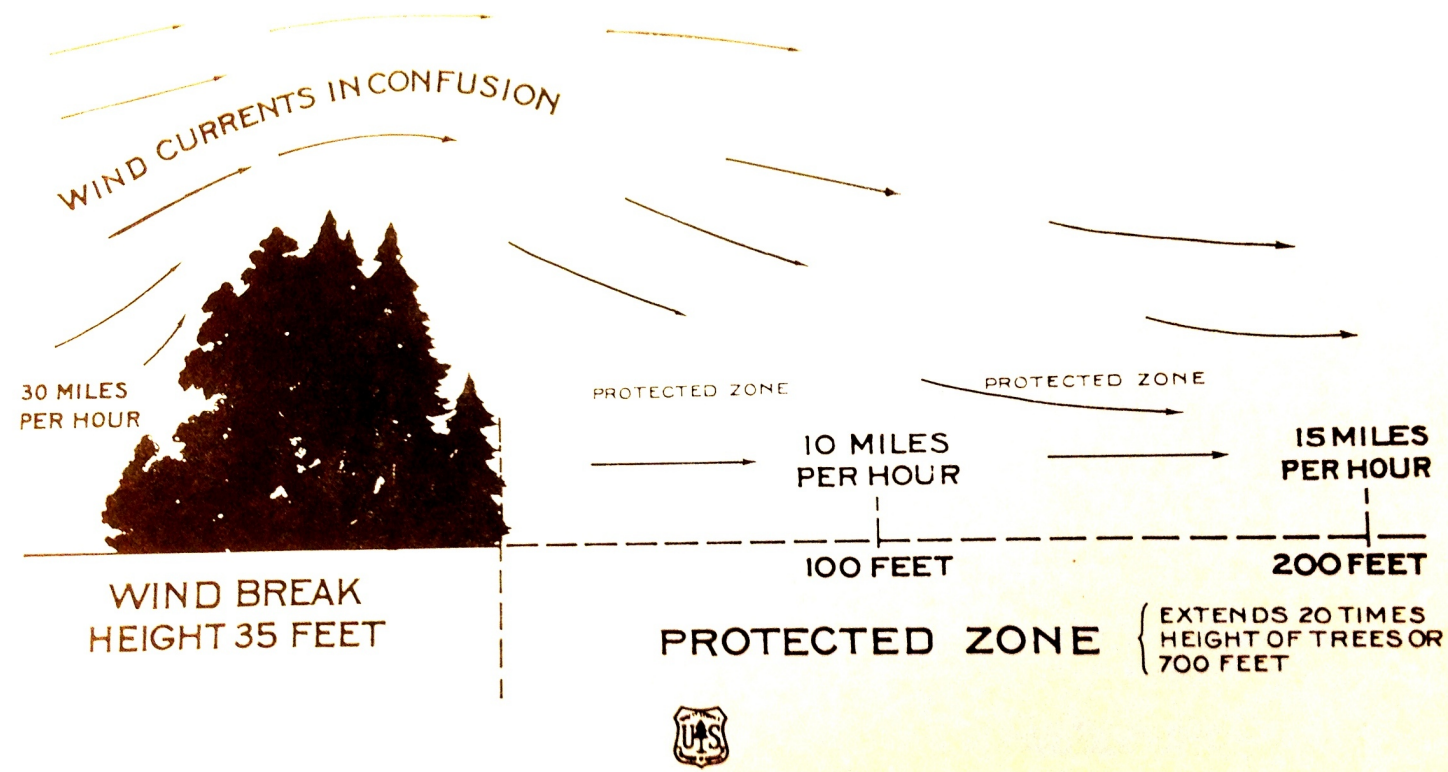

U.S. FOREST SERVICE

(hart showng effects of shelterbelts on wind velocity. Courtesy of U.S. Forest Service.

Source: US Forest Service; "Trees, Prairies, and People: A History of Tree Planting in the Plains States" by Wilmon Henry Droze (1977) 
Figure 1.3: An Example of Shelterbelt Planting

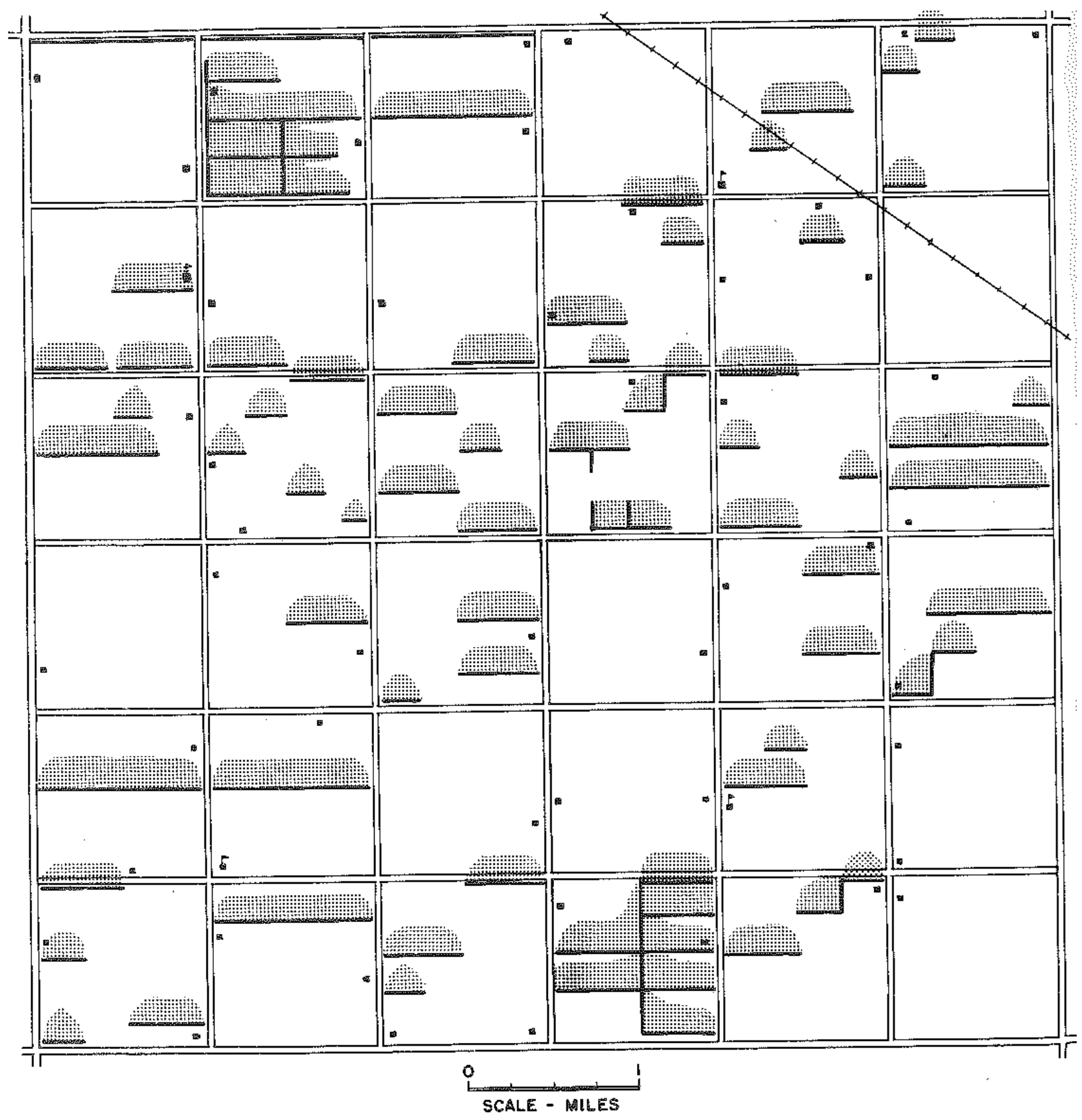

NOTE: Shaded areas show protected zone where wind velocity is reduced by $50 \%$, assuming due south wind and 50 feet effective height.

Source: US Forest Service; "Trees, Prairies, and People: A History of Tree Planting in the Plains States" by Wilmon Henry Droze (1977) 
FiguRE 1.4: The Pre-treatment Trends for Agricultural Revenue per Acre

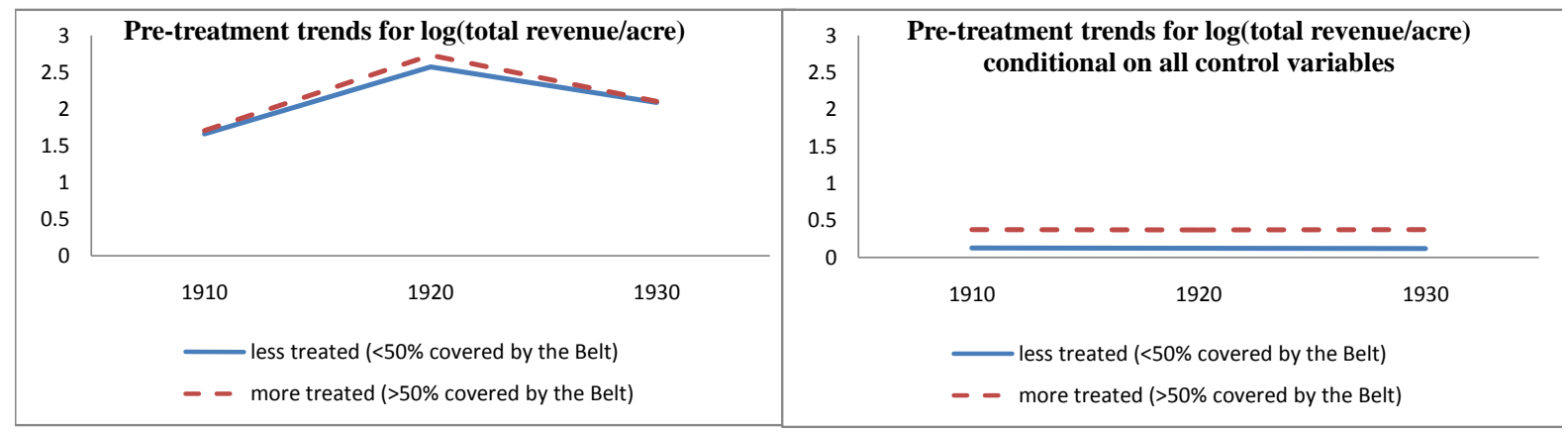

Note: All control variables used in the graph to the right include the list of control variables reported Table 1.1 and the outcome variables from 1910-30 interacted with the year dummies, the treatmentspecific pre-trends, the county-, and year-fixed effects. 
Figure 1.5: The Location of the Ogallala Aquifer and the 100-mile-wide Belt

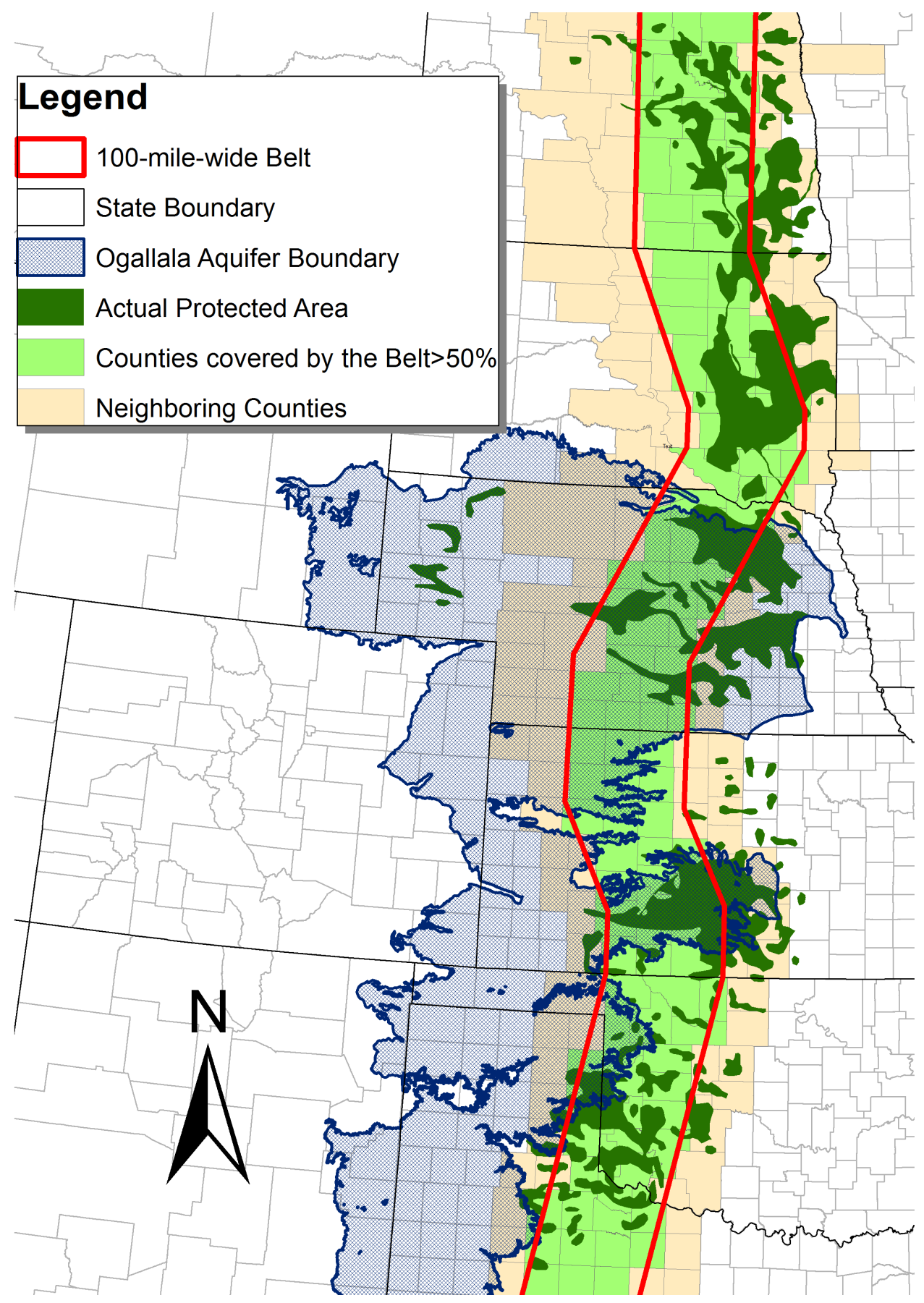

Source: US Geological Survey and US Forest Service. 
Figure 1.6: Designated Counties under the Great Plains Conservation Program

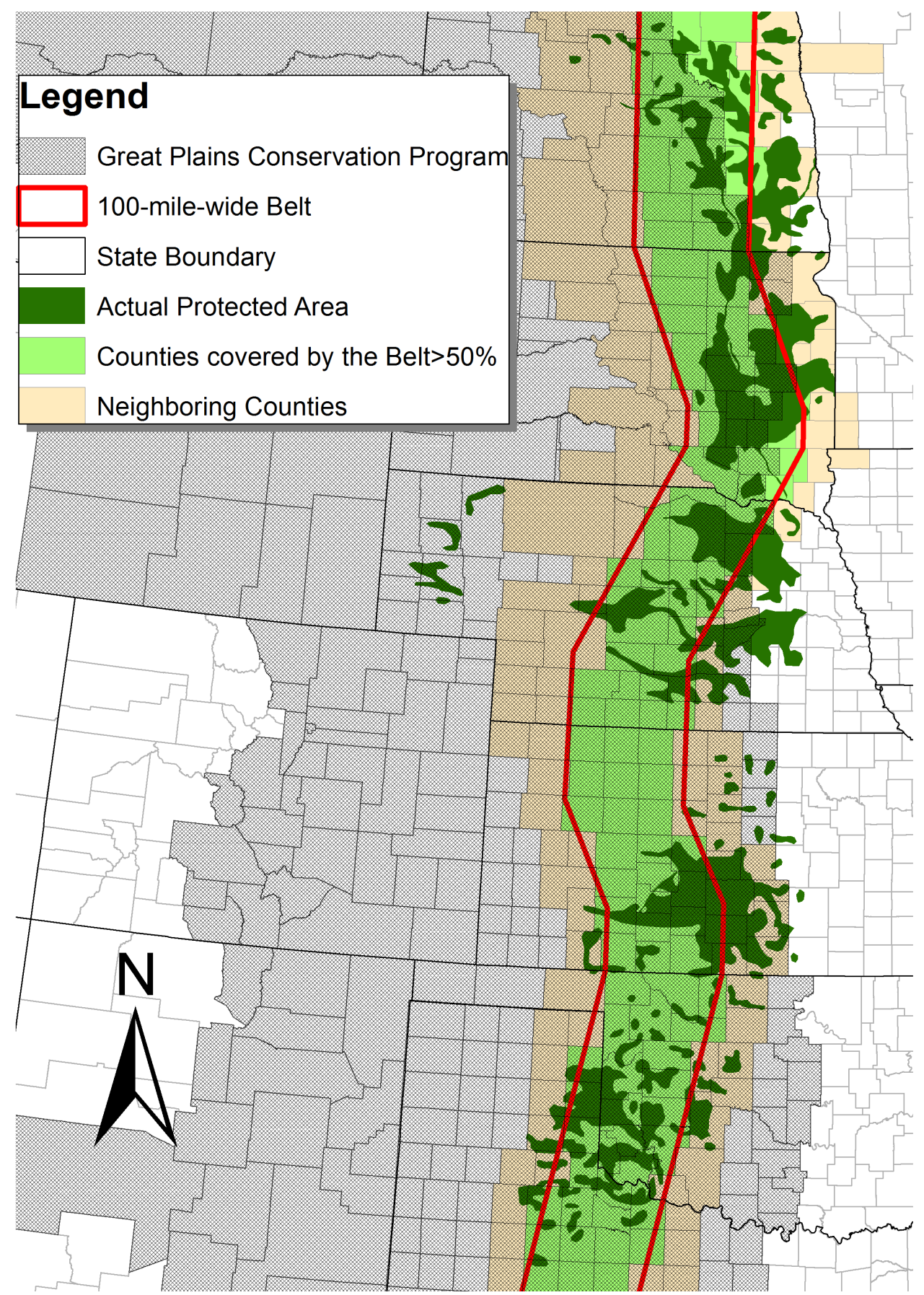

Source: "The Great Plains conservation program", Washington, D.C.: U.S. Dept. of Agriculture, Soil Conservation Service, [1982]; US Forest Service. 
TABle 1.1: Comparison of Treated and Control Counties in 1930 (weighted by farmland area)

\begin{tabular}{|c|c|c|c|c|c|c|c|}
\hline \multirow[b]{2}{*}{ Variables } & \multicolumn{3}{|c|}{$\begin{array}{c}\text { More Treated } \\
\text { Proportion within 100-mile-wide } \\
\text { Belt }>50 \%\end{array}$} & \multicolumn{3}{|c|}{$\begin{array}{c}\text { Less (or not) Treated } \\
\text { Proportion within 100-mile-wide } \\
\text { Belt }<50 \%\end{array}$} & \multirow[b]{2}{*}{ Difference } \\
\hline & Obs & Mean & s.d. & Obs & Mean & $\overline{\text { s.d. }}$ & \\
\hline $\begin{array}{l}\text { Proportion in planted area } \\
\text { Other Right-hand-side Variables: }\end{array}$ & 117 & 0.30 & 0.28 & 117 & 0.19 & 0.28 & $0.11 *$ \\
\hline Proportion mediumly-eroded & 117 & 0.41 & 0.35 & 117 & 0.38 & 0.35 & 0.03 \\
\hline Proportion highly-eroded & 117 & 0.20 & 0.32 & 117 & 0.13 & 0.26 & 0.07 \\
\hline Proportion above the Ogallala Aquifer & 117 & 0.32 & 0.42 & 117 & 0.37 & 0.45 & -0.05 \\
\hline Total precipitation in recent two years $(\mathrm{mm})$ & 117 & $1,114.28$ & 166.05 & 117 & $1,118.22$ & 239.92 & -3.94 \\
\hline Avg temperature in recent two years $\left({ }^{\circ} \mathrm{C}\right)$ & 117 & 10.51 & 4.35 & 117 & 9.82 & 3.99 & 0.69 \\
\hline Farmland/County area & 117 & 0.91 & 0.07 & 117 & 0.89 & 0.09 & 0.02 \\
\hline Woodland/County area & 117 & 0.01 & 0.02 & 117 & 0.02 & 0.04 & -0.01 \\
\hline Cropland/Farmland & 117 & 0.58 & 0.17 & 117 & 0.57 & 0.18 & 0.00 \\
\hline Population per 1000 Acre & 117 & 21.22 & 11.38 & 117 & 26.15 & 29.24 & -4.93 \\
\hline Fraction of rural population & 117 & 0.90 & 0.16 & 117 & 0.86 & 0.22 & 0.04 \\
\hline Fraction of farming population & 117 & 0.62 & 0.11 & 117 & 0.58 & 0.16 & $0.04 *$ \\
\hline No. of farms/1000 Acre & 117 & 2.64 & 1.23 & 117 & 2.63 & 1.50 & 0.01 \\
\hline Avg Farm Size (in Acre) & 117 & 443.19 & 323.11 & 117 & 508.53 & 460.90 & -65.33 \\
\hline Area of corn/Cropland & 117 & 0.17 & 0.19 & 117 & 0.17 & 0.17 & 0.00 \\
\hline Area of wheat/Cropland & 117 & 0.29 & 0.27 & 117 & 0.31 & 0.24 & -0.02 \\
\hline Area of hay/Cropland & 117 & 0.11 & 0.13 & 117 & 0.13 & 0.14 & -0.02 \\
\hline Area of cotton/Cropland & 117 & 0.12 & 0.25 & 117 & 0.05 & 0.15 & $0.07 *$ \\
\hline Area of oat, barley, and rye/Cropland & 117 & 0.12 & 0.12 & 117 & 0.15 & 0.12 & $-0.03 *$ \\
\hline No. of cows/1000 Acre & 117 & 52.24 & 17.45 & 117 & 53.83 & 23.79 & -1.60 \\
\hline No. pigs/1000 Acre & 117 & 52.38 & 63.31 & 117 & 57.40 & 76.20 & -5.03 \\
\hline No. of chickens $/ 1000$ Acre & 117 & 241.55 & 159.19 & 117 & 245.50 & 189.27 & -3.95 \\
\hline
\end{tabular}

Notes: * means t-test with p-value $<0.05$. 


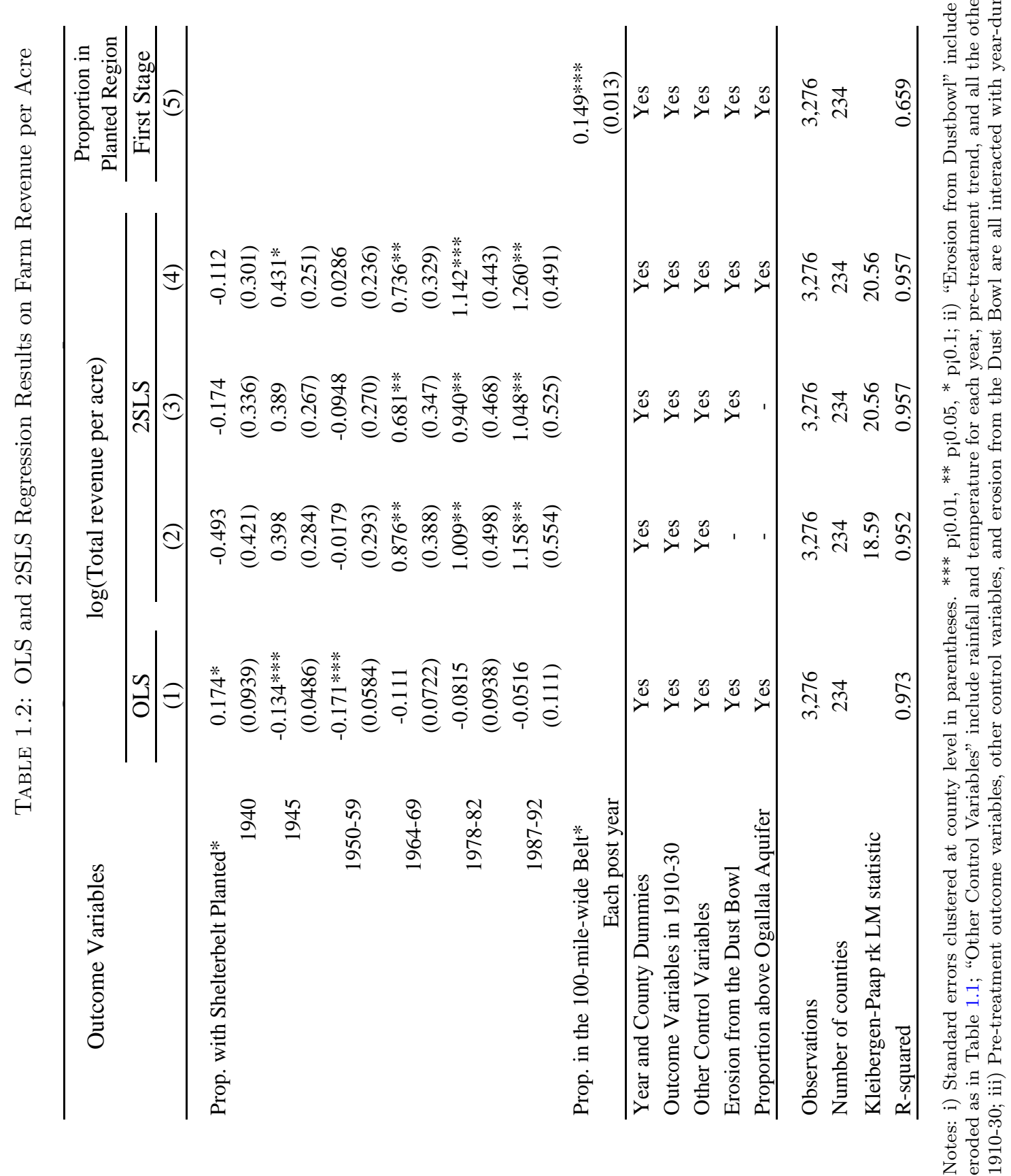




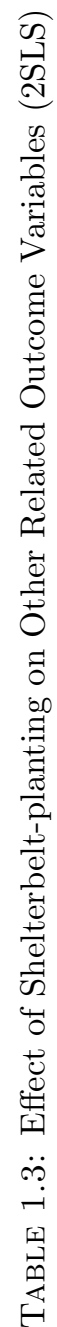

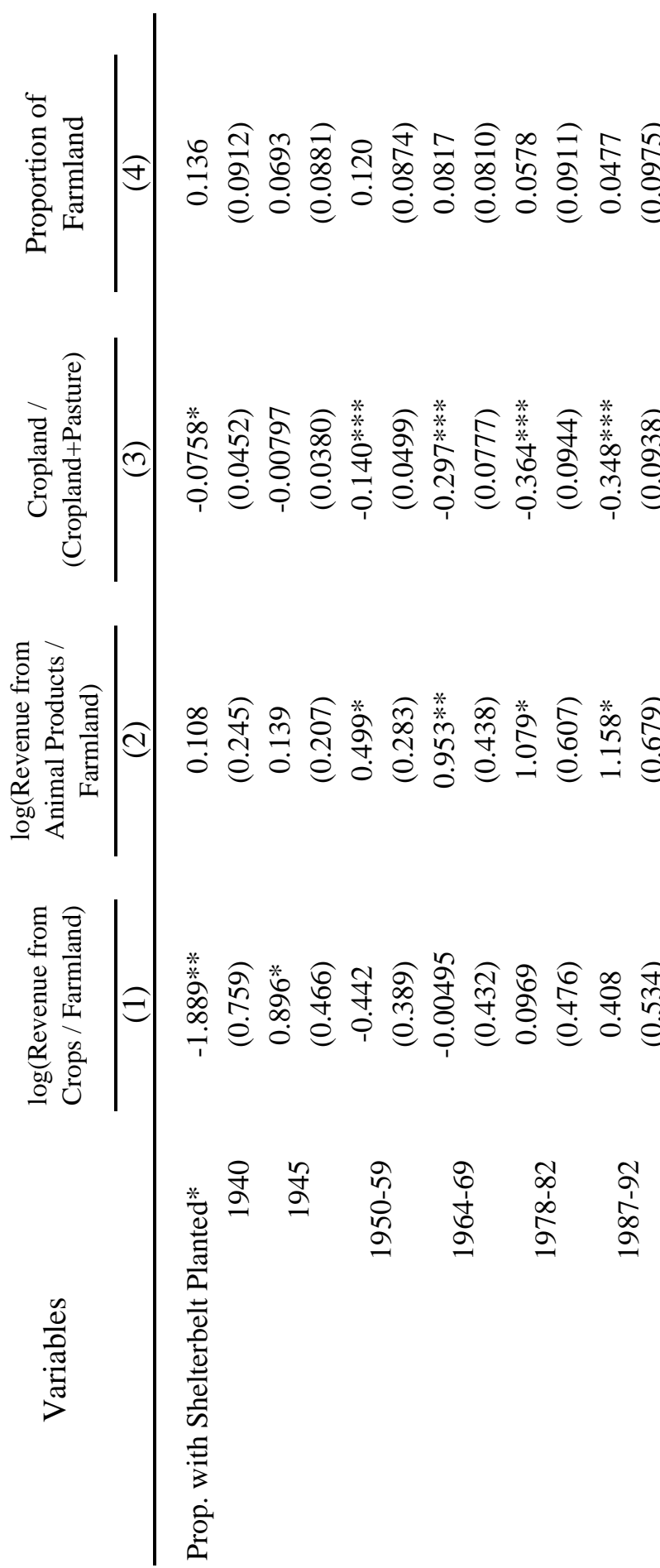

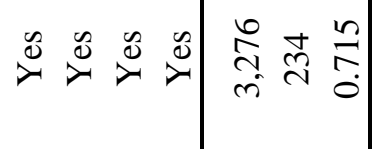

范

然

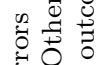

范范

焉焉焉

$\Xi . \nexists \approx$

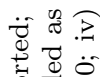

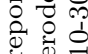

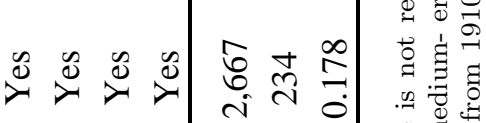

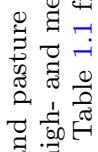

त.

范

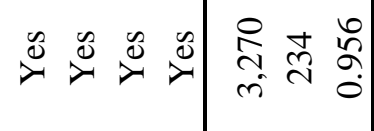

पे

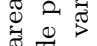

产要

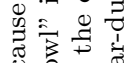

造需

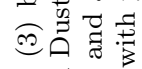

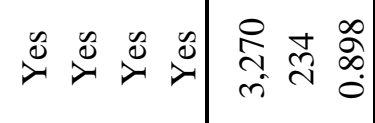

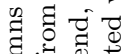

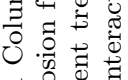

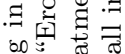

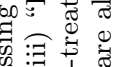

$\begin{array}{lll}0 & \\ 0 & 1 & \\ 0 & 3\end{array}$

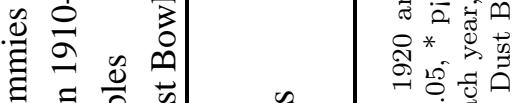

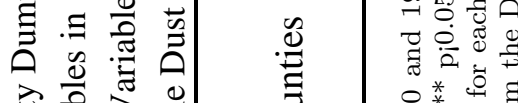

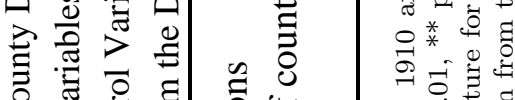

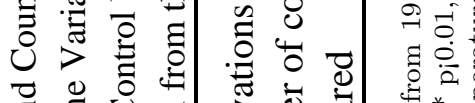

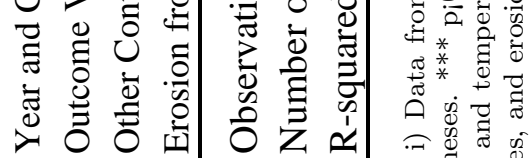




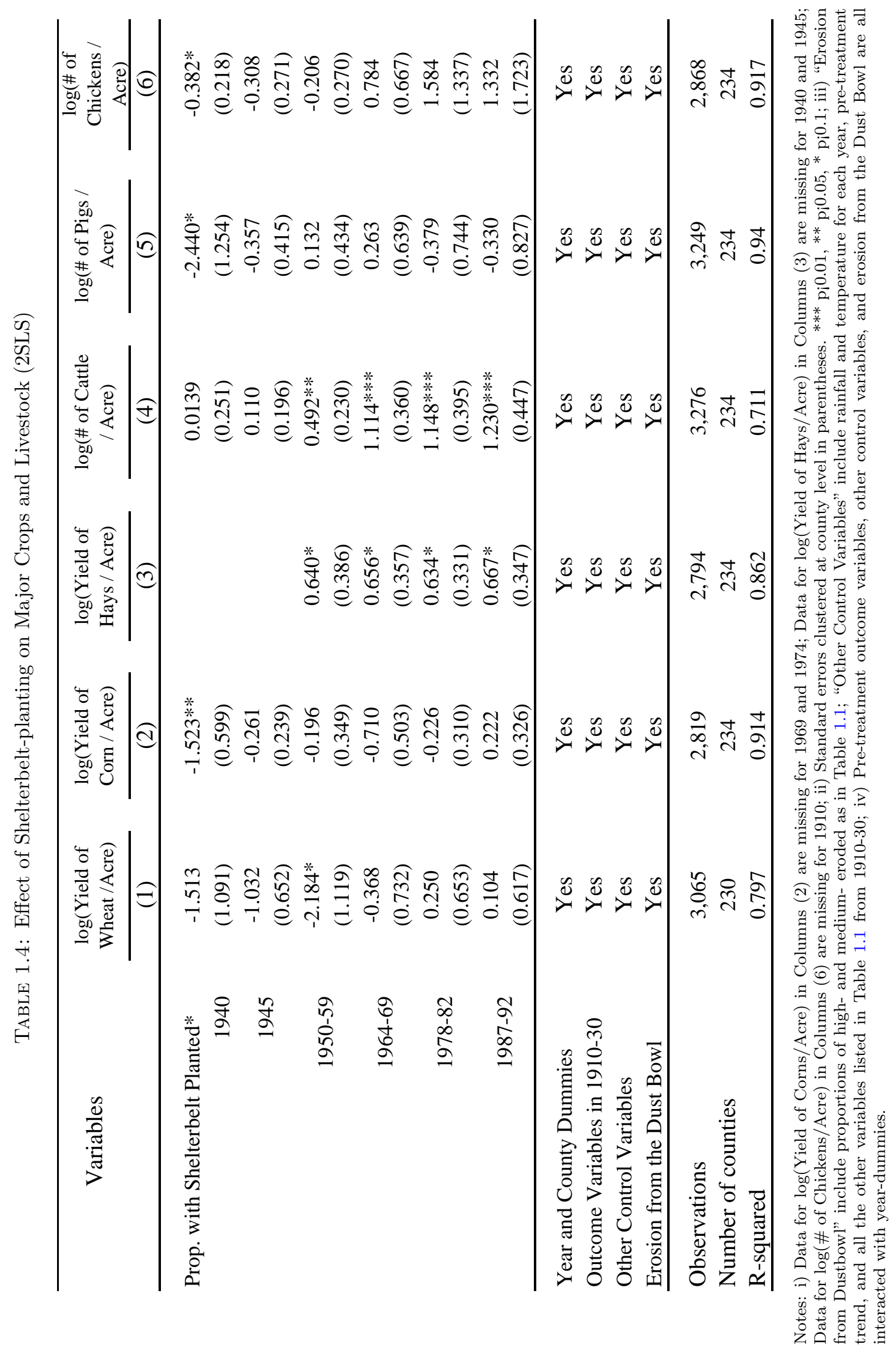




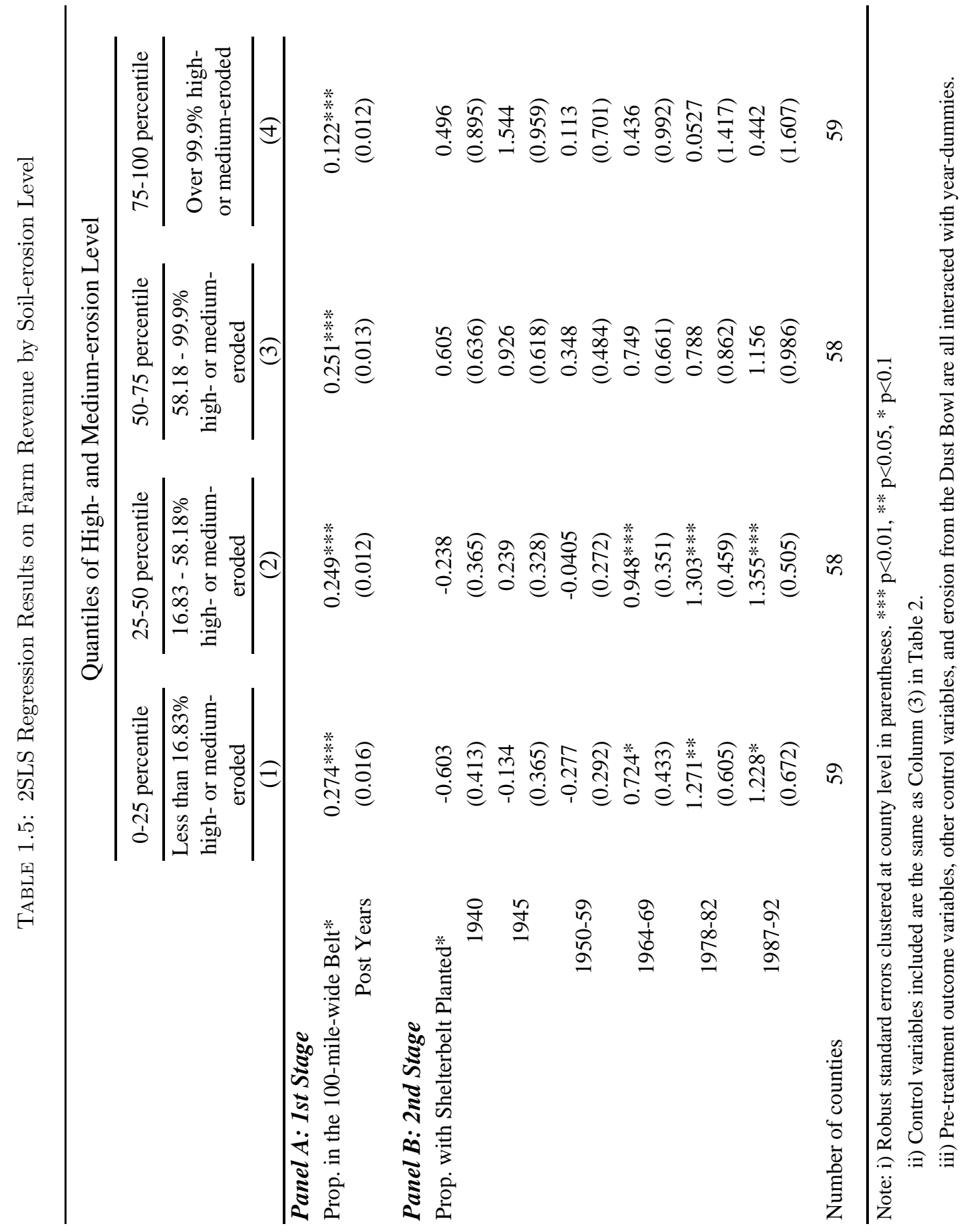




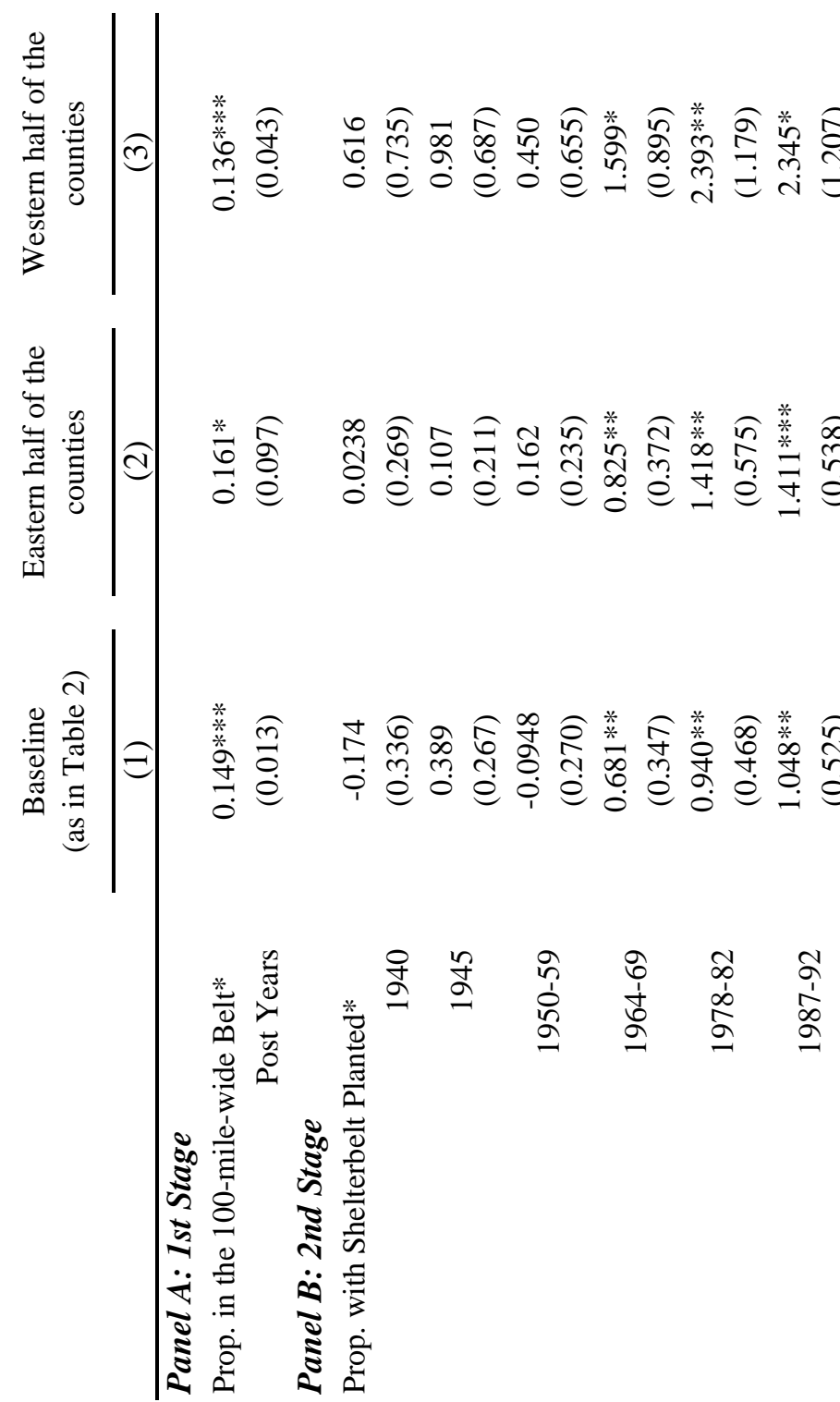

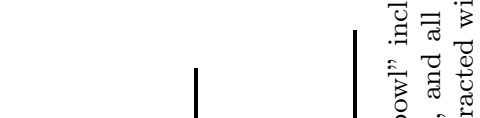

焉语.

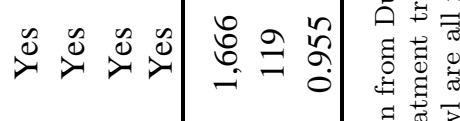




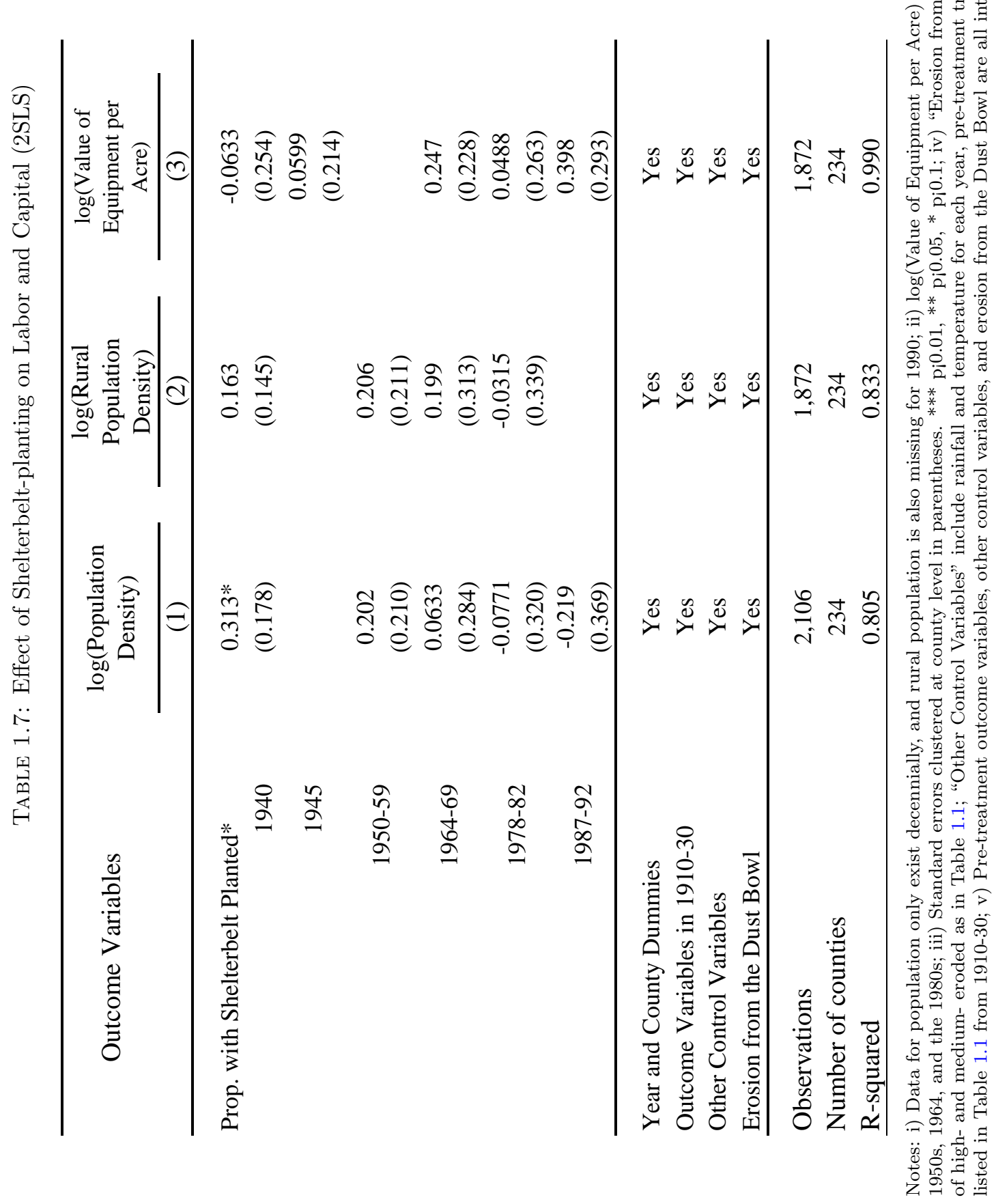




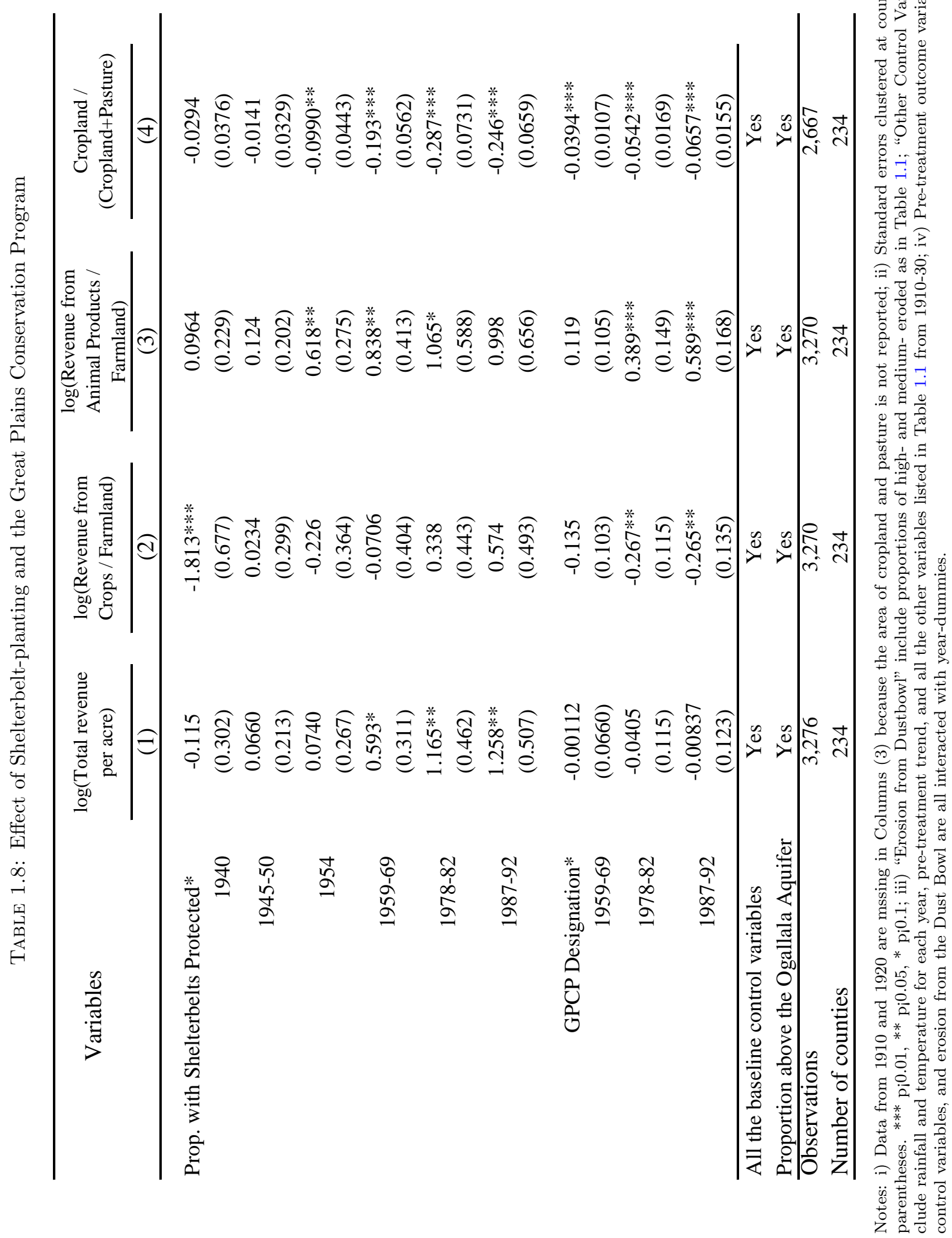


TABle 1.9: Comparison of Treated and Control Counties in 1930 by Different Cutoff

\begin{tabular}{|c|c|c|c|c|c|c|c|}
\hline \multirow[b]{2}{*}{ Variables } & \multicolumn{3}{|c|}{$\begin{array}{c}\text { More Treated } \\
\text { Proportion within 100-mile-wide } \\
\text { Belt }>60 \%\end{array}$} & \multicolumn{3}{|c|}{$\begin{array}{c}\text { Less (or not) Treated } \\
\text { Proportion within 100-mile-wide } \\
\text { Belt }<40 \%\end{array}$} & \multirow[b]{2}{*}{ Difference } \\
\hline & Obs & Mean & s.d. & Obs & Mean & $\begin{array}{c}\text { s.d. } \\
\end{array}$ & \\
\hline $\begin{array}{l}\text { Proportion in planted area } \\
\text { Other Right-hand-side Variables: }\end{array}$ & 114 & 0.30 & 0.29 & 110 & 0.18 & 0.28 & $0.12 *$ \\
\hline Proportion mediumly-eroded & 114 & 0.41 & 0.35 & 110 & 0.36 & 0.33 & 0.05 \\
\hline Proportion highly-eroded & 114 & 0.20 & 0.32 & 110 & 0.13 & 0.27 & 0.07 \\
\hline Proportion above the Ogallala Aquifer & 114 & 0.33 & 0.42 & 110 & 0.37 & 0.45 & -0.04 \\
\hline Total precipitation in recent two years $(\mathrm{mm})$ & 114 & 1113.42 & 167.55 & 110 & 1110.24 & 242.79 & 3.18 \\
\hline Avg temperature in recent two years $\left({ }^{\circ} \mathrm{C}\right)$ & 114 & 10.49 & 4.37 & 110 & 9.64 & 3.99 & 0.85 \\
\hline Farmland/County area & 114 & 0.91 & 0.08 & 110 & 0.89 & 0.09 & 0.02 \\
\hline Woodland/County area & 114 & 0.01 & 0.02 & 110 & 0.02 & 0.04 & -0.01 \\
\hline Cropland/Farmland & 114 & 0.58 & 0.16 & 110 & 0.58 & 0.18 & 0.00 \\
\hline Population per 1000 Acre & 114 & 20.93 & 11.06 & 110 & 26.42 & 30.01 & -5.49 \\
\hline Fraction of rural population & 114 & 0.90 & 0.16 & 110 & 0.86 & 0.22 & 0.04 \\
\hline Fraction of farming population & 114 & 0.62 & 0.12 & 110 & 0.58 & 0.17 & $0.04 *$ \\
\hline No. of farms/1000 Acre & 114 & 2.61 & 1.20 & 110 & 2.63 & 1.52 & -0.02 \\
\hline Avg Farm Size (in Acre) & 114 & 445.82 & 325.17 & 110 & 513.88 & 471.65 & -68.05 \\
\hline Area of corn/Cropland & 114 & 0.17 & 0.19 & 110 & 0.17 & 0.18 & 0.00 \\
\hline Area of wheat/Cropland & 114 & 0.30 & 0.26 & 110 & 0.31 & 0.24 & -0.01 \\
\hline Area of hay/Cropland & 114 & 0.11 & 0.14 & 110 & 0.13 & 0.14 & -0.02 \\
\hline Area of cotton/Cropland & 114 & 0.12 & 0.25 & 110 & 0.05 & 0.13 & $0.07 *$ \\
\hline Area of oat, barley, and rye/Cropland & 114 & 0.12 & 0.11 & 110 & 0.16 & 0.12 & $-0.04 *$ \\
\hline No. of cows/1000 Acre & 114 & 51.43 & 16.76 & 110 & 54.18 & 24.24 & -2.76 \\
\hline No. pigs/1000 Acre & 114 & 49.32 & 58.19 & 110 & 59.42 & 77.93 & -10.10 \\
\hline No. of chickens/1000 Acre & 114 & 233.59 & 142.41 & 110 & 247.92 & 193.95 & -14.33 \\
\hline
\end{tabular}

Notes: * means t-test with p-value $<0.05$. 


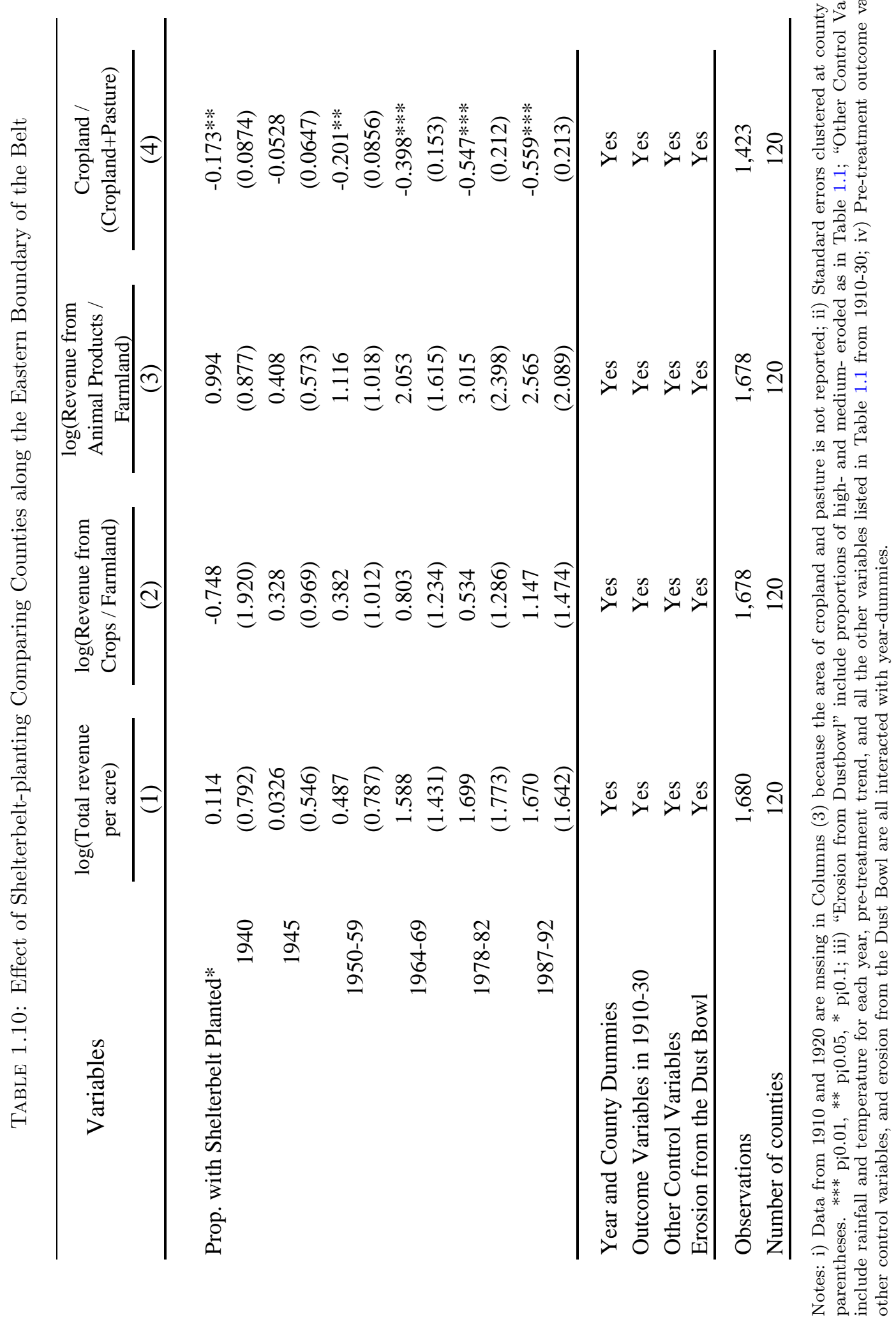




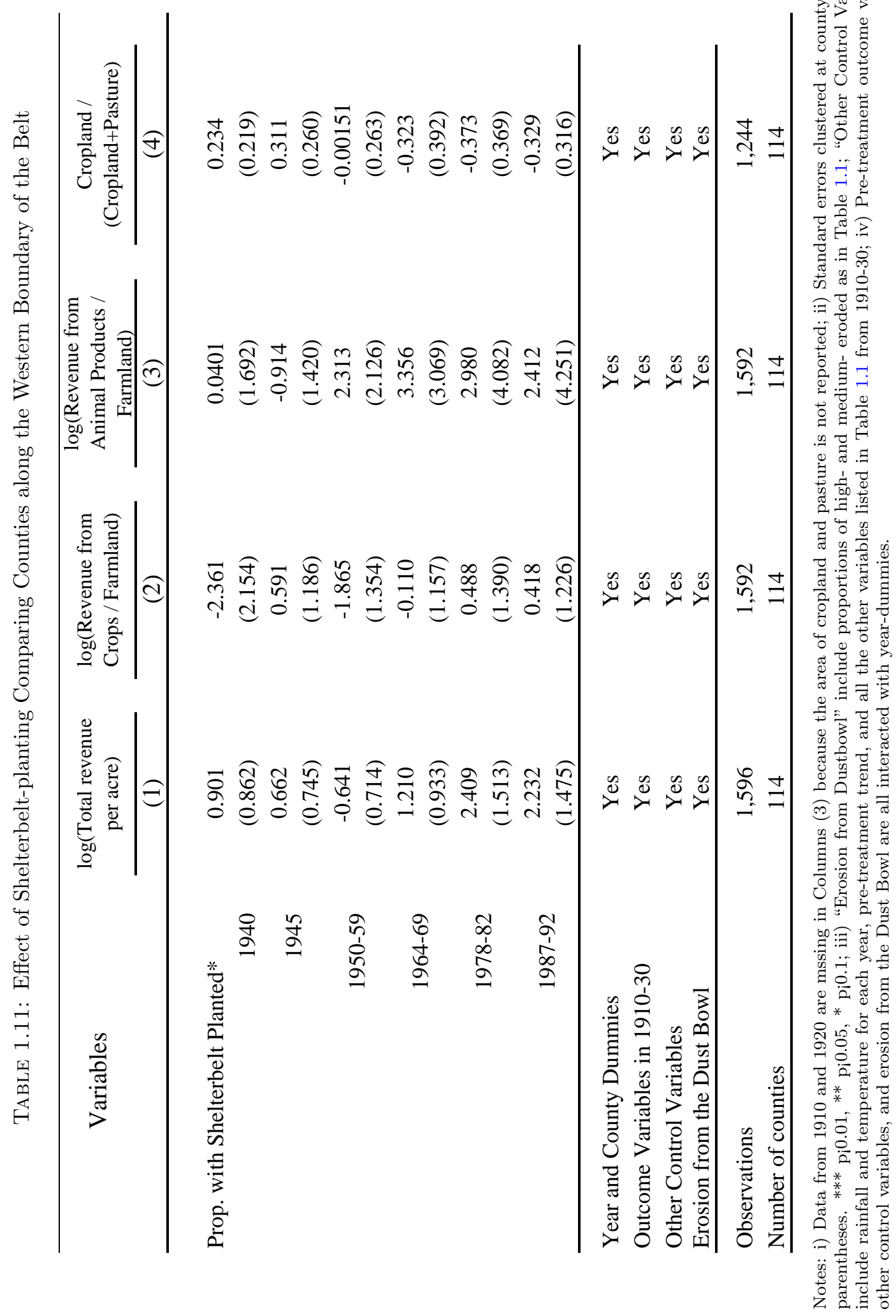




\section{Chapter 2}

\section{Poverty Targeting and Income Distribution: Evidence from} China's National Designated Poor Counties

\section{(co-authored with Sangui Wang)}

\section{$2.1 \quad$ Introduction}

Poverty alleviation remains one of the most pressing problems in developing countries. Even when a country is achieving sustained economic growth, people residing in impoverished regions may have few economic opportunities. Many countries have implemented regional development programs to alleviate income inequality and poverty in targeted areas. Although recent studies shows that region-based poverty alleviation policies are potentially wasteful (Glaeser and Gottlieb, 2008), many major policies are still regionbased due to political concerns (Greenbaum and Landers, 2009). ${ }^{1}$

It is important to understand the effect of regional targeting, but solid evaluation of those programs is rare (Greenstone and Looney, 2010). China's large-scale poverty alleviation program, the National Designated Poor Counties (NDP counties, hereafter),

\footnotetext{
${ }^{1}$ Some well-known examples include the Appalachian Regional Development Program in the US, SUDENE in Brazil, and Structural Funds and Cohesion Funds in the EU (Wei, 2011).
} 
offers a good opportunity to evaluate regional poverty targeting. In order to resolve the growing inter-regional disparity accompanying the reforms and opening-up policies initiated in the late 1970s, China implemented three waves of poverty alleviation programs in 1986, 1994, and 2001, eventually covering about $28 \%$ of all county-level administrative regions and roughly $72 \%$ of the rural poor (Park et al, 2002; Li and Meng, 2008). Most previous studies used data at the regional level, but I have household-level data geographically identified by county. Results from earlier studies show a moderate increase in per capita income and agricultural production using the variation in 1986 and 1994 (Rozelle et al, 1998; Park et al, 2002; Zhang et al, 2003; Li and Meng, 2008). Wei (2011) finds that the government's political preference for food security since the mid-1990s biased the inter-sectoral allocation of inputs towards agricultural production under the expansion of the program in 1994. Using village-level data aggregated from households in the NDP villages, Park and Wang (2010) use the timing of implementation in treated villages from 2001 to 2004 to show that the benefits of the program accrue to high-income households. ${ }^{2}$ However, previous studies provide little evidence about the mechanism at the sub-regional level and fail to consider the demographic features of households, as well as redistributive consequences of agricultural and non-agricultural income separately. Therefore, our study offers the first estimates of the effect of China's NDP county designation on heterogeneous households.

Our main household-level data come from the National Fixed-point Survey (NFS), taken annually from over 350 rural villages all over the country since 1988. This panel data enable us to investigate three natural experiments using the designation adjustments in 1994 and 2001. The first experiment compares the newly designated counties in 1994 with those never designated before; similarly, the second experiment compares those newly designated in 2001 with those never designated; lastly, the third experiment compares the counties lost their designation in 2001 with those continuously designated since $1994 .^{3}$

From our difference-in-difference analyses on the three experiments described above, we consistently find that when government publicity promoted agriculture, agricultural income of households in newly designated counties increased while non-agricultural income declined, which is consistent with the county-level analyses in Wei (2011). In addition,

\footnotetext{
${ }^{2}$ We are not accounting for the timing of actual project implementation among treated villages for two reasons. First, it is not clear what leads to differential timing of implementation; in addition, Park and Wang (2010) shows that the variation in timing happened mainly within each county, so my observations at the county level do not capture much of the variation.

${ }^{3}$ We do not observe a similar experiment in 1994 as the third one because no county lost designation status in 1994.
} 
we examine the redistributive effects of the policy: an increase in agricultural income benefited the rich rather than the poor while a decline in non-agricultural income (mainly wage income) affected both the rich and the poor. More interestingly, once the designation ceased, people received less income from both agricultural and non-agricultural sources. Overall, this regional targeting policy led to an inter-sectoral distortion favoring agricultural production and provided no evidence that its policy package benefited the poorest households in the poor county.

Our paper contributes to two strands of literature. First, we contribute to the literature evaluating the impact of poverty targeting. Mansuri and Rao (2004) summarize the mixed results about regional poverty targeting. Our analysis at the household-level in China confirms the ambiguous findings and sheds lights on channels, indicating differential effects across varying income levels caused by the households' distorting investment towards agriculture and away from non-agricultural sectors. Meanwhile, we find evidence suggesting differential responses from households with political connections under the policy package, which supports the argument that the success of decentralized regional targeting programs depends on its susceptibility to elite capture (Bardhan and Mookherjee, 2000, 2002, 2005). In addition, we contribute to the limited evidence on how politicians' preferences affect public policy. Chattopadhyay and Duflo (2004) show that having more women on village councils raises investment in public goods which women hold in higher value. We find that the central government's concerns about food security distort inter-sectoral investment under the poverty alleviation program.

The remainder of this article is organized as follows. In Section 2.2, we provide detailed information about the program and the criteria used to select the NDP counties. Section 2.3 outlines a simple theoretical framework that captures the economic mechanism under the policy package. Section 2.4 provides an introduction of data used. Section 2.5 discusses three policy experiments to be examined and our empirical strategy. Section 2.6 shows the results assessing the impact of the program on agricultural and nonagricultural income and the distributional effects across different quantiles. Section 2.7 examines the robustness of our main results through two placebo tests, and Section 2.8 offers concluding remarks. 


\subsection{Contextual Information}

\subsubsection{Background of the Targeting Program}

In 1986, the Chinese government designated 258 counties as officially poor to target an ambitious series of poverty alleviation policies. The number of NDP counties had increased to 328 by 1988, then to 592 in 1994, constituting roughly $28 \%$ of all county-level administrative regions in China (Park et al, 2002). About $72 \%$ of the rural poor lived in the designated counties in 1994 according to government estimates (Li and Meng, 2008). Since then, the list of the designated counties was slightly adjusted twice in 2001 and in 2012, but the total number has been fixed at 592 .

The support package for the officially designated poor counties includes three components, so the analyses of this paper necessarily estimate the overall effect of combination of all of them. The specific programs include subsidized loans, a Food-for-Work program, and a budgetary grant program (Park et al, 2002).

The first component covering over half of the total expenditure in the package is subsidized loans, which are offered to rural households and firms at well below market rate. ${ }^{4}$ The loans can be used in both agriculture and industry. ${ }^{5}$ The second component, the Food-for-Work program, develops infrastructure such as roads, terraced fields, irrigation and drinking-water systems by hiring local labor (Wang et al, 2004; Wei, 2011). The last tool, the budgetary grant for local government, is used to finance a wide range of issues including agriculture, infrastructure, industry, education, and health (Park et al, 2002). Since the mid-1990s, the emphasis of the latter two components have been used on projects favoring agricultural production in response to increasing grain prices. The shift is marked by the keynote speech given by Former Chairman Jiang Zemin at the Poverty Reduction Conference in 1996, emphasizing grain production and agriculture. We study this last policy change, which seems to have been particularly effective in altering spending goals.

\footnotetext{
${ }^{4}$ The nominal interest rate of subsidized loans has been fixed at $2.88 \%$, while the nominal interest rate of commercial loans was $8-12 \%$ during most of the 1990 s and around $6 \%$ after 1999 . Hence, the real interest rate of the loans had been negative until late 1990s, given the high CPI during the decade (Wei, 2011).

${ }^{5}$ The program initially tended to finance household agriculture production, but in the late 1980's the focus switched to support of rural industry (Wang et al, 2004; Rozelle et al, 1998). Park et al (2002) report that $56 \%$ of the loans went to industry and 35\% to agriculture from 1991 to 1995 . During the period we are interested in, Wang et al (2004) stated that the loans are mainly given to households with activities in industry and agriculture.
} 
Total funding of the project is $5-6 \%$ of the annual central government's budget. ${ }^{6}$ The usage of funds from 1986 to 2002 shows that over half of the total funding was spent on subsidized loans, over $22 \%$ on the Food-for-Work program, and the remaining funds are for the government budgetary grant. ${ }^{7}$

\subsubsection{Criteria for the Designation of the Poor Counties}

The first wave of the NDP counties in 1986 covered those with rural net income per capita below $150 \mathrm{CNY}$ in $1985 .{ }^{8}$ A higher poverty line was applied to "old revolutionary base" counties (that supported the Communist Party's guerrilla warfare before 1949), minority counties, and inland border counties. Similar criteria were used in 1994 based on 1992 income. Among the 592 NDP counties 18\% were "old revolutionary base" counties, $43 \%$ were minority counties, and $6 \%$ were inland border counties, all under looser criteria. In determining the 2001 designation, the central government adopted mixed indicators in 2000 and allowed the local governments to adopt different weights for the indicators in determining the designation (Park and Wang, 2010). ${ }^{9}$ In addition, all designations in comparatively rich coastal provinces were eliminated so that the NDP counties were concentrated in inland provinces. Meanwhile, villages became the basic targeting unit, although the list of designated poor counties were updated accordingly (Wang et al, 2004). Because the list for NDP villages is not available for public use, the effect of the adjustment in 2001 is assessed at the county-level as a proxy for the villagelevel actual treatment. In addition to the announced official criteria, evidence suggests that political appeal by individual counties sometimes affected designation (Park et al, 2002). Despite the lack of uniformly-enforced criteria, Park et al (2002) show that detailed control variables can explain $88 \%$ of the designation in $1994 .{ }^{10}$ We address this concern by controlling for a selected set of control variables similar to Park et al (2002).

\footnotetext{
${ }^{6}$ Wang et al (2004) reports that the central government funding of poverty programs totaled CNY 113 billion ( $\$ 13.6$ billion) from 1994 to 2000. Park and Wang (2010) states that the central government annually spent about CNY 30 - 33 billion (about $\$ 4$ billion) from 2001 to 2004 .

${ }^{7}$ Other inter-regional, international, and non-governmental poverty reduction activities also exist, and support programs ranging from education, professional training, and health care, to micro-credit, economic and technical cooperation. Wang et al (2004) gives more details about all those programs but also states that data on these programs are rarely available.

${ }^{8}$ County-level data we have show that the national average was $338 \mathrm{CNY}$.

${ }^{9}$ Official guidelines give 8 indicators: grain production per capita, cash income per capita, percent of low quality houses, percent of households with poor access to potable water, percent of natural villages with reliable access to electricity, percent of natural villages with all-weather road access to the county seat, percent of women with long-term health problems, percent of eligible children not attending school (Park and Wang, 2010).

${ }^{10}$ These variables are income per capita, grain production per capita, industrial share of total income, status as minority county or revolutionary base county, and provincial dummy variables.
} 
More importantly, our data allow us to include county fixed effects, which will absorb all the unobserved time-invariant characteristics in each county.

\section{$2.3 \quad$ Model}

We introduce a general equilibrium model with two representative households and two sectors, agricultural and non-agricultural production. This will allow us to explain the labor allocation and resulting income flows from each sector, which will generate the heterogeneous responses to the program within a community. ${ }^{11}$ Specifically, the subsidized loans reduce the interest rate for both agricultural and non-agricultural sectors; the Food-for-Work program occupies some of the labor supply, especially from poorer households (for simplicity, we assume here the labor used in the Food-for-Work program is solely from the poor household in the model); most importantly, the budgetary grant leads to infrastructure construction favoring agriculture so increases agricultural productivity.

In rural China, suppose there exist two sectors, agriculture (sector 1) and non-agriculture (sector 2). Suppose we have two representative households, one rich and one poor. The rich household is self-employed in both agriculture and non-agriculture, while the poor is only self-employed in agriculture but can also be hired to work in non-agriculture. We assume that the poor are not self-employed in non-agriculture because the fixed cost is too high to afford and the poor may have limited access to capital due to lack of collateral. ${ }^{12}$ The two sectors have Cobb-Douglas production functions as follows for $\mathrm{F}$ agriculture and $\mathrm{M}$ non-agriculture:

$$
\begin{gathered}
F_{x}=A_{1 x} K_{1 x}^{\alpha} L_{1 x}^{\beta}, \forall x=r, p \\
M=A_{2} K_{2}^{\gamma} L_{2}^{\delta} \\
L_{2}=L_{2 p}+L_{2 r}
\end{gathered}
$$

where $A_{1 x}$ represents the Total Factor Productivity (TFP), and $K_{1 x}$ and $L_{1 x}$ are the inputs in capital and labor in agriculture for $\mathrm{x}=$ rich $(\mathrm{r})$ or poor $(\mathrm{p})$, respectively; $A_{2}$

\footnotetext{
${ }^{11}$ This model is extended from the model with one homogeneous agent constructed by Wei (2011). Including two agents adds the heterogeneity that it is important to study the impact on income redistribution in this paper.

${ }^{12}$ On the other hand, all land in rural area of China is collectively owned so most households are assigned to cultivate some land. Hence, we assume that both the rich and the poor are self-employed in agriculture.
} 
is the TFP for non-agriculture, $K_{2}$ the total investment in non-agriculture by the rich. Equation (3) means the total labor input in non-agriculture comes from both the rich and the poor. ${ }^{13}$

In addition, the government hires a certain amount of labor in the Food-for-work Program in communities that are designated. We assume only the poor can be hired to work in the Food-for-work Program and the labor used $(l)$ is exogenously determined by the government (i.e. $l>0$ if designated, and $l=0$ otherwise).

To achieve an interior solution, we assume decreasing returns to scale for both of the two sectors, i.e. $\alpha+\beta<1, \gamma+\delta<1$. In addition, we assume the total amount of labor for each household is fixed, i.e. $L_{1 r}+L_{2 r}=\bar{L}$ for the rich and $L_{1 p}+L_{2 p}+l=\bar{L}$ for the poor. The interest rate for capital is $r$, and the wage rate for labor is $w$. Because a county is only one of the 2,862 county-level regions in China, it is reasonable to regard it as a "small economy" where $r$ is exogenous. However, it is not the same case for $w$ because the labor market is assumed to be closed within the county. Then, a representative rich household who can allocate labor and capital to both sectors and hire labor for non-agricultural production solves

$$
\operatorname{Max}_{\left\{K_{1 r}, K_{2}, L_{1 r}, L_{2}\right\}} \quad A_{1 r} K_{1 r}^{\alpha} L_{1 r}^{\beta}+p A_{2} K_{2}^{\gamma} L_{2}^{\delta}-r\left(K_{1 r}+K_{2}\right)-w\left(L_{2}-L_{2 r}\right)
$$

s.t. $L_{1 r}+L_{2 r}=\bar{L}$, where $p$ is the relative price of non-agricultural goods compared to agricultural goods (the price for agricultural goods is assumed to be 1). On the other hand, a representative poor household who can only invest their capital in agriculture solves

$$
\operatorname{Max}_{\left\{K_{1 p}, L_{1 p}\right\}} \quad A_{1 p} K_{1 p}^{\alpha} L_{1 p}^{\beta}+w\left(L_{2 p}+l\right)-r K_{1 p}
$$

s.t. $L_{1 p}+L_{2 p}+l=\bar{L}$. In addition, considering the economy with one rich and one poor household, we need $L_{2}=L_{2 r}+L_{2 p}$ to make the labor market clear. According to the policy package described above, one would expect $r$ to be lowered by subsidized loans. Moreover, the Food-for-work Program and government grant finance the construction of infrastructure, especially terraced fields and irrigation appliances favoring agricultural production. Hence, $A_{1 x}$ and $A_{2}$ may both have been raised, for x=r or $\mathrm{p}$, but after the government started to emphasize agriculture-related infrastructure in 1996, $A_{1 x}$ should have increased more than $A_{2}$. For simplicity, we assume that $A_{2}$ stays the same and $A_{1 x}$ increases in the model.

\footnotetext{
${ }^{13}$ The mobility of labor in China is comparatively low due to the household registration system. Hence, we assume that the labor market is closed within the county.
} 
By solving for the first order conditions for two types of households, we have

$$
r^{\frac{\gamma-\alpha}{1-\gamma}} A_{1 x}=B L_{1 x}^{1-\alpha-\beta} L_{2}^{-\frac{(1-\delta-\gamma)(1-\alpha)}{1-\gamma}} .
$$

where $B=\alpha^{-\alpha} \beta^{-(1-\alpha)} \delta^{1-\alpha} \gamma^{\frac{\gamma}{(1-\gamma)(1-\alpha)}}\left(p A_{2}\right)^{\frac{1-\alpha}{1-\gamma}}$, for $\mathrm{x}=\mathrm{r}$ or $\mathrm{p}$.

From the equation above, we have $L_{1 r} / L_{1 p}=\left(A_{1 r} / A_{1 p}\right)^{\frac{1}{1-\alpha-\beta}}$. Then, $L_{2}=2 \bar{L}-l-[1+$ $\left.\left(A_{1 p} / A_{1 r}\right)^{\frac{1}{1-\alpha-\beta}}\right] L_{1 r}$. We get $\partial L_{1 x} / \partial A_{1 x}>0$ for $\mathrm{x}=\mathrm{r}$ or $\mathrm{p}$ by plugging these equations back into (5). Hence, when agricultural productivity $A_{1 x}$ increases in designated counties due to the improvement in agricultural infrastructure, we expect to see that agriculture production expands while non-agriculture production is crowded out as $A_{1 x}$ increases (i.e. $\partial F_{x} / \partial A_{1 x}>0, \partial M / \partial A_{1 x}<0$, for $\mathrm{x}=\mathrm{r}$ or $\mathrm{p}$ ). Moreover, assume the rich are more productive than the poor in agriculture (i.e. $A_{1 r}>A_{1 p}$ ), one can show that $\partial F_{r} / \partial A_{1 r}>\partial F_{p} / \partial A_{1 p}>0$, so the rich expand their agriculture production more than the poor.

On the other hand, the effect of a decrease in $r$ due to subsidized loans is not clear as it depends on the sign of $(\gamma-\alpha)$, or the relative capital intensity of agriculture versus nonagriculture. If we can assume that non-agricultural production is more capital intensive than agricultural production (i.e. $\gamma>\alpha$ ), then the subsidized loans are more likely to benefit the non-agricultural sector. Meanwhile, because some poor people in designated counties are hired in the Food-for-Work Program, an increase in $l$ would crowd out labor input in both agricultural and non-agricultural sectors. Thus, $\partial F_{x} / \partial l<0, \partial M / \partial l<0$, for $\mathrm{x}=\mathrm{r}$ or $\mathrm{p}$.

Because being chosen as a National Designated Poor County leads to increases in $A_{1 x}$ for $\mathrm{x}=\mathrm{r}$ or $\mathrm{p}$ and a positive $l$, but lowers $r$, agriculture production will increase if the effect of raising $A_{1 x}$ dominates the effect of a positive $l$ and lowering $r$ under the assumption that non-agricultural production is more capital intensive than agricultural production. On the other hand, non-agriculture production will decline if the effect of raising $A_{1 x}$ and a positive $l$ dominates the effect of lowering $r$ under the same assumption.

As for the wage income, the first order conditions show that

$$
w=\delta(\gamma / r)^{\frac{\gamma}{1-\gamma}}\left(p A_{2}\right)^{\frac{1}{1-\gamma}} L_{2}^{-\frac{1-\gamma-\delta}{1-\gamma}} .
$$

One can see that the wage rate $w$ should decrease as labor demand in the non-agriculture sector decreases (i.e. $\partial w / \partial L_{2}<0$ ), but should increase as the interest rate $r$ is lowered by subsidized loans (i.e. $\partial w / \partial r<0$ ). Hence, the overall effect on the wage rate living 
in the NDP communities is ambiguous. However, because the increase in agricultural productivity in agricultural sector under the designation may decrease non-agricultural labor input, $\left(L_{2 p}+l\right)$, the poor's non-agricultural income, $w\left(L_{2 p}+l\right)$, is ambiguous but more likely to decrease under previous conditions.

\subsection{Data}

The household level data used in the main analysis of the paper come from the National Fixed-point Survey (NFS), housed at the Research Center of Rural Economy under China's Ministry of Agriculture. This is a restricted-access annual panel data set that only scholars from domestic institutions are allowed to use at the Center. The NFS offices located all over the country have endeavored to visit the same households from over 350 villages repeatedly every year since 1986, except for 1992 and 1994 when the annual survey could not be executed. We use annual data from 1988 - 91, 1995 - 1998, 2000, and $2002-08$, disregarding data from a few years around each time the designations are adjusted to avoid ambiguity in the timing of treatment (1986, 87, 93, and 2001) and those with quality problem (1999). In addition, we exclude villages from suburban districts because the NDP counties are usually located in remote areas. All villages from Tibet are also excluded because there is a separate poverty alleviation program designed there. ${ }^{14}$ The annual number of villages left is around 330 with 36, 83, and 79 located within the NDP counties in Phases I - III, respectively. As a village is an administrative unit under a county, at which the policy was designated, the data set enables us to construct a village-level panel to test the effect of the policy package at the household-level within villages in treated counties.

To control for the selection criteria of the NDP counties as described in Section 2.2, we use pre-1995 county level data collected by China's Ministry of Agriculture and obtain additional information on the NDP counties from Park et al (2002). In addition, we use data from the village-level survey in NFS to account for the adjustment after 1995.

\footnotetext{
${ }^{14}$ Tibet initially took up 5 out of the 592 NDP counties, then the Chinese government decided to design a program targeting the whole Tibet including all counties since 2001 so that Tibetan counties are no longer included in the 592 designations (Yang and Wang, 2005).
} 


\subsection{Estimation Strategy}

\subsubsection{Three Experiments and the Selection Problem}

Using the NFS data from 1988 to 2008, we investigate the effect of three experiments. Firstly, using data from 1988 - 1991 and 1995 - 2000, we look at the effect of the designation in 1993 by comparing the newly designated counties with those never designated before (Experiment I). Similarly, using data from 1995 - 2000 and 2002 - 08, we can analyze two experiments. First, the effect of the designation in 2001 can be measured by comparing the newly designated counties in 2001 with those never designated before (Experiment II). Second, we can study the effect of losing designation in 2001 by comparing counties that ceased to be NDP counties in 2001 and those continuously designated since 1994 (Experiment III). The outcome variables we are interested in are agricultural income, industrial income, and non-agricultural income at the household level. ${ }^{15}$ In the first two experiments of the program, we anticipate an increase in agricultural income and a decrease in non-agricultural income, while Experiment III should mirror the second one with a drop in agricultural income. ${ }^{16}$

Simply comparing the difference between designated and non-designated counties is inappropriate to estimate the treatment effect on the treated because the designated counties are generally more backward by definition. However, with a difference-in-difference (DID) estimation, the identification of the causal treatment effect relies on the condition that the treatment and the control groups share the same trends. Unfortunately, choosing all other non-designated counties as the control group may not satisfy this condition because the richer coastal areas had a higher trend in economic development than the lagging inland areas before the program started. As a result, we ended up with 61 - 94 counties with roughly $10-20 \%$ in treated group for the three experiments.

In order to choose a comparable control group, we eliminate the control counties that do not share common support with the treated counties in selected variables. In particular, for the first experiment of the treatment in 1994, we use county-level per capita total income and grain output in 1993. On the other hand, in the other two experiments of

\footnotetext{
${ }^{15}$ Agricultural income is from household managed farm, livestock, forest, etc; industrial income is from household managed factories and shops in food processing, construction, trade, etc; non-agricultural income refers to all sources of income other than agricultural income, which include wage earnings, government transfers, and others in addition to industrial income.

${ }^{16}$ Non-agricultural income may not increase due to losing benefits from the Food-for-work Program and other government expenditure in Experiment III.
} 
the treatment in 2001 we use village-level per capita net income and grain output in 2000 from the NFS data. ${ }^{17}$

Figures 2.1, 2.2, and 2.3 show the maps of selected counties covered by the NFS data for the three experiments, with summary statistics of all control variables before each experiment shown in Table 2.1 by treated and control groups. Each panel of Table 2.1 represents statistics for one of the policy experiments, with each panel showing first household-level and then community-level statistics (Panel I at county-level; Panel II and III at village-level). Across Panels 1 - 3, most statistics are similar in magnitude and statistically indistinguishable in treatment and control counties. These include characteristics like household size, household infrastructure like access to water and electricity, school enrollment, and infant mortality. Meanwhile, in Panels 1 and 2, county-level per capita income is statistically higher in designated counties, although we already restricted the non-designated counties to those with common support as the designated counties. Hence, we also control for those county-level variables in Table 2.1 to address remaining concerns that differences in income rather than differences in treatment might explain outcomes for treated counties. In addition, we further test the robustness of our core results with a placebo test by comparing poorer and richer villages within the control group as specified in Section 2.7. The results of the placebo test give us more confidence that the differences in per capita income between treated and control groups are not driving our main results under the real treatment.

\subsubsection{Estimation Procedure}

The baseline OLS regression is estimated as the following:

$$
Y_{h c t}=\beta_{0}+\beta_{1} \text { PostTreatment }_{c t}+X_{h c t} \beta_{2}+Z_{c t} \beta_{3}+\text { Year }_{t}+\text { Village }_{c}+\epsilon_{\text {hct }}
$$

where $Y_{h c t}$ is the outcome variable for household h living in county c in year t; PostTreatment $t_{c t}$ is 1 if county c is treated in an experiment in year t, and 0 otherwise; $X_{h c t}$ is a vector of household-level demographic controls (numbers of members in household, of working age, and illiterate); $Z_{c t}$ is a vector of regional level controls determining designation as an NDP county and a village-level pre-treatment trend; ${ }^{18}$ Year $_{t}$ is a vector of the yearfixed effect; Village $_{c}$ is a vector of the village-fixed effect to control for time-invariant

\footnotetext{
${ }^{17}$ Other relevant backwardness measures are highly correlated with the variables we are using.

${ }^{18}$ The validity of my identification strategy would be threatened if the trends over the pre- and posttreatment time period were not parallel. Hence, we control for those pre-treatment trends in case there are differences between the treatment and control groups.
} 
county-specific factors including indicators for minority or old revolutionary base counties, as well as other unobserved static factors affecting a county's lobbying ability; and $\epsilon_{h c t}$ is the idiosyncratic error term clustered at the county-level.

Because the main outcome variables we are interested in, agricultural and industrial (or non-agricultural) earnings, are determined jointly by each household, we use seemingly unrelated regression to estimate the mean outcomes jointly. The regression expression for each outcome variable is the same as Equation (8), but we assume the two error terms are correlated for each household, rather than clustering them at the county-level. In addition, in order to measure how the treatment affects the distribution of welfare from the program, we will also perform the same regressions at different quantiles of the outcome variables. ${ }^{19}$

\subsection{Results}

\subsubsection{Inter-sectoral Effect under the Experiments}

The results in the three experiments as discussed in Section 2.5 are shown in Tables 2.2 and 2.3 using Seemingly Unrelated Regressions on the income sources from agricultural and non-agricultural sectors.

The logarithmic values of agricultural and self-employed industrial income are regressed jointly in Table 2.2 to estimate the trade-off between self-employed income sources within households. Columns (1) and (2) show results for the first experiment. Living in a newly-designated NDP county leads to an average of $8.3 \%$ increase in agricultural income and the coefficient is statistically significant at $99 \%$. This is caused by subsidized loans and the increase in agricultural productivity due to government investment in agriculture-related infrastructure. On the other hand, its effect on industrial income is not statistically significant, which is potentially because the positive impact from subsidized loans is offset by the negative crowding-out effect from agriculture (due to the increase in agricultural productivity) as well as the Food-for-work program. As for the second experiment in Columns (3) and (4), the effect of the designation on agricultural

\footnotetext{
${ }^{19}$ In particular, the estimation of $\alpha^{q}$, the vector for all corresponding coefficients in Equation (8) at quantile $q$ is

$$
\operatorname{argmin} Q\left(\alpha^{q}\right)=\Sigma_{j: Y_{j} \geq W^{\prime}{ }_{j} \alpha^{q}}^{N} q\left|Y_{j}-W^{\prime}{ }_{j} \alpha^{q}\right|+\Sigma_{j: Y_{j}<W^{\prime}{ }_{j} \alpha^{q}}^{N}(1-q)\left|Y_{j}-W^{\prime}{ }_{j} \alpha^{q}\right|
$$

where $j$ represents the subscript " $h c t$ " in Equation (8), and $W^{\prime}{ }_{j}$ contains all the right-hand-side variables in Equation (8).
} 
income is consistently positive and statistically significant, but the scale is estimated to be as large as $38.8 \%$ in Column (3). Meanwhile, its effect on industrial income is estimated to be a $64.5 \%$ increase. The differences between Experiments I and II can potentially be caused by the change in the targeted geographic unit from county level to village level in Experiment II: Poverty targeting at the village level can be more effective than at the county level; meanwhile, because the policy variation in Experiment II is inaccurately captured at the county level, the estimates in Experiment II may also include the spill-over effects to richer non-designated villages in targeted counties. Hence, we observe larger positive impacts in both of the two sectors.

From the results in Columns (5) and (6) for the third experiment, losing the designation as an NDP county causes an average of $15.9 \%$ drop in agricultural income. This effect is statistically significant at $99 \%$, which mirrors those in the first and second experiments. Meanwhile, losing the designation increases industrial income although the coefficient is not statistically significant. Please note that the policy variation here is also inaccurately captured at the county level as in Experiment II, so the richer non-designated villages in designated counties are also included.

Table 2.3 shows the results for the joint regressions of agricultural income and the overall non-agricultural income including self-employed industrial income (estimated in Table 2.2), wage earnings, government transfer, and any other income source. The results in Columns (1) and (2) show that new designation in Experiment I leads to an $8 \%$ increase in agricultural income and a $18.7 \%$ decrease in non-agricultural income, and both of the coefficients are statistically significant at $95 \%$ or more. Comparing with corresponding columns for Experiment I in Table 2.2, we can see the negative impact on non-agricultural income is not driven by self-employed industrial income, but rather by other sources where wage income is usually the most important one. Columns (3) and (4) for Experiment II show qualitatively the same outcomes as in Experiment I although the scale of the effects is larger. Lastly, the results for Experiment III are shown in Columns (5) and (6). What is worth noticing here is that the overall non-agricultural income decreases by $43.8 \%$ in Column (6) in Experiment III although one would expect a positive sign if Experiment III is supposed to mirror Experiments I and II. This negative impact may be caused by a loss in the benefit from government expenditures, such as the Food-for-Work program, and the difficulties in restoring wage income due to the substitution effect from extra investment in capital previously under the designation or the attrition in searching for new jobs (comparing with the much easier cases when quitting jobs as in Experiment I and II). This negative impact is contributed by the 
comparatively poorer households (or poorer villages) with evidence provided in the next subsection.

\subsubsection{Within County Distributional Effect}

The distributional effect of the designation within each county is estimated by quantile regressions on each of the three outcome variables at the $25 \mathrm{th}, 50 \mathrm{th}$, and 75 th percentiles as shown in Tables 2.4, 2.5, and 2.6.

The regression results for Experiment I are in Table 2.4. The increase in agricultural income shown in Columns (1)-(3) is mainly driven by the higher quantile: the coefficient at the 25 th percentile is almost zero; the coefficient at the 50 th percentile is positive but only statistically significant at $90 \%$; yet, the coefficient at the 75 th percentile is around $3 \%$ and is statistically significant at $95 \%$. This means households with lower agricultural income are not as benefited as those with higher agricultural income. On the other hand, the change in industrial income is nearly zero at the 25 th or the 50 th percentiles in Columns (4) and (5) and is not statistically significant at the 75 th percentile in Column (6). Columns (7)-(9) show that the decrease in total non-agriculture income is around $10-13 \%$ across the quantiles with the largest magnitude appearing at the lowest quantile in Column (7). Consistent with our previous results in Tables 2-1 and 2-2, the first experiment shows that the designation of NDP counties increases agricultural income, but does not raise self-employed industrial income and further reduces other non-agricultural income, mostly wage income. Specifically, the increase in agricultural income is contributed by higher quantiles while the decrease in non-agricultural income affects all the three quantiles at approximately the same scale although the larger loss of households are likely to appear at the lowest quantile.

In Table 2.5 for Experiment II, the increase in agricultural income is only statistically significant at the lowest quantile, with a value of $29.4 \%$ in Column (1). This may be because the adjustment in 2001 targeting low-income households in poorer villages became more effective than the previous round of adjustment in 1993 when the policy package was implemented at the county level. As for self-employed industrial income, we can see a huge decrease at the 50th percentile but a huge increase at the 75 th percentile. This could be driven by some non-agricultural business relocating from middle-level income designated villages to higher income non-designated villages, which suggests the policy package under the designation can potentially drive away non-agricultural business, although we do not have the information to test this possibility directly. Columns 
(7)-(9) for total non-agricultural income exhibits negative impact at all quantiles. The scale of decrease at the 25th percentiles is especially large in Column (7) because the implementation of the policy package was mainly concentrated in the poorest villages and the crowding-out effect of wage income for the households in those villages were much stronger. Meanwhile, the non-agricultural income for the richer households at the 50 th and the 75th percentiles also decreases even if less likely to be directly under the designation. This is possibly due to decreasing employment opportunity caused by the crowding out effect on non-agricultural business in nearby designated villages.

Table 2.6 shows the results for Experiment III where the treated counties lose their designation. The decrease in agricultural income appears at the 10th percentile and is $33.5 \%$ in Column (1) with $95 \%$ confidence. This is the mirrored effect for Column (1) in Table 2.5, as the poor households appear to have been more effectively targeted since 2001. As for industrial income in Columns (5)-(7), we can infer from the huge coefficient in Column (7) that the benefit is concentrated among households at the highest quantile, who can presumably expand their non-agriculture business in richer (=less likely to be originally designated) villages by taking advantage of the extra labor supply; this is caused by the elimination of the crowding-out effect from the Food-for-Work program and other government support for agriculture in poorer designated villages. Lastly, total non-agriculture income decreases by $12-39 \%$ in Columns (8)-(10) with households at the two lower quantiles suffered more from this negative impact. Consistent with the results in Table 2.3, these outcomes do not mirror those in Experiment II for the same reason. Meanwhile, the households that are more likely to be living in originally designated villages are more severely affected by this negative impact as shown in Columns (8) and (9).

\subsubsection{Overall Effect and the Effect of Political Background}

(Please note that the results in this subsection are not updated with the preferred set of controls as in the previous two subsections.)

The effects on gross income are reported in Table 2.7. From Columns (1)-(6), we can see that the first two experiments show overall muted effects. In Experiment III, Columns (8) and (9) exhibit a 5-8\% increase at the 50th and the 75 th percentile, which means the households who live in richer (less likely to be designated) villages in originally designated counties experience an increase in gross income. One possible explanation is 
that more labor and investment is available when neighboring poorer (more likely to be designated) villages ceased to receive the preferential policy package.

Moreover, it is also interesting to learn whether households' political background matters in designated counties as in Table 2.8. ${ }^{20}$ From the results for the interaction term of the DID variable and an indicator for political background, we find that households with political background generally earn more non-agricultural income in Experiments I and II as in Columns (3) and (7). Note that the sources contributing to this increase in nonagricultural income are not self-employed industrial income because the corresponding coefficients in Columns (4) and (8) are not statistically significant, but more likely to be wage income or transfers. This suggests political connections affect the allocation of resources from the program within designated communities. As for Experiment III, we find that there is a switch from agriculture to non-agriculture for households with political background from the results for the interaction term of the DID variable and the indicator for political background in Columns (10) and (11). One caveat worths noticing here is that the political background of the households is not an exogenous variation, but the results above still suggest differential effects for households with and without political background.

\subsection{Robustness Checks}

As robustness check, we do two placebo tests by altering cross-sectional variation and longitudinal variation, respectively.

In the first placebo test, we restrict the sample to the control group and re-assign treated counties for the placebo test based on their county level per capita income in the baseline years. In Experiment I, counties with per capita income lower than 441 CNY (the 25th percentile) in 1992 are assigned to be "treated". In Experiments II, counties with per capita income lower than 1,464 CNY (the 25th percentile) in 2001 are assigned to be "treated". In Experiment III, counties with per capita income higher than 1,585 CNY (the 75th percentile) in 2001 are assigned to be "treated". Regression results for this placebo test are reported in Tables 2.9 and 2.10, which compare to the results under real treatment in Tables 2.2 and 2.3. Table 2.9 shows the results for the Seemingly Unrelated joint regressions for logarithmic values of self-employed agricultural income and industrial income. Across all three experiments in Columns

\footnotetext{
${ }^{20}$ Households with a political background refer to households with government officers, local cadres, or party/military members.
} 
(1) - (6), the placebo treatment for households from hypothetically treated counties generates no similar results as real treatment in Table 2.2. As for Table 2.10 where the logarithmic values of agricultural income and non-agricultural income are regressed jointly in Seemingly Unrelated Regressions, no similar results as real treatment in Table 2.3 can be found except for Column (6). Experiments III under the placebo test and real treatment both cause a drop in non-agricultural income at somewhat close magnitude and are both statistically significant at $99 \%$ as in Column (6) of Table 2.3 and the same column of Table 2.10. However, if we put it together with the previous set of tables, we can see this seemingly close results are actually driven by different factors. The effect of real treatment on self-employed industrial income under Experiment III is positive and statistically insignificant as shown in Column (6) of Table 2.2. Hence, its negative impact on non-agricultural income as in Column (6) of Table 2.3 is not driven by self-employed industrial income, but other factors such as wage earnings. On the other hand, the effect of the placebo test on self-employed industrial income under Experiment III exhibits a huge negative impact and is statistically significant at $99 \%$ as shown in Column (6) of Table 2.9, which is highly likely to be the main driver of the negative impact on non-agricultural income shown in Column (6) of Table 2.10. Overall, the placebo test does not generate similar results as the real treatment for any of the three experiments. Therefore, the core results of the paper as in Tables 2.2 and 2.3 are not driven by the fact that the designated counties are on average poorer.

In the second placebo test, we restrict the sample to pre-treatment years and use the same sets of treated and control counties as in the real experiments. Specifically, 1990 and 1991 are assumed to be post- "treatment" years in Experiment I, while 1998 - 2000 are assumed to be post- "treatment" years in Experiments II and III. Similar to the previous placebo test, the regression results for this second test are reported in Tables 2.11 and 2.12, which compares to the results under real treatment in Tables 2.2 and 2.3. Table 2.11 shows the results for logarithmic values of self-employed agricultural income and industrial income and Table 2.12 shows the results for logarithmic values of agricultural income and non-agricultural income with both tables regressed jointly under Seemingly Unrelated Regressions. We can see that there is no statistically significant result in either of the two tables, which means this placebo test generates completely muted outcomes for all the three experiments. Through this placebo test, we demonstrate that the core results in Tables 2.2 and 2.3 are not likely to be driven by pre-treatment trends that originally existed between treated and control counties. 


\subsection{Conclusion}

This paper studies the impact of poverty targeting on household income using policy adjustments in China's National Designated Poor Counties program between 1988 and 2008. By setting up a two-sector two-agent general equilibrium model, we find theoretically ambiguous effects under the policy package. Then, we use the National Fixed-point Survey, an annual household-level data set from 1988 to 2008 covering over 350 rural villages all over the country to exploit three natural experiments generated by the adjustments in the NDP Counties in 1994 and 2001. Two of the experiments compare the newly designated counties with those never designated before, and the third experiment compares the counties that lost their designation with those continuously designated. We consistently find that when government publicity promoted agriculture, agricultural income of households in newly designated counties increased, while non-agricultural income declined. In addition, we examine the redistributive effects of the policy: an increase in agricultural income benefited the rich rather than the poor while a decline in non-agricultural income (mainly wage income) affected both the rich and the poor. More interestingly, once the designation ceased, people received less income from both agricultural and non-agricultural sources. Overall, this regional targeting policy led to an inter-sectoral distortion favoring agricultural production and provided no evidence that its policy package benefited the poorest households in the poor county. Meanwhile, we check the robustness of the results with two placebo tests by altering the cross-sectional and longitudinal variations, respectively. Results from the two placebo tests verify that the core results of the paper are not driven by the difference in per capita income across treated and control counties or by pre-existing trends before the designations adjusted.

Policy implications of this paper are two-folded as summarized below. Firstly, government publicity promoting agriculture through poverty alleviation program can lead to a decline in non-agricultural income. Overall, the designation of the program may not increase the gross income in the poor region. Secondly, regional poverty targeting policies may not benefit the poorest within the targeted poor region. The government needs to think carefully about the redistributive effect of the policy package in order to achieve its goal effectively. 


\section{Bibliography}

Bardhan, Pradan, and Dilip Mookherjee (2000), "Capture and Governance at the Local and National Levels", American Economic Review Papers and Proceedings, Vol. 90, No. 2, pp 135139.

Bardhan, Pradan, and Dilip Mookherjee (2002), "Decentralization of Governance and Development", Journal of Economic Perspectives, Vol. 16, No. 4, pp 185205.

Bardhan, Pradan, and Dilip Mookherjee (2005), "Decenteralizing Antipoverty Program Delivery in Developing Countries", Journal of Public Economics, Vol. 89, pp 675704.

Chattopadhyay, Raghabendra and Esther Duflo (2004), "Women as Policy Makers: Evidence from a Randomized Policy Experiment in India", Econometrica, Vol. 72, No. 5, pp 1409-1443.

Glaeser, Edward L. and Joshua D. Gottlieb (2008), "The Economics of Place-Making Policies", Brookings Papers on Economic Activity, Economic Studies Program, The Brookings Institution, Vol. 39, No. 1, pp 155-253.

Greenbaum, Robert T. and Jim Landers (2009), "Why are State Policy Makers Still Proponents of Enterprise Zones? What Explains Their Action in the Face of a Preponderance of the Research?", International Regional Science Review, Vol. 32, No. 4, pp 466-479.

Greenstone, Michael and Adam Looney (2010), An Economic Strategy to Renew American Communities, The Hamilton Project.

Li, Hongbin, Lingsheng Meng (2008), "Evaluating China's Poverty Alleviation Program: A Regression Discontinuity Approach", Working Paper.

Mansuri, Ghazala, and Vijayendra Rao (2004), "Community-based and -driven Development: a Critical Review", The World Bank Research Observer, Vol. 19, No. 1, pp $1-39$.

Park, Albert, Sangui Wang, and Guobao Wu (2002), "Regional Poverty Targeting in China", Journal of Public Economics, Vol. 86, pp 123-153.

Park, Albert, and Sangui Wang (2010), "Community-based Development and Poverty Alleviation: An Evaluation of China's Poor Village Investment Program", Journal of Public Economics, Vol. 94, pp 790-799. 
Chapter 2. Poverty Targeting and Income Distribution: Evidence from China's National Designated Poor Counties (co-authored with Sangui Wang)

Ravallion, Martin and Jyotsana Jalan (1999), "China's Lagging Poor Area", American Economic Review, Vol. 89, No. 2, pp 301-305.

Rozelle, Scott, Albert Park, Vincent Benziger, and Changqing Ren (1998), "Targeted Poverty Investment and Economic Growth in China", World Development, Vol. 26, No. 12, pp 2137-2151.

Wang, Sangui, Zhou Li, and Yanshun Ren (2004), "The 8-7 National Poverty Reduction Program in China - The National Strategy and Its Impact", Scaling Up Poverty Reduction: A Global Learning Process and Conference.

Wei, Zhichao (2011), “Blessing or Curse: A Study of China's Place-based Pro-agriculture Poverty Alleviation Program" Job Market Paper.

Yang, Hongming and Yongli Wang (2005), Zhongguo Xibu Jingji Fazhan Baogao (Report on Economic Development in Western China), 2005, Social Science Academic Press (China).

Zhang, Linxiu, Jikun Huang, and Scott Rozelle (2003), "China's War on Poverty: Assessing Targeting and the Growth Impacts of Poverty Programs" Journal of Chinese Economics and Business Studies, pp 301-317. 
Chapter 2. Poverty Targeting and Income Distribution: Evidence from China's National Designated Poor Counties (co-authored with Sangui Wang)

Figure 2.1: Treated and Selected Control Counties in Experiment I

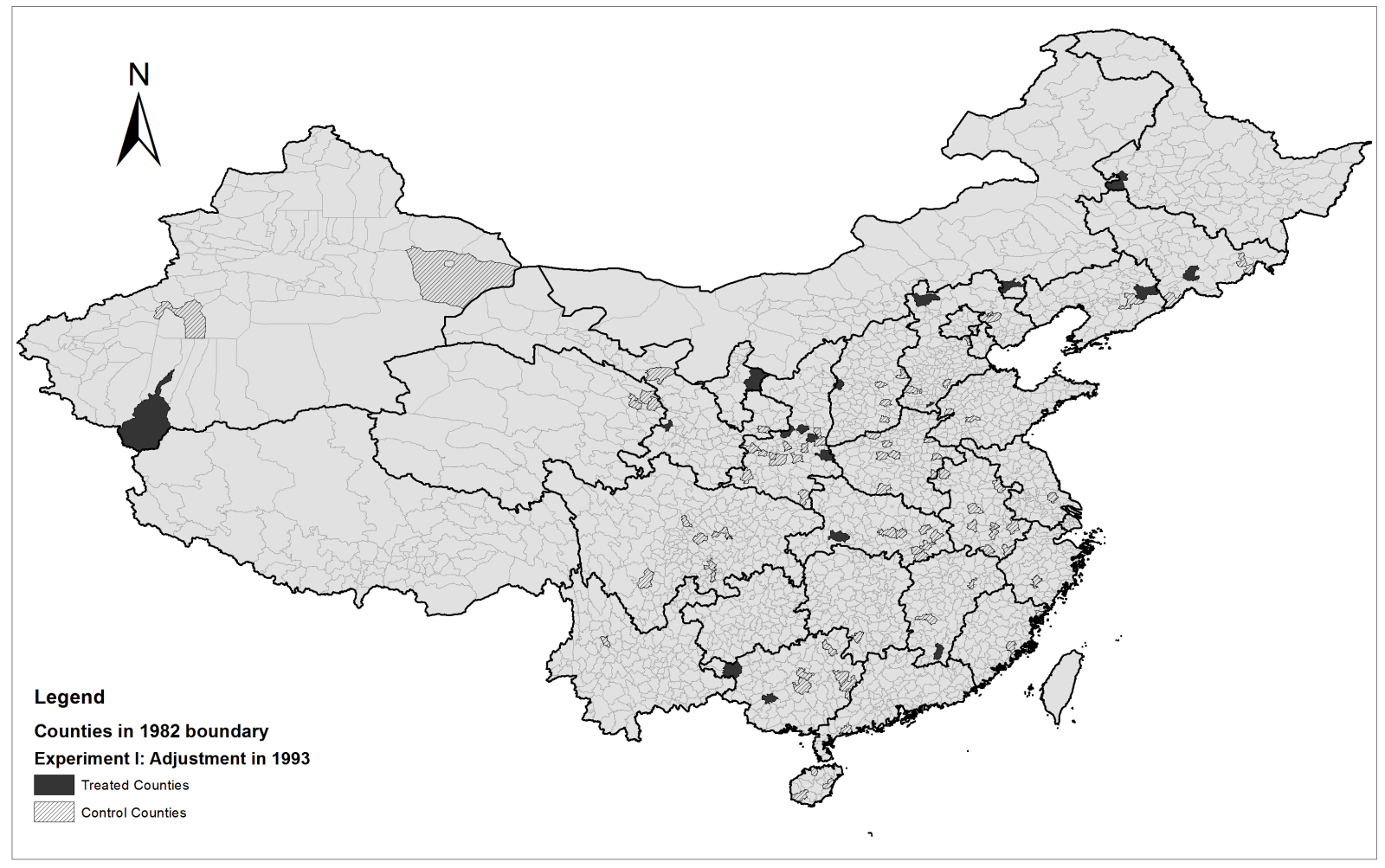


Figure 2.2: Treated and Selected Control Counties in Experiment II

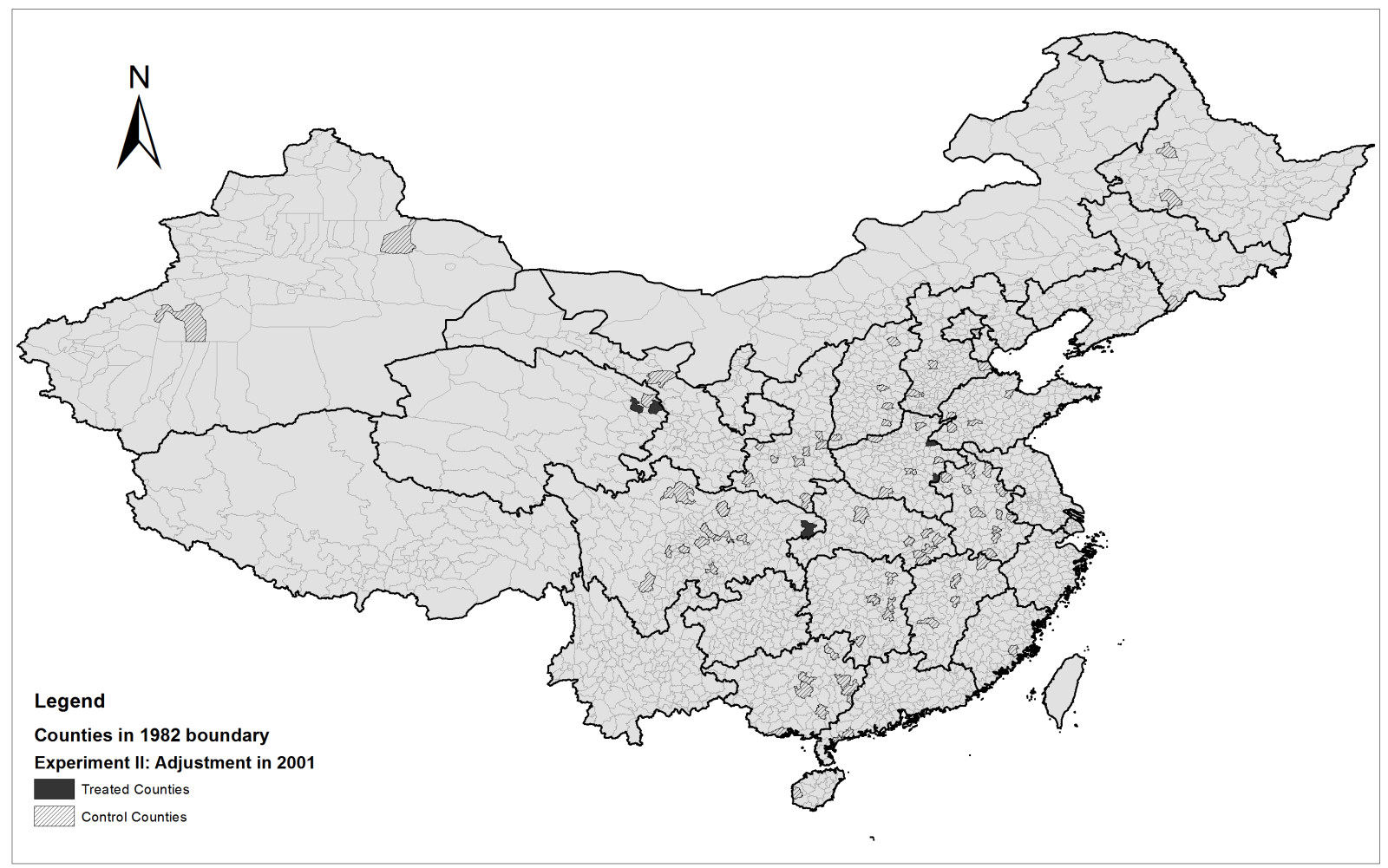


Figure 2.3: Treated and Selected Control Counties in Experiment III

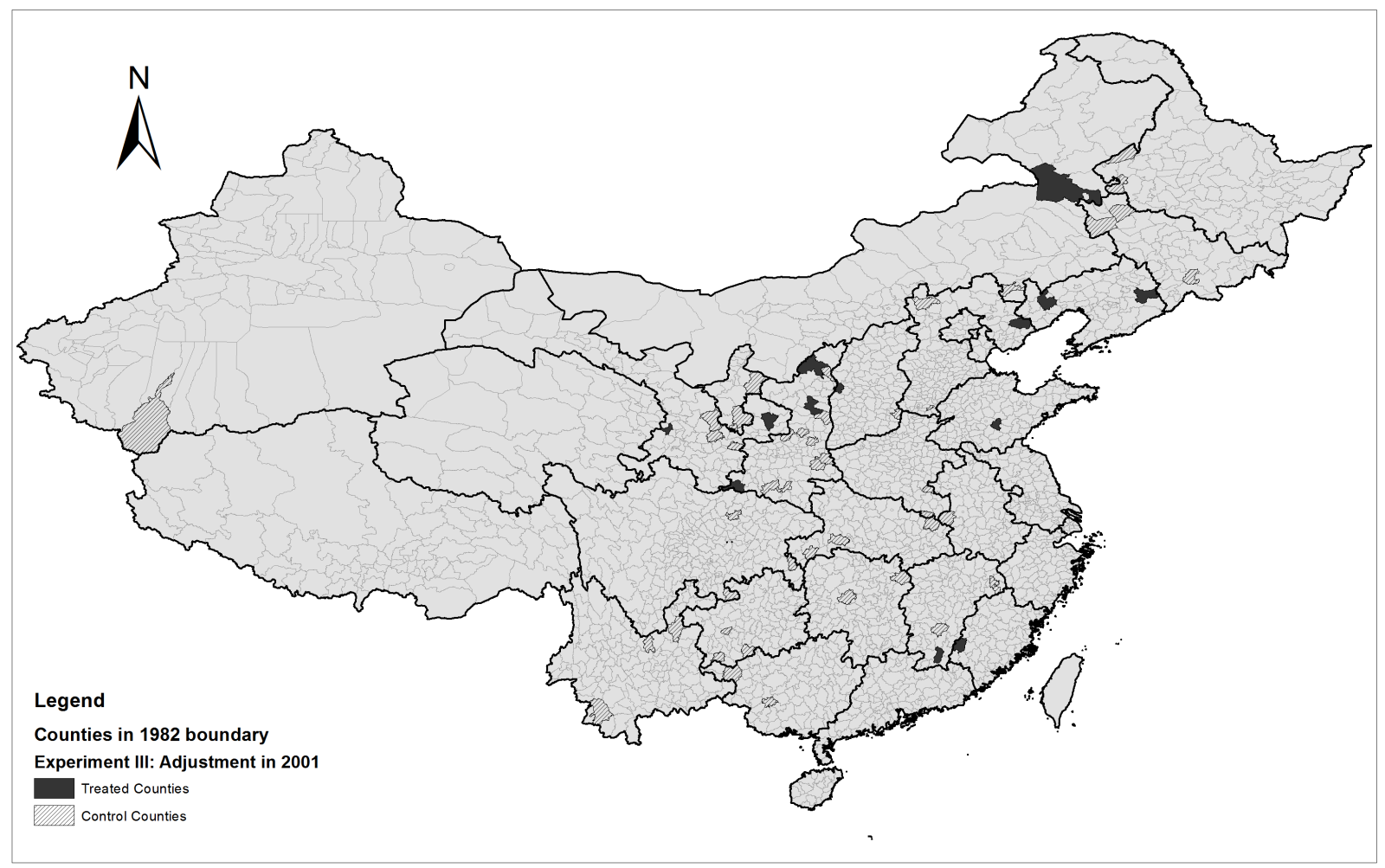


Table 2.1: Summary Statistics by Treated and Control Groups

\begin{tabular}{|c|c|c|c|c|c|c|c|}
\hline \multirow[b]{2}{*}{ Variables } & \multicolumn{3}{|c|}{ Treated } & \multicolumn{3}{|c|}{ Control } & \multirow[b]{2}{*}{ Difference } \\
\hline & Obs & Mean & Std. & Obs & Mean & $\overline{\text { Std. }}$ & \\
\hline \multicolumn{8}{|c|}{ Panel 1: Baseline for Experiment I (in 1991) } \\
\hline Household size & 1,322 & 4.86 & 1.95 & 6,368 & 4.79 & 1.78 & 0.07 \\
\hline Per capita income (CNY) & 17 & 460.47 & 79.33 & 77 & 617.58 & 137.90 & $-157.11 *$ \\
\hline Per capita grain output (kg) & 17 & 342.92 & 103.36 & 77 & 367.16 & 95.21 & -24.25 \\
\hline Per capita industrial income (CNY) & 17 & 168.83 & 129.40 & 77 & 447.16 & 469.79 & $-278.33 *$ \\
\hline Grain yield & 17 & 188.59 & 85.28 & 77 & 263.92 & 65.50 & -75.33 \\
\hline \multicolumn{8}{|c|}{ Panel 2: Baseline for Experiment II (in 2000) } \\
\hline Household size & 310 & 4.49 & 1.59 & 5,460 & 4.36 & 1.76 & 0.13 \\
\hline Per capita net income (CNY) & 6 & $1,212.83$ & 595.06 & 84 & $1,766.18$ & 428.93 & $-553.35 *$ \\
\hline Per capita grain output (kg) & 6 & 518.24 & 304.18 & 84 & 576.64 & 215.32 & -58.40 \\
\hline Prop. with house in good condition & 6 & 1.40 & 1.03 & 84 & 1.37 & 1.18 & 0.03 \\
\hline Prop. with safe water & 6 & 0.50 & 0.55 & 84 & 0.67 & 0.43 & -0.17 \\
\hline Prop. with electricity & 6 & 0.99 & 0.01 & 84 & 0.99 & 0.02 & 0.00 \\
\hline Distance to highway & 6 & 1.00 & 1.26 & 84 & 2.04 & 3.29 & -1.04 \\
\hline School enrollment rate & 6 & 0.99 & 0.02 & 83 & 0.98 & 0.11 & 0.01 \\
\hline Enfant mortality rate & 6 & 0.04 & 0.06 & 74 & 0.04 & 0.12 & 0.01 \\
\hline \multicolumn{8}{|c|}{ Panel 3: Baseline for Experiment III (in 2000) } \\
\hline Household size & 751 & 4.15 & 1.48 & 2,931 & 4.22 & 1.59 & -0.07 \\
\hline Per capita net income (CNY) & 13 & $1,157.39$ & 806.07 & 48 & $1,148.75$ & 608.07 & 8.63 \\
\hline Per capita grain output (kg) & 13 & 388.43 & 315.28 & 48 & 400.18 & 296.34 & -11.75 \\
\hline Prop. with house in good condition & 13 & 1.33 & 1.20 & 48 & 1.29 & 1.42 & 0.03 \\
\hline Prop. with safe water & 13 & 0.44 & 0.50 & 48 & 0.47 & 0.44 & -0.03 \\
\hline Prop. with electricity & 13 & 0.98 & 0.03 & 48 & 0.97 & 0.07 & 0.01 \\
\hline Distance to highway & 13 & 3.62 & 4.79 & 48 & 2.98 & 7.22 & 0.64 \\
\hline School enrollment rate & 13 & 0.84 & 0.37 & 47 & 0.95 & 0.15 & -0.11 \\
\hline Enfant mortality rate & 13 & 0.06 & 0.11 & 47 & 0.05 & 0.10 & 0.00 \\
\hline
\end{tabular}

Note: * means statistically significant over $5 \%$. 


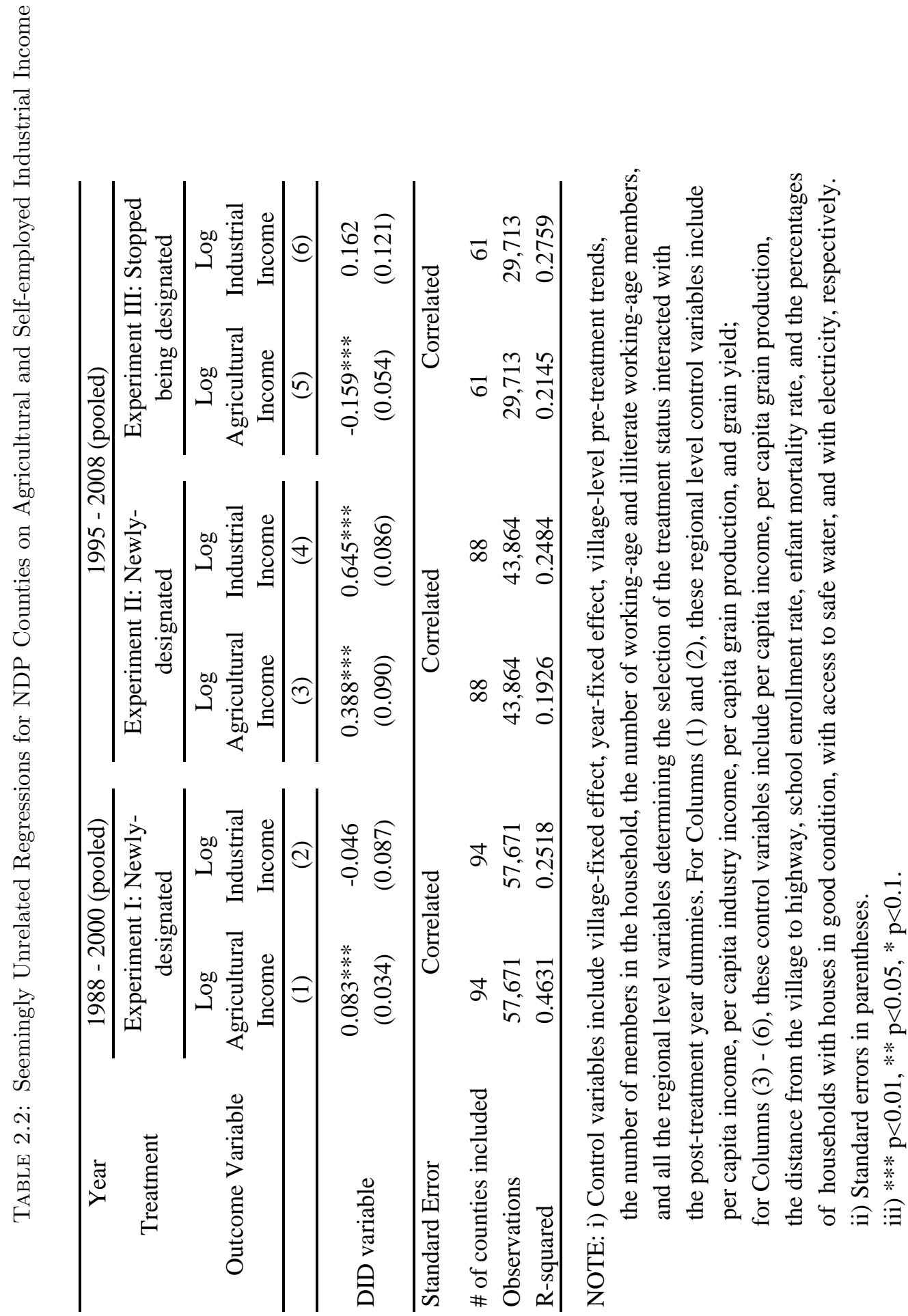




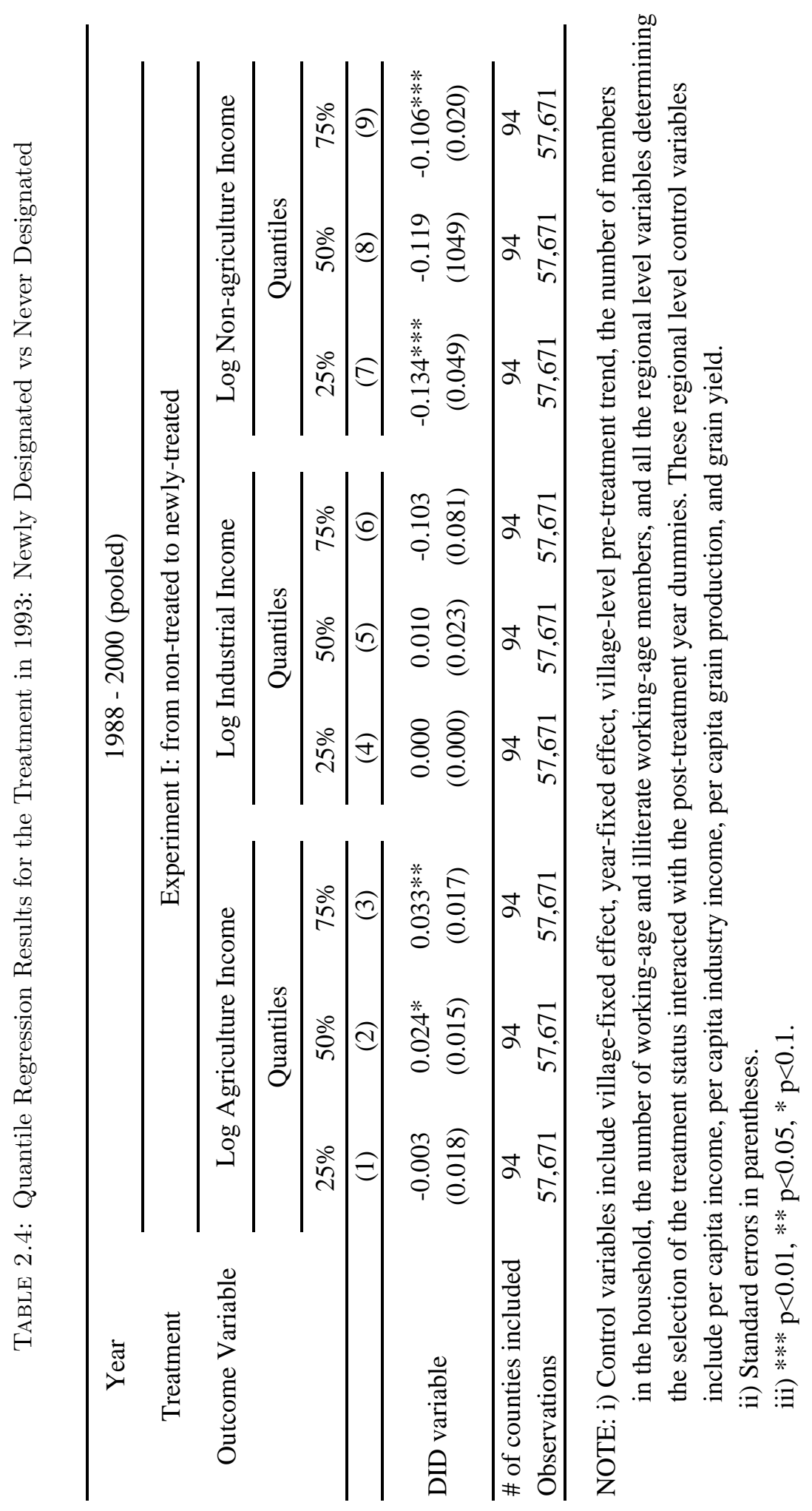




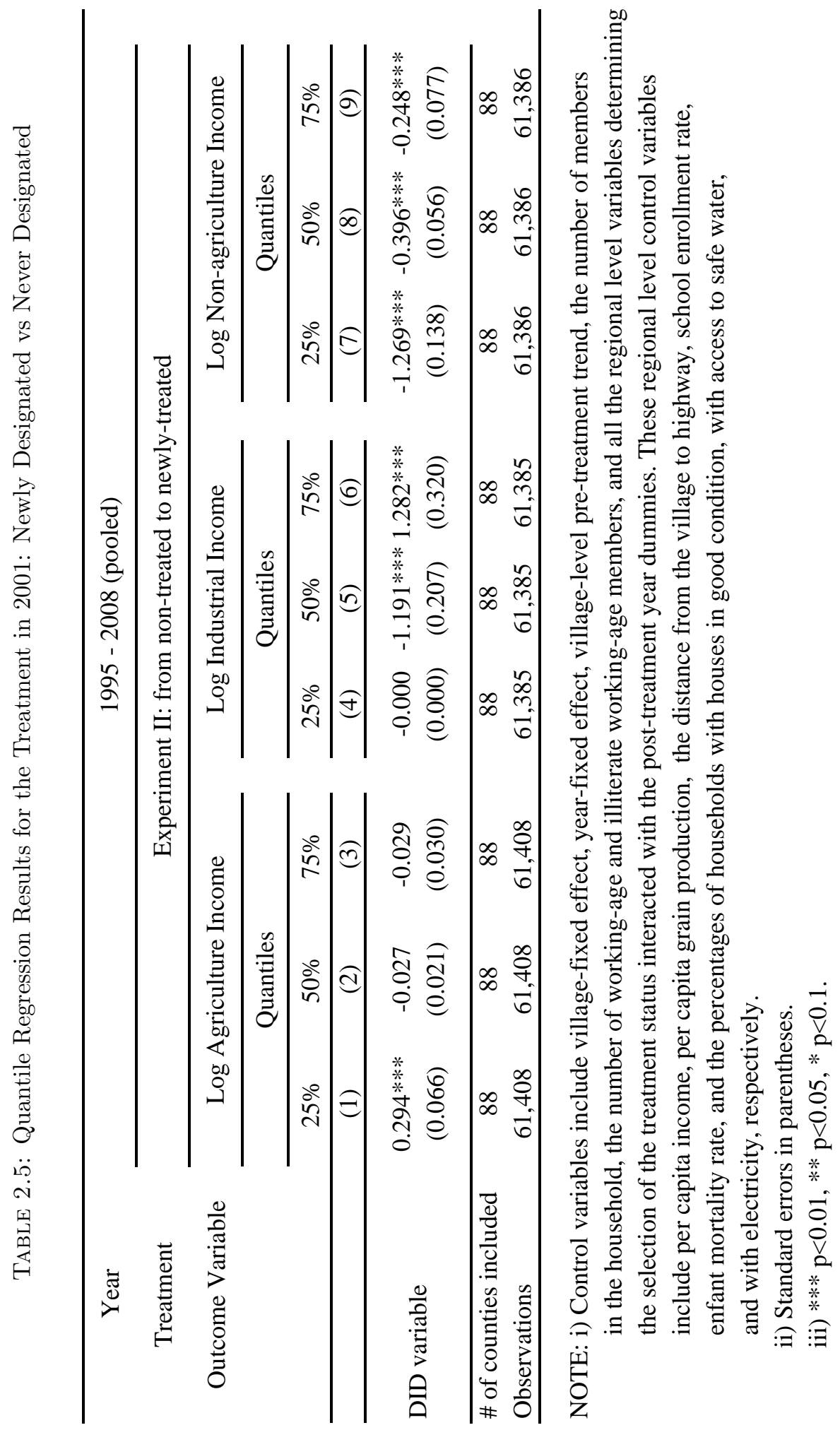




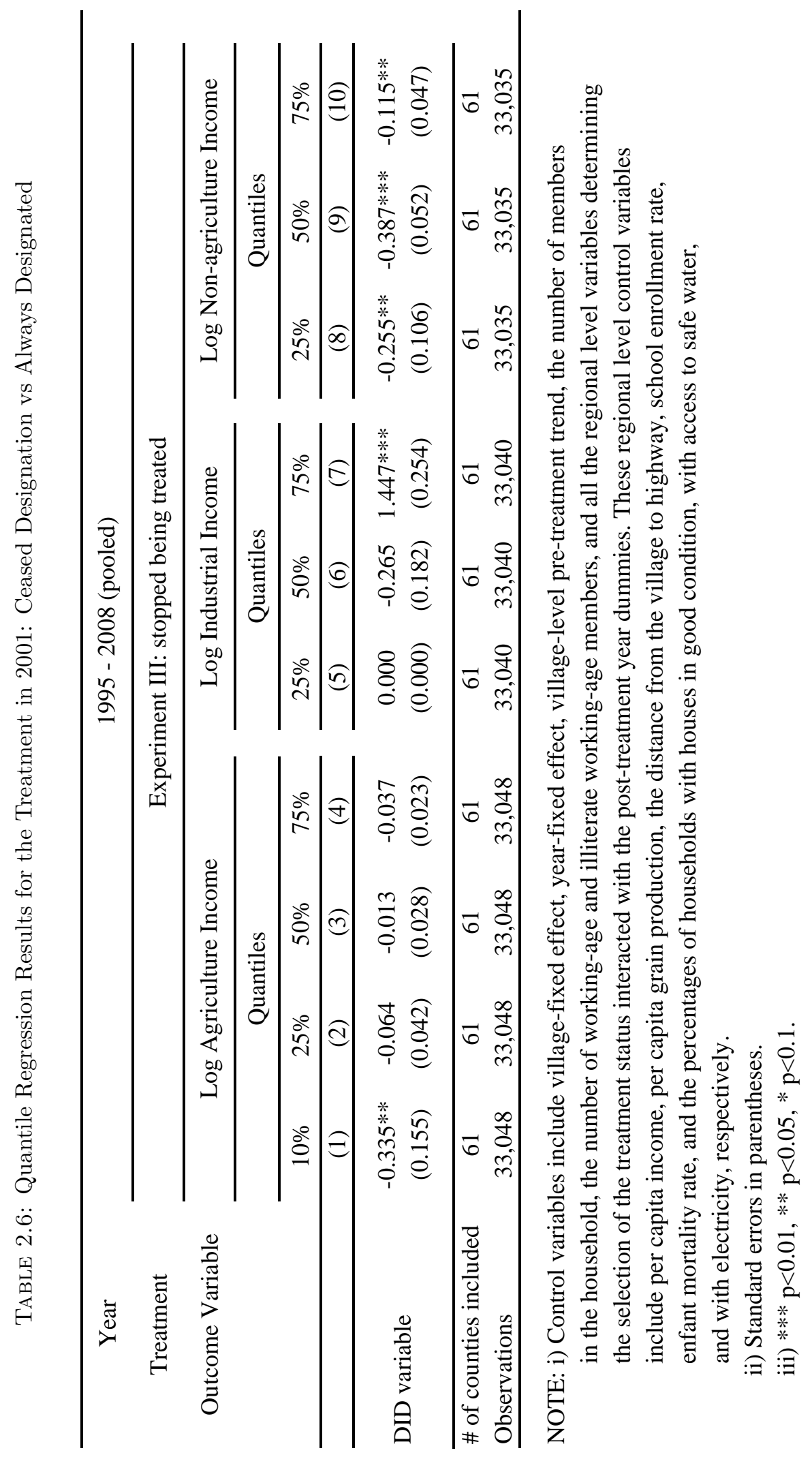




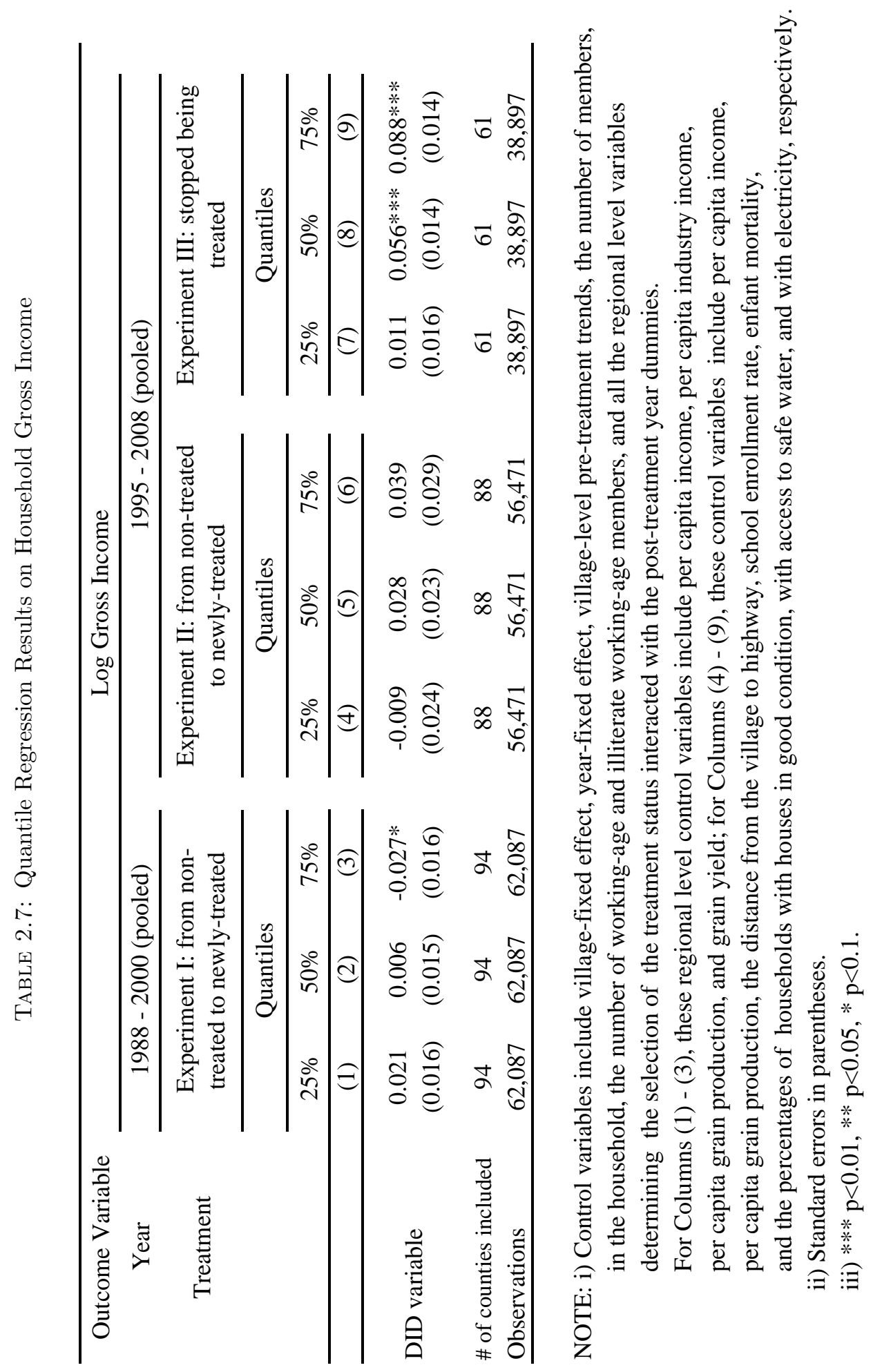




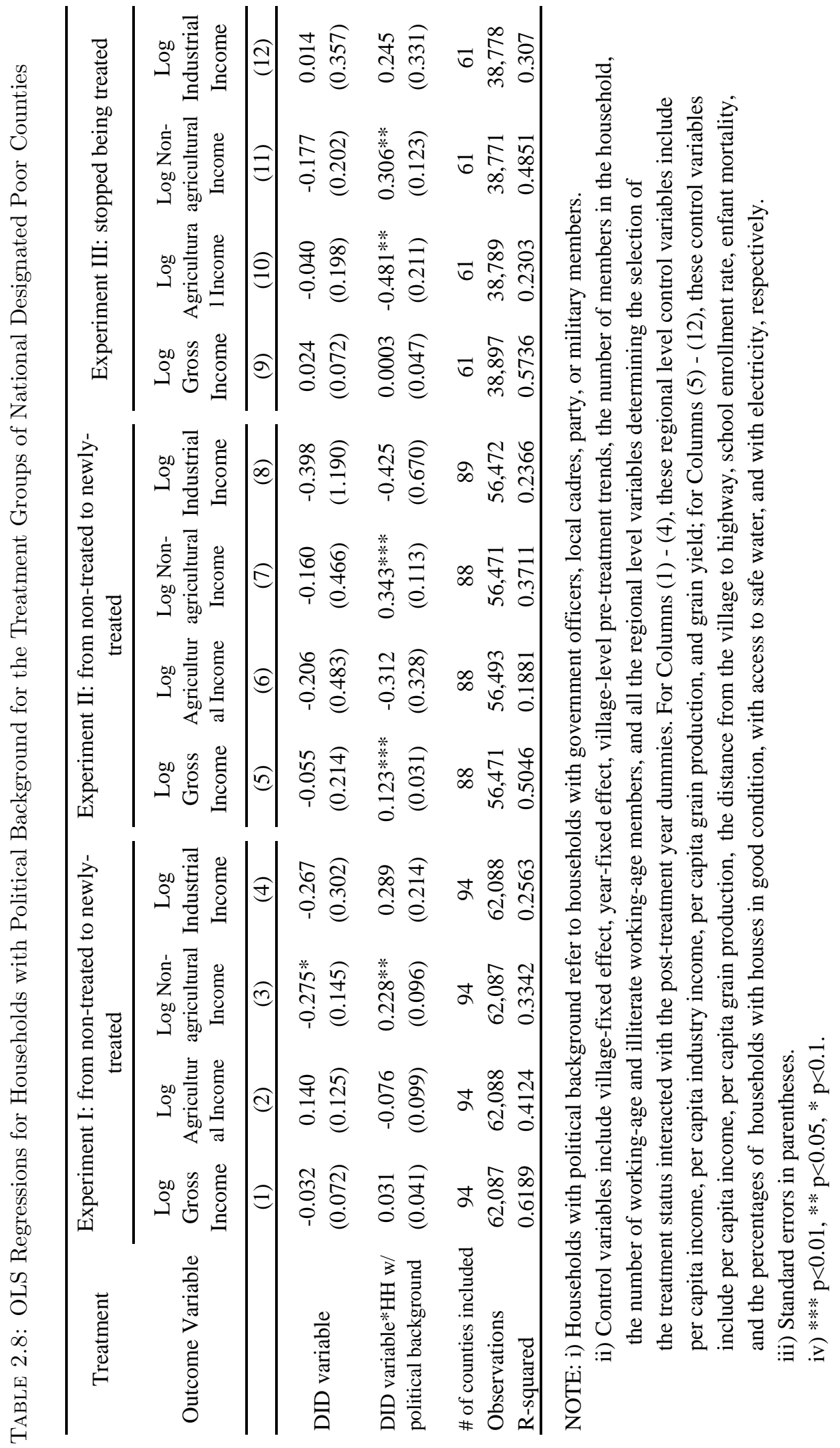




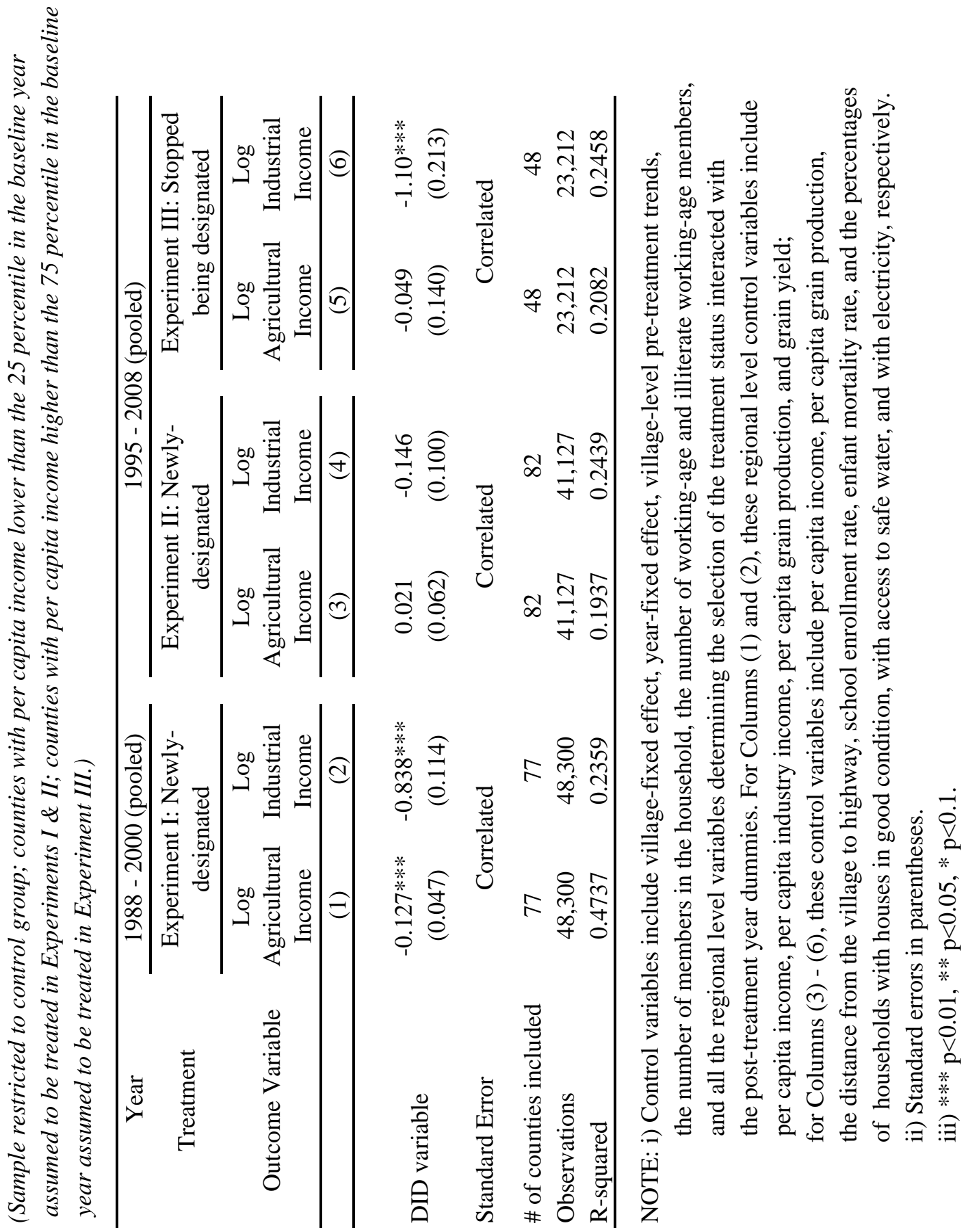




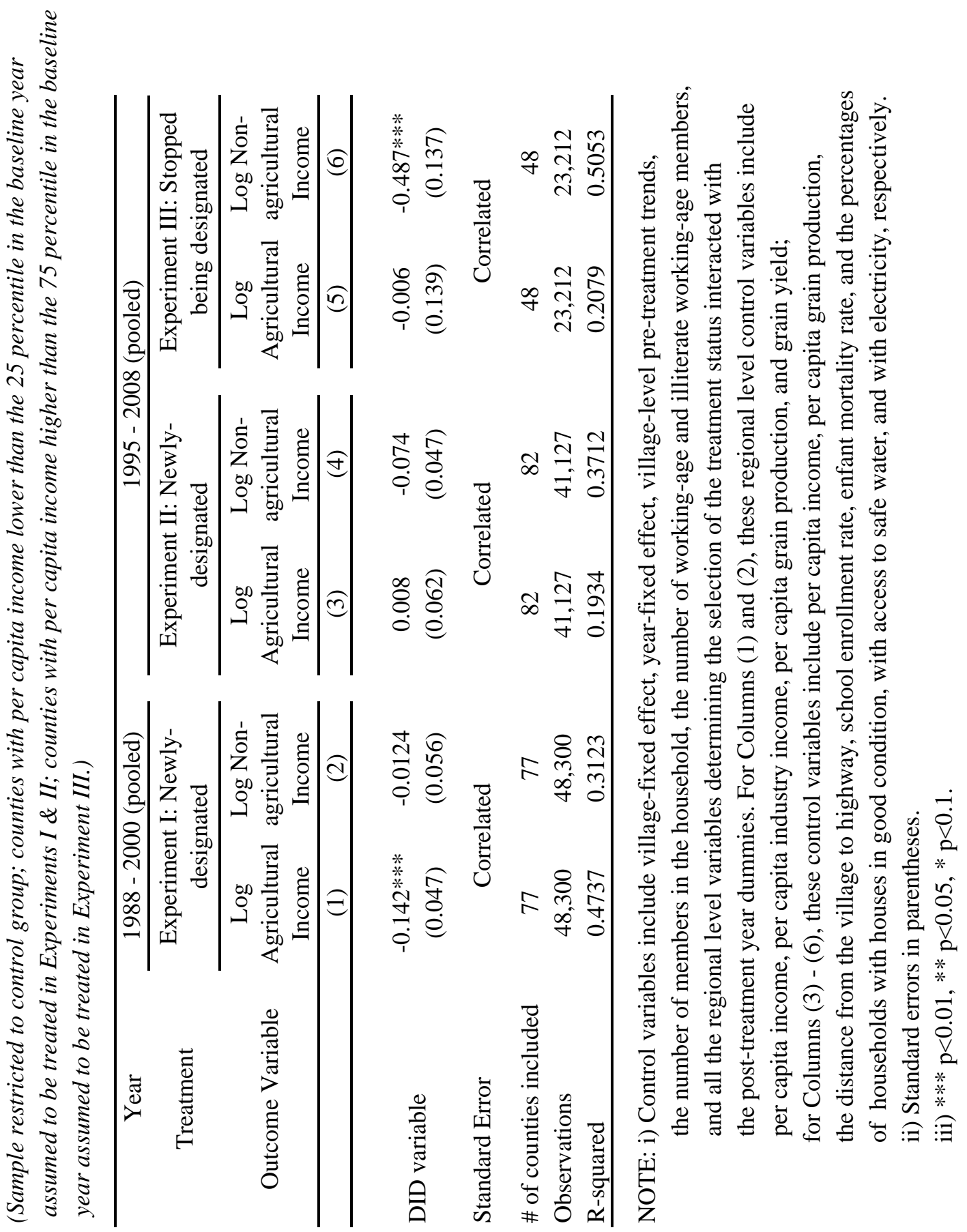




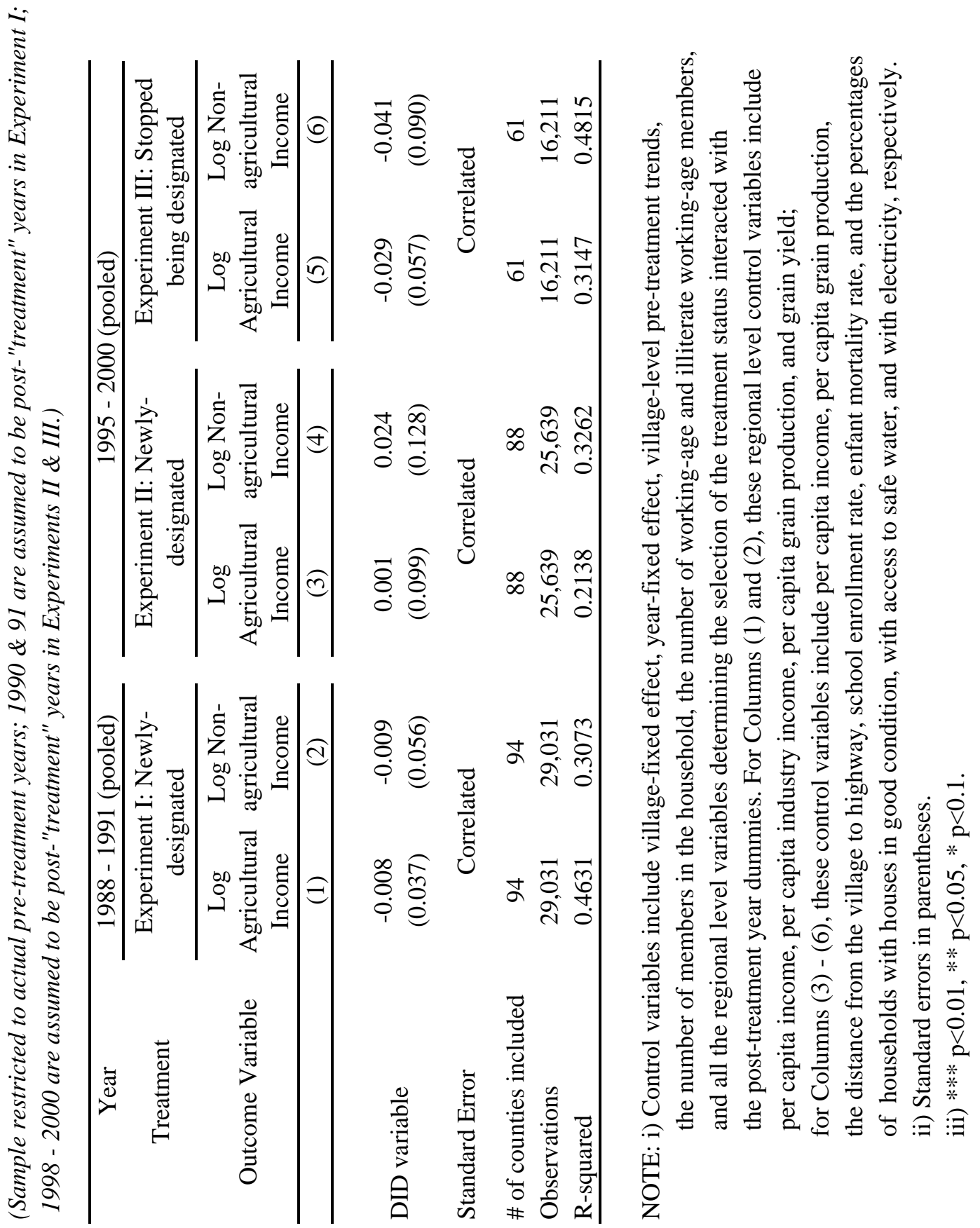




\section{Chapter 3}

\section{The Unintended Consequences of Employment-Based Safety Net Programs \\ (co-authored with Sheetal Sekhri)}

\subsection{Introduction}

Employment Guarantee Schemes have been widely used as anti-poverty policies both in developed and developing countries. ${ }^{1}$ As one of the most successfully implemented safety net schemes, these programs smooth income shocks for vulnerable populations. Consequently, these schemes can affect what beneficiaries spend on their children directly through income and substitution effects. We focus on schooling outcomes, which involve an investment in the human capital of the next generation. This paper uses the temporal and spatial variation in the roll-out of the Indian government's 2005 National Rural Employment Guarantee Act (NREGA, now named MGNREGA) to evaluate the impact of the policy on children's educational and employment outcomes.

\footnotetext{
${ }^{1}$ The earliest experiments with this policy lever date back to the 1817 Poor Employment Act and the 1834 Poor Law Amendment Act in Great Britain (Blaug, 1963, 1964), and the New Deal program of the 1930s in the United States (Kesselman, 1978; Bernstein, 1970). More recently Chile in 1987, India in 1978 and 2001, Pakistan in 1992, Bangladesh in 1983, Philippines in 1990, Botswana in 1960, and Kenya in 1992 have implemented variants of employment grantee schemes. See Mukherjee and Sinha (2013) for details.
} 
Employment guarantee schemes can influence schooling outcomes in opposite directions. The schooling outcomes can improve due to an income effect. However, if adult's work on government program sites, labor becomes scarce, increasing the shadow value of children's time to work either on farms or in the household. The resulting substitution effect arising from intra-household reallocation of labor, could result in deterioration of schooling outcomes. The net result is theoretically ambiguous and depends on which effect dominates. ${ }^{2}$ This paper evaluates the impact of MGNREGA on school enrollment in rural India, shedding light on relative magnitude of the income effect versus the substitution effect.

A number of factors make India's flagship MGNREGA program an ideal setting to study the impact of employment guarantee schemes on schooling and child labor. First, the massive scale of this program makes India a compelling case to study. The program started in 2006, and by the school year 2010-11 the program provided employment opportunities to 53 million households for 2.3 billion man-days, making it the world's largest operating employment guarantee scheme. Second, the program was gradually rolled out in the districts of India as per their "backward" status, which was defined on the basis of pre-determined characteristics measured 10-15 years prior to the program. This variation provides an excellent opportunity to evaluate the impact of this program.

Using a longitudinal data set of 1.13 million primary and upper-primary schools in India, we compare within school enrollment across the districts which received the program early versus late. We find that, conditional on school characteristics, post treatment growth in enrollment slows down in districts where the program is phased in early, and this result is driven by primary schools rather than upper primary schools. This suggests that primary school aged children are either substituting for adults in household production, out of home production, or are being withdrawn from school due to lack of after school adult supervision at home. Qualitative reports indicate that primary age children are substituting for in home production such as taking care of younger siblings and animals or escorting parents to the work sites. Using data from employmentunemployment surveys of India, we directly examine the effect on children's employment and doing chores. We find consistent evidence. Children's likelihood of being employed increases in early phase districts post treatment, whereas the effect on chores is statistically insignificant. Responses to the program are heterogeneous. The effect is driven

\footnotetext{
${ }^{2}$ Alternatively, if parents participate in the program, they may not be able to pick up the children from school and provide after-school supervision, preferring to withdraw them entirely and bring them to work sites.
} 
by enrollment in private schools. ${ }^{3}$ On the intensive margin, we observe deterioration in the performance of students in grade 7 but not in grade 5 .

In order to address non-random placement of the program, we control for the three characteristics that determine the program roll out: district Schedule Caste and Tribe population in the 1991 Census of India, 1996-97 agricultural wages, and the 1990-1993 output per agricultural worker. We include both school and year fixed effects to control for school specific time invariant heterogeneity, and macro trends in enrollment. We also include state-by-year time trends to control for state-specific funding decisions that may impact schooling outcomes. In order to control for supply side effects, we include a very comprehensive set of school- and district-level controls. We also include school type by year fixed effects to allow for differential enrollment trends in government and private schools. Using the data for three years before the policy was implemented (2003-2005) for a large sub-sample of the states, ${ }^{4}$ we also compare the pre-trends in the districts that received the program early to the ones that received it late. We do not see any evidence of differential pre-trends in enrollment. Using this sample, we demonstrate that controlling for changes in yearly enrollment from 2003 to 2005 and allowing the trend to vary over time in subsequent years does not change our results. We show that results are similar in the full sample and in the sub-sample for which we have pre-treatment data to rule out bias emerging from selection into the sample. We also show that the timing of the change in enrollment coincides with the introduction of MGNREGA in early districts.

Our paper contributes to four strands of literature. The first strand examines the causal effects of employment guarantee schemes and other safety net programs on development outcomes. Several other studies have evaluated safety net programs, and in particular, this program. ${ }^{5}$ Previous evaluation has shown that MGNREGA increased unskilled wages (Imbert and Papp, 2015; Azam, 2012; Berg et al, 2012) and female labor force participation (Azam, 2012). Imbert and Papp (2015) develop a theoretical model of labor markets. They use their model to isolate the general equilibrium effects on wages and quantify the redistributive welfare effects of the program. Using survey data, Ravi

\footnotetext{
${ }^{3}$ A number of surveys in India show that the quality of private schools in India is much better than public schools and private schools are much more expensive (Muralidharan and Kremer (2007); Desia et al (2008))

${ }^{4}$ Only 10 states and union territories covering a very small fraction of rural India are excluded in the pre-trend comparison.

${ }^{5}$ See Skoufias and Parker(2003) for an in-depth analysis of the effects of Mexico's PROGRESA on child outcomes. PROGRESA is a conditional cash transfer program where transfers to the households were conditioned on children's attending school. So the incentives households face are very different from MGNREGA.
} 
and Engler (2009) evaluate the effect on the consumption of the participating households relative to non-participants. Afridi et al (2012) examine the effects of a relative increase in mothers' income on schooling outcomes exploiting the increase in women's employment resulting from MGNREGA in a few districts in one state. We complement this literature and examine the effects of the program on schooling outcomes more generally. ${ }^{6}$ Further more, we show that the program has an unintended effect on child labor increasing likelihood of being employed. Our findings have important policy implications: without adequate changes in incentives to attend school, large scale safety net programs designed to smooth household consumption may result in decreased school enrollment.

Our study also contributes to the literature on identifying general equilibrium effects of social programs. Angelucci and Giorgi (2009) show that cash transfer programs can increase the consumption of non-beneficiaries through transfers within social networks. Jayachandran et al (2011) find that food subsidy programs can affect prices of food and other durable household purchases. Ardinton et al (2009) find that social transfers affect labor supply in South Africa. More closely related to this paper, Imbert and Papp (2015) show that employment guarantee programs affect rural wages and employment. They find that MGNREGA had re-distributive effects on rural wealth. We examine the consequences of this widely used program on schooling and employment outcomes of children.

We also contribute to a growing body of research on targeting in social programs. Nichols and Zeckhauser (1982) and Besley and Coate (1992) present theoretical arguments for using micro-ordeals such as work for benefits in designing poverty alleviation programs. Alatas et al (2013) and Dupas et al (2013) empirically study the efficacy of micro-ordeals in welfare targeting. Our study has important implications for policy design. We show that micro-targeting that involves work for benefit can have perverse effects on children and lower their human capital accumulation. This effect needs to be factored in welfare calculations.

\footnotetext{
${ }^{6}$ Unlike Afridi et al (2012), we do not find an improvement in schooling outcomes. There are a number of differences between our paper and their study. While Afridi et al (2012) focus on one state, we use data from the entire country from 2005 to 2008. Their study uses data from 5 districts in Andra Pradesh from 2007 and 2009. Hence, our design allows us to understand nation wide effects of the program. By 2007, MGNREGA was already implemented in the poorest parts of the country, and was being implemented in the rest of the districts. Hence, their study only makes post introduction comparison and uses the intensity of exposure for identification. We use the roll-out timing for identification and compare outcomes pre- and post-implementation. We also examine a very rich set of schooling outcomes, whereas they focus on time spent in school.
} 
Finally, our paper also contributes to the literature on child labor. ${ }^{7}$ Basu and Van (1998) provide a theoretical model that examines conditions under which children work in the labor market. Edmonds (2005) uses data from Vietnam to examine whether improving standards of living reduces child labor. Edmonds and Pavnick (2004) examine the effect of international trade on children's outcomes. Jacoby and Skoufias (1997) study the effects of financial market incompleteness and human capital accumulation. Their main finding is that seasonal fluctuation in school attendance is a form of self-insurance by households. We contribute to this literature by examining the effects of a permanent increase in household income on decision to enroll in school or participate in labor market. Our findings indicate that children are induced to substitute for adults in other activities in response to increased labor opportunities for adults resulting from the program's introduction.

The rest of the paper is organized as follows: In Section 3.2, we offer more detailed information on the MGNREGA in India. Section 3.3 discusses a simple conceptual framework to motivate the empirical analysis. Section 3.4 presents the data used and Section 3.5 presents the empirical strategy. Section 3.6 documents the results. Section 3.7 provides the results of the robustness tests. Sections 3.8 and 3.9 rule out alternate explanations and highlight the caveats. Section 3.10 offers concluding remarks.

\subsection{Contextual Information}

\subsubsection{Background-National Rural Employment Guarantee Act}

The National Rural Employment Guarantee Act, passed in 2005 (now called Mahatma Gandhi National Rural Employment Guarantee Act), provides 100 days of guaranteed wage employment per financial year to every individual residing in rural India. The program provides unskilled manual work at the officially determined minimum wage of about 2 USD per day. In a district covered by the program, an adult can apply for work under MGNREGA and is entitled to public works employment works within 15 days; otherwise, the state government provides a payment of unemployment allowance (Ministry of Rural Development, 2008b). Typical projects under MGNREGA are road construction, earthworks related to irrigation, water conservation, or other rural public projects (Azam, 2012). Any households living in the rural area can apply to work, but they cannot choose what type of project to work on. To become a beneficiary of

\footnotetext{
${ }^{7}$ See Basu (1999) for a review of this literature.
} 
NREGA, adults residing in rural household need to apply for a job card (free of cost) at the local Gram Panchayat where they reside. ${ }^{8}$ Within 15 days of application, the Gram Panchayat issues the Job Card, which bears the photographs of all adult members of the household willing to work under MGNREGA. Meanwhile, a 33\% participation rate for women is mandatory under MGNREGA (Ministry of Rural Development, 2008b).

While the wage is set by each state government, the central government is responsible for the entire cost of wages of unskilled manual workers and $75 \%$ of the cost of material and wages of skilled and semi-skilled workers. On the other hand, the state governments bear the cost of material and wages of skilled and semi-skilled workers, as well as the cost of the unemployment allowance (Ministry of Rural Development, 2008b). Wages are typically paid by piece-rate, but some areas also pay fixed daily wages. Daily earnings are below the set wage due to theft and leakage in the program. ${ }^{9}$ Imbert and Papp (2015) claim that despite its shortcomings, the program is effective at attracting casual labor relative to the private sector.

The budget for MGNREGA is almost 4 billion USD, 2.3 percent of total central government spending, which makes the program the best endowed anti-poverty program in India (Ministry of Rural Development, 2008a; Azam, 2012). The program provided 2.27 billions person-days of employment to 53 millions households in 2010-11 with the whole budget in the country Rs. 345 billions (7.64 billions USD); representing $0.6 \%$ of the GDP (Imbert and Papp, 2015).

\subsubsection{Roll-out of the MGNREGA Program}

MGNREGA was implemented in three phases. Backwardness status of the districts was used to determine roll-out priority with representation in Phase-I provided to each state. The Planning Commission of India explicitly calculated and ranked the backward status of Indian districts (Planning Commission, 2003). The official ranking of backwardness of the districts in each state was based on the Scheduled Caste and Tribe population in 1991, agricultural wages in 1996-97, and output per agricultural worker in 1990-93. In the first phase of the program, 200 backward districts were notified to implement the policy in February 2006. The program was then introduced in additional 130 districts

\footnotetext{
${ }^{8}$ A Gram Panchayat usually comprises of a group of villages, and is the lowest level of administration in the Indian government (Azam, 2012).

${ }^{9}$ See Niehaus and Sukhtankar, 2008 for details.
} 
in the second phase in April 2007, ${ }^{10}$ and all the remaining 270 districts received the program in the last phase in April 2008. ${ }^{11}$ Figure 3.1 shows a map of the districts coverage by phases. Currently, the scheme covers the entire country with the exception of districts that have one hundred percent urban population (Ministry of Rural Development, 2008b). This variation in the introduction of the program enables us to identify the causal effect of this scheme on schooling outcomes. ${ }^{12}$

\subsection{Conceptual Framework}

Decision to Enroll in School: A number of research studies have shown that rural wages increased in response to the introduction of the program (Azam, 2012; Berg et al, 2012; Imbert and Papp, 2015). In a framework where rural households are choosing to send their children to school or not, this would result in an increase in the income and liquidity of the rural households, and hence have a positive effect on enrollment. The program also mandated that 33 percent of the jobs be reserved for women. An increase in the income of the mother may have an independent positive effect on children's enrollment in school due to improved bargaining power within the household (Qian, 2008; Duflo, 2003 ; Thomas, 1994). On the other hand, there are several factors that can reduce enrollment. Women's labor force participation may adversely affect enrollment by raising the shadow value of children's time working in the household. Children of school going age may substitute for adults to provide child care for younger siblings. In the absence of availability of after school care, women may want to take their children to work sites. Finally, if labor farm becomes scarce, children may work in the farms while adults find jobs under MGNREGA. Thus, children may substitute for adult labor in the farm sector or household production. These factors may reduce the enrollment in school. ${ }^{13}$ Thus, given these opposing effects, the program yields ambiguous effects theoretically.

\footnotetext{
${ }^{10}$ The program commenced in May in 17 Phase-II districts in Uttar Pradesh due to state legislative assembly elections

${ }^{11}$ Due to splitting of districts for which data for the parent and split district was not available in all years, the number of districts in our sample are 193, 123, and 254, respectively.

${ }^{12}$ Prior to February 2006, the government experimented with a pilot program (the Food for Work Program) in November 2004 in 150 of the 200 Phase-I districts. Field observations (Dreze, 2005) and research studies (Imbert and Papp, 2015) have found little evidence of increase in public works due to this pilot.

${ }^{13}$ Note that liquidity constraints can impede households from sending their children to school (Edmonds, 2006). Households will also weigh the immediate pecuniary benefits of enrolling children in the schools against the cost. Thus, the pecuniary benefits of school enrollment (for example- if midday meal is offered) will have an impact on the enrollment decision.
} 
We use school level enrollment data to understand the relative importance of the above mentioned mechanisms. An increase in enrollment will imply that the income effect dominates. However, a decline in enrollment is consistent with four possible explanations: (1) Children substitute in for adults outside the house, (2) Children substitute in household production, (3) Adults are unable to find suitable after school child care so they take their children to work sites with them, (4) Returns to schooling fall locally due to the program so children are withdrawn from school. ${ }^{14}$ It is also possible that among those who are enrolled, children could be reducing the hours devoted to school work. We also examine schooling outcomes to explore this intensive margin effect. We use data from the National Sample Survey Organization (NSSO) employment and unemployment surveys (rounds from 2004-05 to 2008-09) to shed light on these mechanisms.

\subsection{Data}

The principal source of data is the annual panel of Indian elementary schools called the District Information System for Education (DISE). ${ }^{15}$ The data covers grades 1 through 8 in 1.13 million schools in the country. School characteristics include: staff characteristics such as gender and qualification of teachers, infrastructure measures including availability of common toilets, gender specific toilets, drinking water facilities, and electrification, and enrollment by gender and grade. The data also include appearance and pass rates for school examinations for grades 5 and 7 and grade repetition for all grades. Primary schools in India may have only primary classes (grades 1 through 5 ), only upper-primary classes (grade 6 through 8), or both (grade 1 through 8). The data provide information about whether the school offers only primary classes, only upperprimary classes, or both. The school management categories in the data include (1) Department of Education, (2) Tribal/Social Welfare Department, (3) Local body, (4) Private Aided, (5) Private Unaided, (6) Others, and (7) Un-recognized. We construct three aggregate categories - government run schools (1 and 2), private schools (4 and 5 ) and others $(3,6$, and 7$)$. In addition to these features, the data report ongoing incentive schemes in various schools to increase enrollment. Various schemes running in

\footnotetext{
${ }^{14}$ Jensen (2010) shows the enrollment in India responds to information about returns to education.

${ }^{15}$ DISE is collected every year in a joint collaboration between the Government of India, UNICEF, and the National University of Educational Planning and Administration (NUEPA). The data is publicly available from NEUPA.
} 
schools before MGNREGA provide free uniforms, textbooks, stationery, and attendance fellowships. ${ }^{16}$

The district level characteristics are from the Census of India 1991 and 2001. These include total population, population growth rate, percentage of female population, literacy rate, female literacy rate, percentage of Scheduled Caste and Scheduled Tribe population, and percentage of working population. Agricultural wages 1996-97 and total output per agricultural worker for 1990-93 are from the Planning Commission's 2003 report. Tables 3.1, 3.2, and 3.3 present the summary statistics.

Table 3.1 provides the summary statistics for the outcome variables for the schools in the sample period. The average enrollment is 220.22 students per school, of these 114.8 are boys and 106 are girls. Average enrollment in primary classes is higher at 214 students compared to 108 in upper primary classes. The pass rate for enrolled students is approximately 90 percent for grade 5 and 87 percent for grade 7 . Some children do not take exams and the pass rate in grades 5 and 7 conditional on taking exams is 96 and 91 percent, respectively. Passing with 60 percent or above marks is around $43 \%$ in grade 5 , and falls to $39 \%$ for grade 7 .

Table 3.2 provides the summary statistics of outcome variables by phases of MGNREGA districts. Consistent with the roll-out criterion, Phase-III districts have better educational outcomes. Finally, Table 3.3 compares the overall characteristics of the districts in the three phases of MGNREGA. While there is no difference in the population growth rate, the literacy rate is much higher in Phase-III districts. The three criteria used to determine the roll-out confirm that Phase-I districts are the most "backward". Average Schedule Castes and Tribes population at 38.4 percent is the highest, while agricultural wages and output per worker are the lowest.

\subsection{Estimation Strategy}

We use the timing of roll-out of the MGNREGA program across districts of India for identification. Phase-I districts received the program in February 2006, Phase-II in 2007, and Phase-III in April 2008. We use 2005 as the baseline year and include data

\footnotetext{
${ }^{16}$ These data are collected using a district level administrative structure. School principals fill a standardized survey about the school. The data are manually checked at various levels for completeness, accuracy, and inconsistencies. States also implement checks. NEUPA has commissioned an external audit of the school data. These audits check 5 percent of the schools chosen randomly from at least 10 percent of the districts from each state. The auditors also visit the schools. These audits have established that the enrollment data reported by the principals are remarkably accurate.
} 
from 2005-2008 in our analysis. Later we use data from 2003 to provide support to our identifying assumption.

\subsubsection{Roll-out and Selection}

The timing of the roll-out of the program was not randomly determined. The selection criterion based on characteristics described above would not be orthogonal to schooling decisions of households. For example, higher output per agricultural worker may generate higher income which would affect a household's allocation toward education. Thus, a simple comparison of the districts across different phases is not likely to generate causal estimates of the program. In order to circumvent this issue, we compare outcomes within districts that received program in different phases over time. This allows us to control for time invariant differences in unobserved characteristics of districts that received the program in different phases. We also use within-school variation for identification by including school fixed effects to purge any time invariant school level characteristics that may be correlated with the treatment.

We further interact the three variables determining selection into the phase of roll-out with year indicators to control for trends in these variables. In addition, we include a rich set of district specific controls including: 2001 levels of total population, percentage of rural population, population growth rate, overall literacy rate and female literacy rate interacted with year indicators. We also control for a state specific time trend to control for state specific time-varying unobserved heterogeneity, such as discretionary state-level education funding. We allow for a differential trend for government and private schools over time by interacting school type with year indicators.

Our identifying assumption is that the outcomes in districts that received the program in different phases are not trending differentially prior to treatment after controlling for trending program criteria. For a sub-sample of states for which data is available from 2003 , we show that growth in school enrollment in districts that received the program in different phases is very similar prior to the program. We also show that the withinschool results are invariant to including changes in enrollment from 2003 to 2005 . We do not have data from 2003-2005 for 10 small states and union territories. We verify that excluding these 10 states in our empirical analysis does not influence the results to rule out selection into the sample. 


\subsubsection{Estimation Procedure}

We use school level data from 1.13 million schools from 2005 to 2008 to test our hypotheses. Our empirical specification is as follows:

$Y_{i d s t}=\alpha_{0}+\alpha_{1} M G N R E G A_{d t}+\alpha_{2} X_{i d s t}+\alpha_{3} Z_{d s} * T_{t}+\alpha_{4}$ State $_{s} *$ trend $+T_{t}+I_{i d s}+\epsilon_{i d s t}$

where $Y_{i d s t}$ is the outcome variable for school $i$ in district $d$ in state $s$ in year $t$. $M G N R E G A_{d t}$ is an indicator that takes value 1 if district $d$ in state $s$ has started the MGNREGA program in year $t$, and 0 otherwise; $X_{i d s t}$ is a vector of school level controls including different kinds of incentives received by the students, and the characteristics of the teachers and infrastructure of the school $i$ in district $d$ in state $s$ in year $t$; $Z_{d s}$ is a vector of district-level controls for demographic characteristics, and is interacted with year indicators to control for trends; State $_{s}$ is a vector of state indicators, and is interacted with time trends to control for state-specific trends; $T_{t}$ and $I_{i d s}$ are year- and school-fixed effects,respectively, and $\epsilon_{i d s t}$ is the idiosyncratic error term. We drop the MGNREGA phase indicators due to multi-collinearity in our school fixed effects model. We cluster errors at the district level to account for arbitrary correlation over time.

In order to examine the school choices by school type, we interact the introduction of MGNREGA with the type of school. The empirical model is as follows:

$$
\begin{aligned}
Y_{i d s t}= & \beta_{0}+\beta_{1} M G N R E G A_{d t}+\beta_{2} P_{i d s} * M G N R E G A_{d t}+\beta_{3} G_{i d s} * \text { MGNREGA } A_{d t} \\
& +\beta_{4} X_{i d s t}+\beta_{5} Z_{d s} * T_{t}+\beta_{6} \text { State }_{s} * \text { trend }+\beta_{7} \text { Schooltype }_{i} * T_{t}+T_{t}+I_{i d s}+\epsilon_{i d s t}
\end{aligned}
$$

where $Y_{i d s t}$ is the outcome variable for school $i$ in district $d$ in state $s$ in year $t$. $P_{i d s}$ is an indicator equal to 1 for private schools and 0 otherwise and $G_{i d s}$ is an indicator which takes value 1 for government schools and 0 otherwise. The omitted category is others. We include the the interaction of the MGNREGA policy indicator with each of these type indicators to examine whether enrollment differs by school type. Schooltype are indicators for government and private schools, and these are interacted with year indicators to control for differential trends in different types of schools. Note that once we include the school fixed effects, indicators for school type (private and government) are not included as these are time invariant properties of schools. As before, we also drop the phase indicators due to multi-collinearity in the school fixed effects model.

The outcomes we examine are: enrollment, pass rate, pass rate conditional on taking the exams, pass rate of those who pass with more than 60 percent marks. 


\subsection{Results}

\subsubsection{Overall Enrollment}

We test the implications of the the conceptual framework we presented in Section 3.3. First, in order to evaluate the effect of MGNREGA on equilibrium overall enrollment, we estimate equation 1 and present the results in Table 3.4. Column (i) presents the basic difference-in-difference specification with school and year fixed effects. This result is robust to controlling for state specific time trends as reported in Column (ii), which may capture state spending priorities. Both specifications control for district level controls that influenced the roll-out priorities. We control for the Scheduled Castes and Tribes population as per Census of India 1991, agricultural wage in 1996-97, and output per agricultural worker in 1990-93, interacted with time indicators to account for the backward district status that influenced selection into the program. In addition, we also control for the districts level total population, percentage of urban population, population growth rate, overall literacy rate, and women's literacy rate. The schoollevel controls include any attendance scholarships being offered at the time, uniform, books, stationery and other such subsidies offered to girls, the number of classrooms, the number of classrooms in good condition, availability of common toilets, girls toilets, drinking water facilities, electrification status, number of male teachers, and number of female teachers.

The coefficient in Column (i) is -2.23 and is statistically significant at the 5 percent level. Overall, enrollment in this period is increasing and thus this coefficient indicates that introduction of MGNREGA results in a smaller increase in within school enrollment in treated districts across the years in the sample. Hence, implementation of MGNREGA results in relative slower growth in enrollment, with 2 fewer children enrolled per school in the treated districts.

When split by primary and upper primary grades, it is clear that this effect is driven by primary classes where the magnitude is 2.23 (Columns (iii) and (iv)). This implies that young children either substitute for adults in home production or are being taken to work sites due to unavailability of suitable after school child care. We do not find any change in the enrollment of children in upper-primary classes. Since these children are already past elementary school (which is free in case of government schools), it is 
possible that households do not want to withdraw these children from schools as they have invested in their schooling substantially. ${ }^{17}$

\subsubsection{Effects on Enrollment by Type of Schools}

In order to examine if the type of school that children attend is affected due to an increase in the income of the parents, we evaluate equation 2 and report the results in Table 3.5. In Table 3.5, we show the interaction of the MGNREGA implementation policy dummy interacted with government school indicator and private school indicator. The excluded category is 'other types' schools. Columns (i), (iii), and (v) repeat the results of the estimation of equation 1 for overall enrollment, primary enrollment and upper-primary enrollment with additional controls for school type by year fixed effects.

Overall enrollment in government schools is not influenced, whereas there is a significant reduction in enrollment for private schools (Column (ii)). The coefficient on the interaction term with the private school indicator is significant at the 5 percent level. This result is driven by primary schools (Columns (iii) - (vi)). Since 66 percent schools in the data are government schools and only 13 percent are private schools, the decrease in enrollment per private school is much larger in magnitude. The effect of the program on overall enrollment is small in magnitude. Using the average number of government, private and other schools per district in the sample period, our results indicate that 9,824 children per district are not attending school due to the program. ${ }^{18}$

\subsubsection{Schooling Outcomes}

We examine the effect on schooling outcomes to determine if the program has intensive margin effects. Data reports passing outcomes and passing with more than 60 percent for grade 5 and grade 7 . In Table 3.6, we show that the passing rate in government schools falls by 1.8 percent for grade 7 students (Columns (ii) and (iv)) with the coefficient significant at the 10 percent significance level, whereas there is no effect on grade 5 (Columns (i) and (iii)). Passing with more than 60 percent marks undergoes a significant change. For grade 7 students, both in private and government schools, there is a decline

\footnotetext{
${ }^{17}$ However, it is also possible that households who are employed in MGNREGA sites are younger and do not have children beyond the primary grades. In our subsequent analysis, we do observe heterogenous effects on children in upper primary schools as well. Hence we do not think that participating household's demographic composition is driving these results.

${ }^{18}$ In results not shown, we do not find any differences in effects for girls versus boys.
} 
in pass rate with more than 60 percent marks. This effect is almost twice as large for government schools than the private schools and the difference is statistically significant (Columns (vi) and (viii)).

Thus, younger children seem to be effected on the extensive margin and their enrollment falls. Older children, on the other hand, continue in school but their schooling outcomes deteriorate.

\subsubsection{Mechanisms}

Several qualitative findings corroborate our quantitative finding that the program induces primary school aged children to withdraw from school. ${ }^{19}$ In order to shed direct light on the mechanism, we examine the employment outcomes of children in our DID framework. The data on child labor come from the National Sample Survey Organization (NSSO) employment and unemployment surveys (rounds 2004-05 to 2008-09) and we employ earlier rounds to carry out a falsification check. The data asks individuals to identify their principal occupation in the last month. We examine two outcome variables: Child reports working (employed, self employed or unpaid family labor) and child reports doing chores (housework or free collection of goods). We restrict our sample to 206,321 non-disabled children aged between 5 and 15 from the two rounds and look at their reported principle activities. The indicator for 'working' equals to 1 if a child's reported principle activity is working in the household enterprises (paid or unpaid), as wage employee, or in other types of work, and 0 otherwise. The indicator for doing chores is 1 if a child's reported principle activity is attending to domestic duty or doing any other housework, and 0 otherwise. ${ }^{20}$

The empirical model is as follows:

$$
L_{i d s t}=\gamma_{0}+\gamma_{1} \text { PhaseI } * \text { Post }+\gamma_{2} \text { PhaseII } * \text { Post }+\gamma_{3} Z_{d s} * T_{t}+T_{t}+I_{d s}+\epsilon_{i d s t}
$$

\footnotetext{
${ }^{19}$ The field work conducted by Centre for Social Protection (Sudarshan, 2011) indicates that a majority of women who work in MGNREGA projects take their primary school aged children to work sites or leave them at home to provide child care for younger siblings. The study conducted semi-structured interviews of the women on NREGA sites in various districts. One woman reported "Nobody is there to look after the child. Women have to take care of their own children. Some women do come with a small baby but they bring along an older son or daughter to take care of the infant while the woman carries out her work." The field investigators reported that older children seemed to be 10 to 12 years old. When the interviewer asked if these children go to school, one woman said, "Madam jo site par jayega woh school kaise ja sakta hai?" (If a child has to go to the site how can she go to school?). At another place, the response was, "Women do not come with their children but leave their children at home with other siblings who look after them." Other field studies have reported similar findings (Bhatty, 2006).

${ }^{20}$ Other alternatives for principle activity include attending educational institution, seeking jobs, rentiers, pensioners, remittance recipients, and others.
} 
where $L_{i d s t}$ is the reported labor outcome of child $i$ in district $d$ in state $s$ at time t. PhaseI and PhaseII are the indicators for the respective phases; $Z_{d s}$ is a vector of district-level controls for demographic characteristics, and is interacted with year indicators to control for trends; $T_{t}$ and $I_{d s}$ are year- and district-fixed effects, respectively, and $\epsilon_{i d s t}$ is the idiosyncratic error term.

After the program, there is a 1.33 percent increase in the likelihood of child reporting working in Phase-I districts relative to Phase-III districts (Column (i) of Table 3.7). This is significant at the 5 percent significance level. In Phase-II districts, this effect is 1.17 percent increase marginally significant at the 10 percent significance level. We cannot reject the equality of these two coefficients. In column (ii), we do not find any changes in reporting doing chores. Hence, these effects are driven by increase in labor substitution. Our findings indicate that child labor supply increases in response to the program.

\subsection{Robustness Checks and Sensitivity Analysis}

Our identifying assumption is that there are no pre-trends in enrollment in districts belonging to different phases prior to MGNREGA's implementation. DISE data is not available for all states prior to 2005, although major states are covered since 2003. We use data from 2003 to 2005 to check if there are differential pre-trends in enrollment by phases of MGNREGA roll-out. Since we are using a sub-sample of states from our main sample to conduct this test, we first show that this sub-sample is not selected in any way that can confound our results. There are 10 states or Union Territories for which data is not available in years subsequent to 2003 but prior to 2005 and are thus used in the empirical analysis in the paper. ${ }^{21}$ We exclude these states from our sample and replicate the analysis from Table 3.4 and Table 3.5 for only the states for which DISE data is available since 2003. The results from this exercise are reported in Tables 3.10 and 3.11 and are remarkably similar to those reported in Tables 3.4 and 3.5. This test assures that selection into the sample does not confound our results.

Given that our main results are no different if we exclude or include these states, we proceed to show that for the sample for which we have the pre-program data, the pretrends in enrollment are similar. Phase-III districts are better in levels. But the growth

\footnotetext{
${ }^{21}$ These states or Union territories are: Jammu and Kashmir, Haryana, Arunachal Pradesh, Manipur, Daman and Diu, Dadra and Nagar Haveli, Goa, Lakshadweep, Pondicherry, and Andaman and Nicobar Islands.
} 
rate in enrollment is similar. Figures 3.2 and 3.3 show that between 2003 and 2005, the growth in enrollment and number of schools looks similar across districts in different phases. ${ }^{22}$ In Table 3.8, we control for district-specific changes in enrollment from 2003 to 2005 (pre-treatment years) and allow this to vary over time by interacting with year indicators for the states for which we have pre-program data. ${ }^{23}$ The overall effect on enrollment and enrollment by primary and upper primary are similar to those reported in Table 3.5 and Table 3.11. These two tests together show that pre-trends in enrollment are not biasing our results.

We also conduct an event study analysis to examine the timing of the effects for the states that we have the data from 2003 onwards. We run a year-by year difference-in-difference model comparing early versus late MGNREGA districts and plot the coefficients in Figure 3.4. We observe a large decline in enrollment in 2006, the year MGNREGA was introduced and subsequently enrollment in early phase districts continues to be lower relative to the pre-program years. This further substantiates our study design. ${ }^{24}$

In Table 3.9, we run a placebo falsification exercise to test if the increase in likelihood of employment post treatment in Phase-I and Phase-II districts relative to Phase-III districts is due to a pre-trend. We use 1998-99 and 2004-05 years and run the same equation (3) DID empirical specifications as Table 3.7. The results from this placebo test reveal insignificant effects on child employment in in Phase-I and Phase-II districts unlike the results reported in Table 3.7.

\subsection{Alternative Channels}

\subsubsection{Other Programs}

The Government of India introduced two programs in the early 2000s to promote direct enrollment in schools. The first program, the Sarva Shiksha Abhiyan (SSA, was intended to provide universal access to elementary education for children between 6-14 years. SSA directly aimed to increase enrollment, retention, and the quality of education in

\footnotetext{
${ }^{22}$ Limited data for a few states is also available for 2001 and 2002 but the coverage is not as expansive. Since data for many states and many variables is not available, we do not use these years.

${ }^{23}$ We lose 0.7 percent of our sample schools as new districts were carved in 2004 and we are unable to use their pre-trend data.

${ }^{24}$ Note that for 2003 and 2004, we do not have several school level control variables in the data. Specifically, we do not have data on teacher characteristics and school infrastructure variables. Thus, the regression analysis in this event study excludes these variables. Also, we get the same patterns if we use 2002 as baseline year instead of 2003 .
} 
elementary schools by infrastructure provision and scholarships for marginalized social groups. The provisions also aimed to eliminate gender differences. This program was started in 2001, much earlier than the launch of MGNREGA. Although this program targeted educationally backward blocks, these did not coincide with the districts in a particular phase of MGNREGA. Another government of India program, the Midday meal scheme, was also intended to increase school enrollment. This program was in effect prior to 2000 and following a 2001 Supreme Court directive, states increased outlays for this program. Thus the intensity of coverage increased sharply in many states following this directive. This program was in place for several years before the introduction of MGNREGA. In addition, many states increased provision of midday meals at the same time. Therefore, the timing did not coincide with MGNREGA's phased roll-out and we do not think that our results are confounded by these programs.

\subsubsection{Growth and Demand for Private Schools}

One concern might be that the increase in private schools driven by growth in the private school market, independent of the program, affects our results. For example, economic growth may increase the demand for private schooling. During this time, the Indian economy was growing very rapidly and the demand for schooling maybe increasing as well. We see significant declines in the enrollment in the private schools. Hence, an increase in number of schools cannot be causing this decline. Nevertheless, we address this concern. Any global economic shocks are captured by the time fixed effects. In addition, the estimates are robust to including state specific trends, and school type by year fixed effects. Therefore, different trajectories of growth across states is not generating our results and it is unlikely that growth driven demand for private schools drives our results. In addition, we examine trends in expansion of schools visually. Figure 3.5 shows phase wise trends in expansion of schools. Panel A shows trends for government schools and Panel B shows the trends for private schools. Regardless of the school type, these trends are very similar across early and late MGNREGA districts. Thus, an independent increase in demand for private schools is unlikely to be driving our results.

\subsubsection{Migration and Population Changes}

Anecdotal evidence suggests that MGNREGA reduced out-migration from poor districts to richer ones. To the extent that this does not change the composition of the districts 
before and after the program, this should not be a concern for our analysis. One concern is that we show changes in enrollment but not enrollment rate. We address this using the baseline district population from the Census of India 2001 and interacting it with time indicators to control flexibly for trends in population. If MGNREGA attracts migrants into districts, then the results could be driven by changes in population. Across district migration in India is very low (Topolova, 2010). Land markets are thin so households do not tend to permanently migrate, at least in the short run. Finally, if migration were responsible for the changes in enrollment, then we would expect similar sized effects for primary and upper primary grades and individual classes within these grades. As shown in Tables 3.4 and 3.5 and Tables 3.10 and 3.11, the size of the effect is much larger in primary school with no effect discerned in upper primary school. It seems implausible that households with children only in specific age groups would migrate into the MGNREGA districts to find work, especially since the early phase districts were poorer and have worse infrastructure. It is less likely that our results are confounded by the changes in population due to massive in-migration. ${ }^{25}$

\subsection{Caveats}

We do not have age specific population data. Ideally, we should normalize our results by this age specific population data. But since we do not have this data, we control for trends in district specific total population. In addition, as argued above, any changes in population growth cannot explain all our findings. ${ }^{26}$ But our results should be interpreted in light of this limitation.

\subsection{Conclusion}

We use the phased roll-out of MGNREGA to estimate the impact of safety net programs such as employment guarantee schemes on schooling outcomes of children. Our findings have important policy implications. We find that the enrollment in primary grades increases less due to the program. Our results show that the program induces younger

\footnotetext{
25 Also, anecdotal evidence suggests that beneficiaries use the employment guarantee in summer months. One concern might be that schools are already closed for vacation. However, schools in India generally close for only around 40 days and the timing varies spatially ranging from mid-May to end of June in North to mid-June to end-July in the South. Also, Imbert and Papp (2015) show that the program impacts rural wages in a general equilibrium framework. Given that there is an incentive to substitute for adult labor year round.

${ }^{26}$ We also get similar results using log specifications.
} 
children to substitute for adults in employment outside the house. Among those already enrolled, school pass rate with more than 60 percent marks declines for grade 7 but not grade 5 students. Hence, these older children are influenced on the intensive margin. Unless state or market institutions increase support to offset this perverse effect, such safety programs are not likely to improve the schooling outcomes of children. Social welfare programs are increasingly becoming reliant on micro-ordeals like work for benefits. Our study shows that these programs can have unintended consequences for children of the beneficiaries, which are not accounted for in welfare calculations. 


\section{Bibliography}

Afridi, F. , A.p Mukhopadhyay, and S. Sahoo (2012), "Female Labour Force Participation and Child Education in India: The Effect of the National Rural Employment Guarantee Scheme”, IZA Discussion Paper No. 6593.

Alatas, V., A. Banerjee, R. Hanna, B. Olken, R. Purnamasari, and M. Wai-poi (2013), "Ordeal Mechanisms In Targeting: Theory And Evidence From A Field Experiment In Indonesia", NBER working paper 19127.

Angelucci, M. and G. Giorgi (2009), "Indirect Effects of an Aid Program: How do Cash Injections Affect Ineligibles' Consumption?", American Economic Review, Vol. 99 (1), pp.486-508.

Ardington, C., A. Case, and V. Hosegood (2009), "Labor Supply Responses to Large Social Transfers: Longitudinal Evidence from South Africa," American Economic Journal: Applied Economics, Vol. 1 (1), pp. 22-48.

Azam, M. (2012), " The Impact of Indian Job Guarantee Scheme on Labor Market Outcomes: Evidence from a Natural Experiment," IZA Discussion Paper.

Basu, A. K. (2011), "Impact of Rural Employment Guarantee Schemes on Seasonal Labor Markets: Optimum Compensation and Workers' Welfare" IZA Discussion Paper No. 5701.

Basu, A. K., N. H. Chau, and R. Kanbur (2009), “ A Theory of Employment Guarantees: Contestability Credibility and Distributional Concerns," Journal of Public economics, Vol. 93 (4), pp. 482-497.

Basu, K. (1999), "Child Labor: Cause, Consequence, and Cure, with Remarks on International Labor Standards," Journal of Economic Literature, vol. 37(3), pp. 1083-1119.

Basu, K. and P. H. Van(1998), "The Economics of Child Labor", American Economic Review, vol. 88, pp. 412-27.

Berg, E., S. Bhattacharyya, R. Durgam, and M. Ramachandra (2012), " Can Rural Public Works Affect Agricultural Wages? Evidence from India", CSAE Working Paper 2012-05.

Bernstein, Barton J. (1968), " The New Deal: The Conservative Achievements of Liberal Reform" Towards a New Past: Dissenting Essays in American History, edited by Bernstein, Barton J., New York: Pantheon Books. 
Besley, T. and S. Coate (1992), "Workfare versus Welfare: Incentive Arguments for Work Requirements in Poverty-Alleviation Programs," American Economic Review, Vol. $82(1), 249-261$.

Bhatty, K. (2006) "Employment guarantee and child rights", Economic and Political Weekly, pp. 1965-1967.

Blaug, M. (1963), "The Myth of the Old Poor Law and the Making of the New," Journal of Economic History Vol. 23, 151 - 184.

Blaug, M. (1964), " The Poor Law Report Re-examined," Journal of Economic History Vol. 24, $229-245$.

Datt, G. and M. Ravallion (1994), "Transfer Benefits from Public-Works Employment: Evidence for Rural India,” The Economic Journal,Vol. 104 (427), 1346-1369.

Desia, S., Dubey,A., Vanneman,R. and R. Banerji (2008), "Private Schooling in India: A New Educational Landscape", India Human Development Survey Working Paper 11.

Dreze, J. and A. Goyal (2003), " The future of mid-day meals, Economic and Political Weekly November 1, 4673-4683.

Duflo, E. (2003), "Grandmothers and Granddaughters: Old-Age Pensions and Intrahousehold Allocation in South Africa", World Bank Economic Review, Vol. 17, pp. $1-25$.

Dupas, P., V. Hoffmann, M. Kremer, and A. Zwane (2013), "Micro-ordeals and preventive health products: Evidence on short-term take-up and habit formation".

Edmonds, E. (2006), "Child Labor and Schooling Responses to Anticipated Income in South Africa," Journal of Development Economics, vol. 81(2), pp. 386-414.

Edmonds, E. and N. Pavnick (2004), "The Effect of Trade Liberalization on Child Labor," Journal of International Economics.

Edmonds,E. (2005), "Does Child Labor Decline with Improving Economic Status?," Journal of Human Resources, vol. 40(1).

Imbert, C. and J. Papp (2015), "Labor market effects of social programs: Evidence from Indias Employment Guarantee" American Economic Journal:Applied Economics, Vol. 7(2), pp. 233-263 
Institute of Applied Manpower Research (2009), " All-India Report on Evaluation of NREGA: A Survey of Twenty Districts".

Kremer, M. and K. Muralidharan (2007) , "Public and Private Schools in Rural India", Harvard University unpublished manuscript.

Jacoby, H. and E. Skoufias (1997), "Risk, Financial Markets, and Human Capital in a Developing Country", Review of Economic Studies, vol. 64, pp. 311-335.

Jayachandran, S., J. Cunha, and G. D. Giorgi (2010), " The Price Effect of Cash Versus In-Kind Transfers", CEPR Development Economics Workshop Working Paper.

Jensen, R. (2010), "The (Perceived) Returns to Education and the Demand for Schooling," Quarterly Journal of Economics, Vol. 125(2), pp. 515-548.

Kesselman, Jonathan R. (1978), "Work relief programs in the Great Depression" Creating Jobs: Public Employment Programs and Wage Subsidies, edited by Palmer, J.L., Washington, D.C.: Brookings Institution.

Khera, R. (Ed.) (2011). The Battle for Employment Guarantee. Oxford University Press.

Ministry of Rural Development (2008a), “Annual Report (2007-2008)”, Government of India.

Ministry of Rural Development (2008b), "The National Rural Employment Guarantee Act 2005 (NREGA): Operational Guidlines 2008", Government of India.

Mukherjee, D. and U. B. Sinha (2013), "Understanding NREGA: A Simple Theory and Some Facts" Human Capital and Development: The Indian Experience, Ch 7, 103 - 128.

Murgai, R. and M. Ravallion (2005), " Employment Guarantee in Rural India: What Would It Cost and How Much Would It Reduce Poverty?" Economic and Political Weekly, Vol.40 (31), 3450-3455.

Nichols, A. and R. Zeckhauser (1982), "Targeting Transfers through Restrictions on Recipients," American Economic Review, Papers and Proceedings, Vol. 72, pp. 372-7.

Niehaus, P. and S. Sukhtankar (2009), "Corruption Dynamics: The Golden Goose Effect", BREAD Working Paper 223.

Psacharopoulos, G. (1997), "Child Labor versus Educational Attainment: Some Evidence from Latin America", Journal of Population Economics, vol. 10. 
Planning Commision (2003), "Identification of Districts for Wage and Self employment programmes".

Qian, Nancy (2008), "Missing Women and the Price of Tea in China: The Effect of Sex-Specific Income on Sex Imbalance", The Quarterly Journal of Economics, Vol. 123 $(3)$.

Rogers, C. and K. Swinnerton, K. (2004), "Does Child Labor Decrease when Parental Incomes Rise", Journal of Political Economy, vol. 112.

Rosenzweig, M. and R. Evenson (1977), "Fertility, Schooling and the Economic Contribution of Children in Rural India: An Econometric Analysis", Econometrica, vol. 45, 1065-1079.

Ravi, S. and M. Engler (2009), "Workfare in Low Income Countries: An Effective Way to Fight Poverty? The Case of NREGS in India" Working paper.

Ravallion, M. (1991), "Reaching the Rural Poor Through Public Employment: Arguments, Evidence, and Lessons from South Asia," World Bank Research Observer Vol. 6(2), pp. 153175 .

Ray, R. (2000), "Child Labor, Child Schooling and Their Interaction with Adult Labor : Empirical Evidence for Peru and Pakistan", World Bank Economic Review, vol. 14.

Schultz, T. P. (2004), "School Subsidies for the Poor: Evaluating the Mexican Progresa Poverty Program", Journal of Development Economics, vol. 74.

Shastry, G. (2012), "Human Capital Response to Globalization: Education and Information Technology in India," Journal of Human Resources, Vol. 47(2), pp. 287-330.

Skoufias, E. (1993), "Labor Market oppurtunities and Intrafamily time allocation in Rural households in South Asia," Journal of Development Economics, Vol. 40(2), pp. $277-310$.

Skoufias, E. and Parker, S. (2003), "The Impact of Progressa on Child Work and Schooling" in P.F. Orazem, G. Sedlacek and Z. Tzannatos (eds.; forthcoming) 'Child Labor and Education in Latin America'. Washington DC: InterAmerican Development Bank and World Bank.

Sudarshan, R. (2011), “India's National Rural Employment Guarantee Act: women's participation and impacts in Himachal Pradesh, Kerala and Rajasthan" , CSP Research Report 06. 
Chapter 3. The Unintended Consequences of Employment-Based Safety Net Programs (co-authored with Sheetal Sekhri)

Sharma, A. (2009), " NCAER-PIF Study on Evaluating Performance of National Rural Employment Guarantee Act," National Council of Applied Economic Research.

Thomas, D. (1994), "Like Father Like Son; Like Mother Like Daughter: Parental Resources and Child Height", The Journal of Human Resources, Vol. 29, pp. 950-988.

Topalova, P. (2010), " Factor Immobility and Regional Impacts of Trade Liberalization: Evidence on Poverty and Inequality from India, American Economic Journal: Applied Economics, Vol. 2 (4), pp. 1-41. 
Chapter 3. The Unintended Consequences of Employment-Based Safety Net Programs (co-authored with Sheetal Sekhri)

Figure 3.1: Districts in Different Phases of NREGA

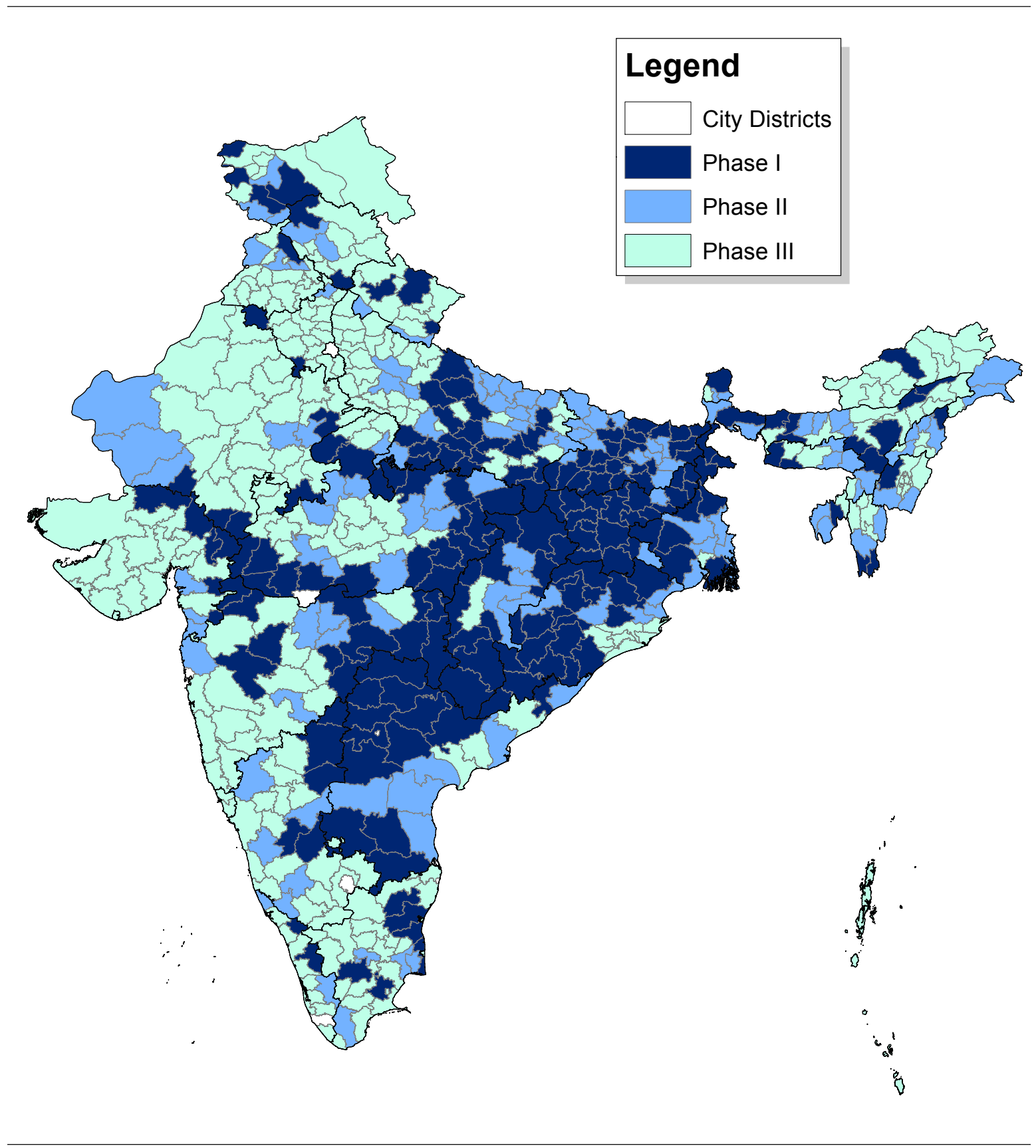


Chapter 3. The Unintended Consequences of Employment-Based Safety Net Programs (co-authored with Sheetal Sekhri)

Figure 3.2: Total Enrollment by Phases

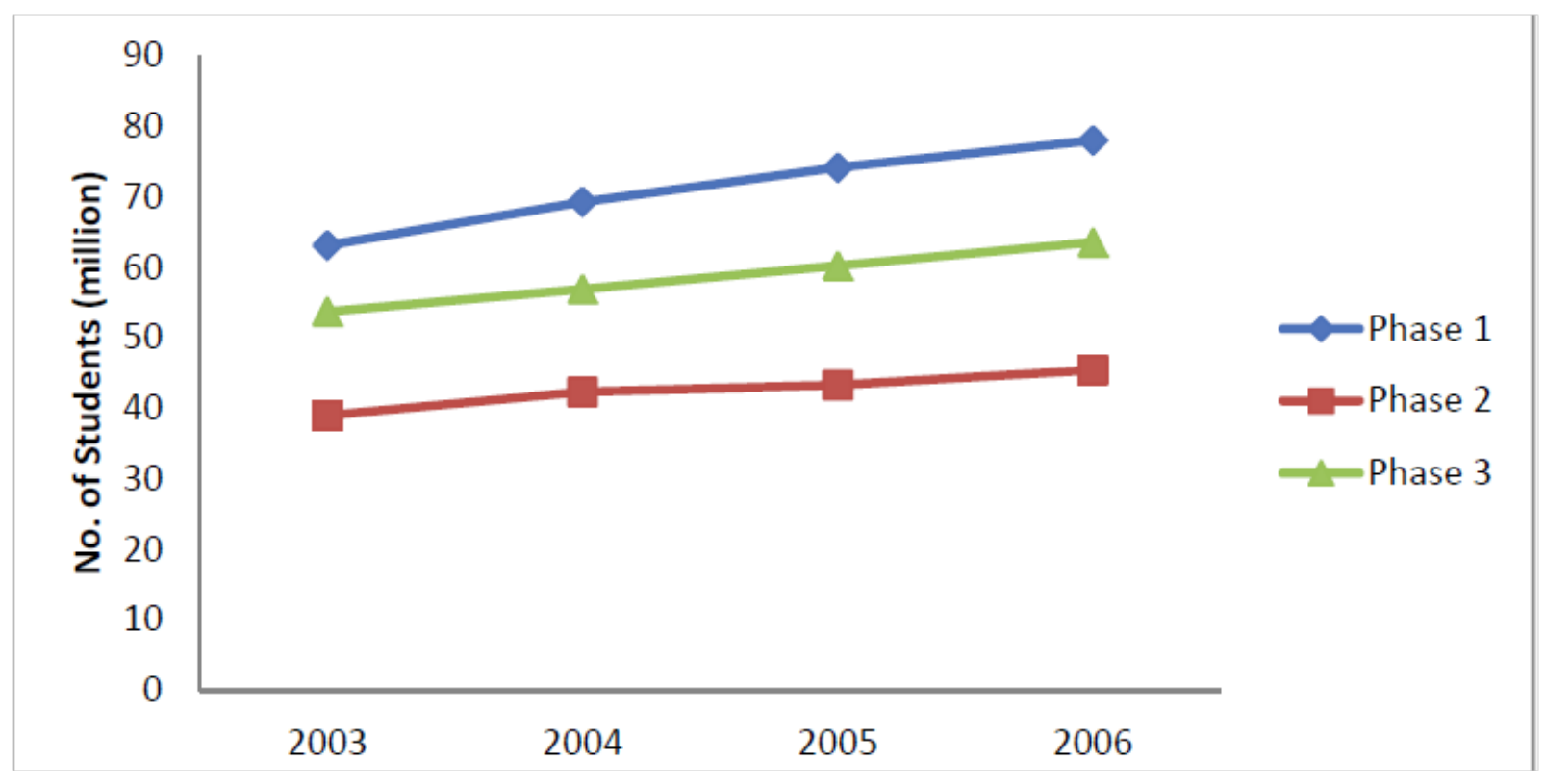

Figure 3.3: Total Number of Schools by Phases

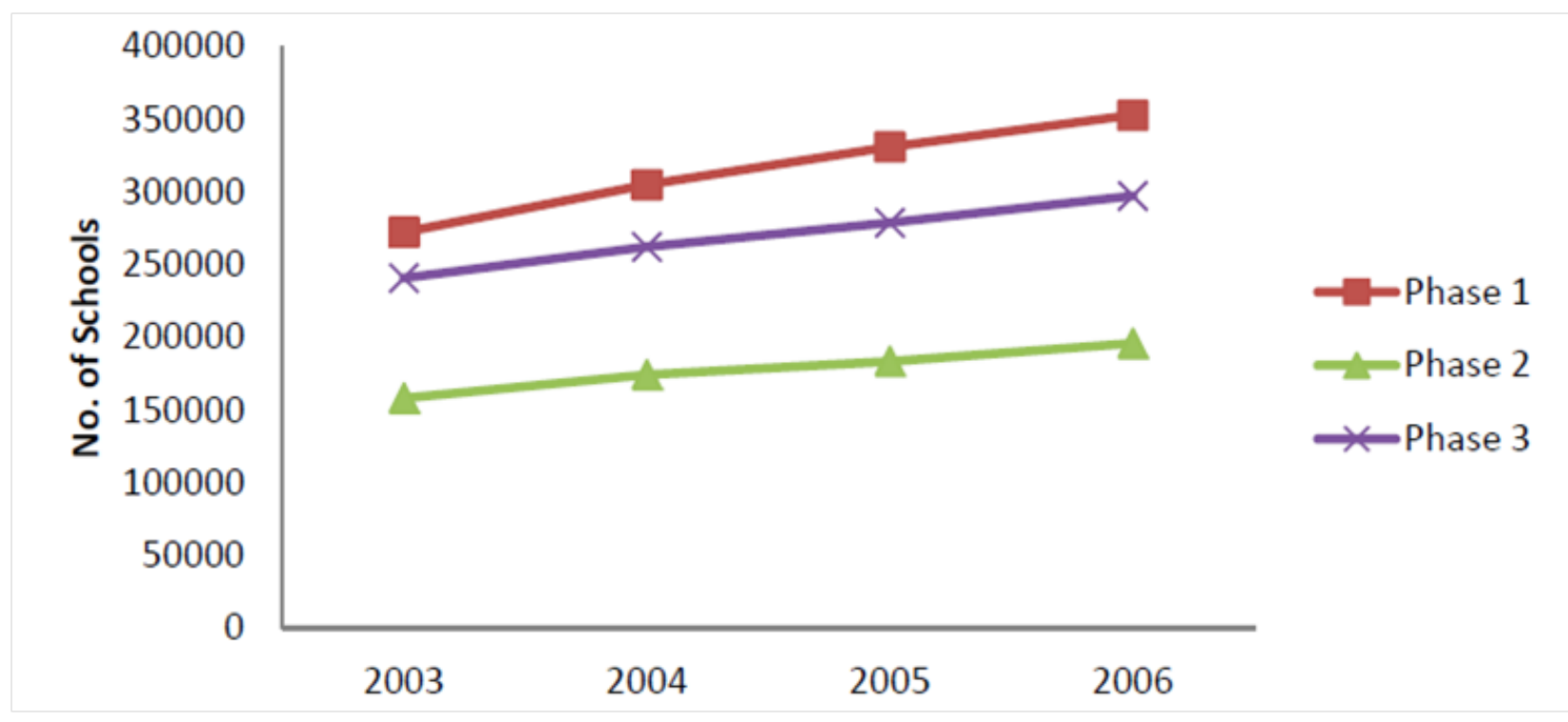


Figure 3.4: Year Wise Impact

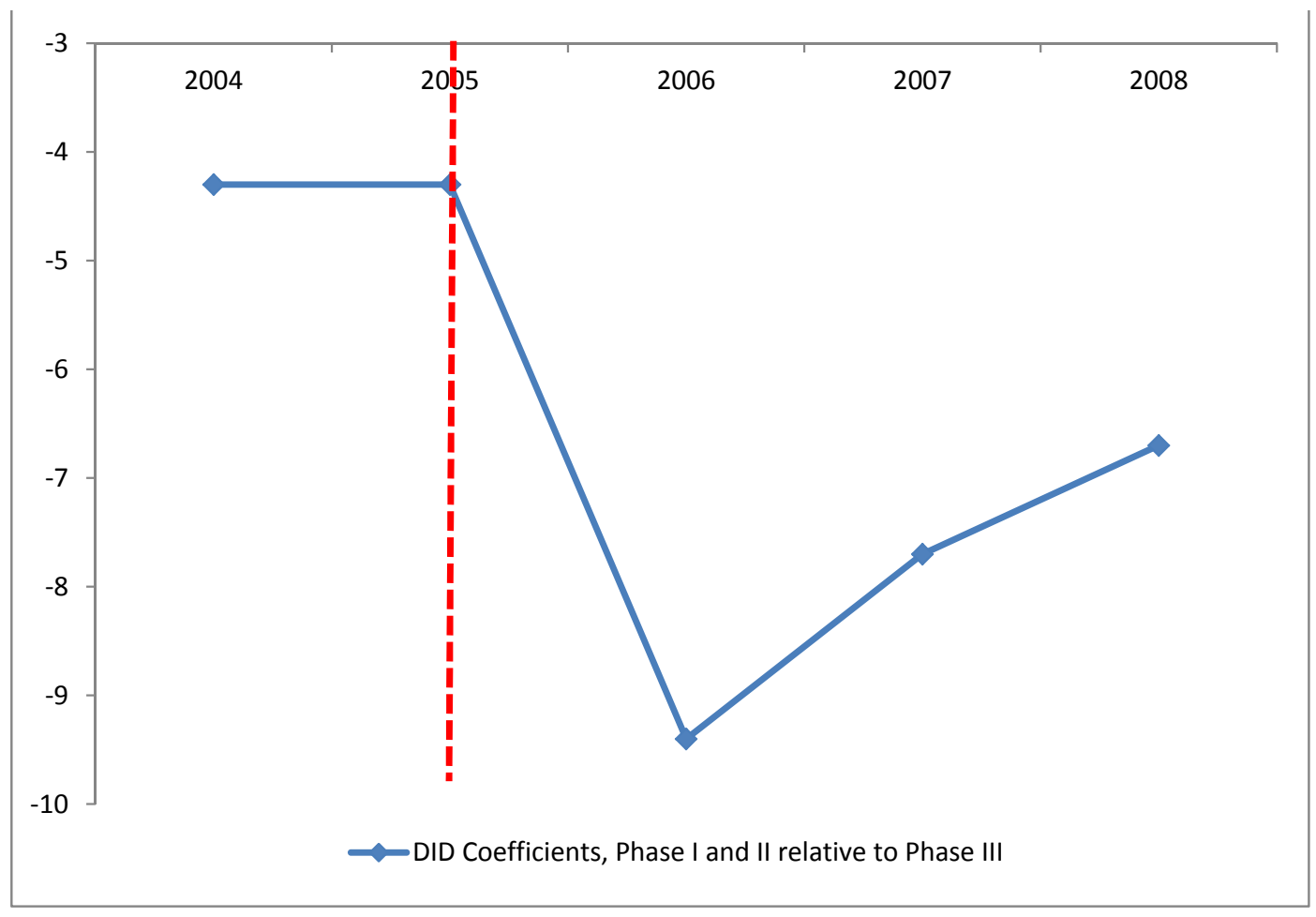

Note: The figure plots year by year DID coefficients relative to baseline year 2003. NREGA was introduced in February, 2006. We observe a significant relative decline in enrollment in 2006 in early NREGA districts relative to later ones. Subsequently, the enrollment is lower compared to pre-program years. 
Figure 3.5: Phase Wise Expansion in Different Types of Schools
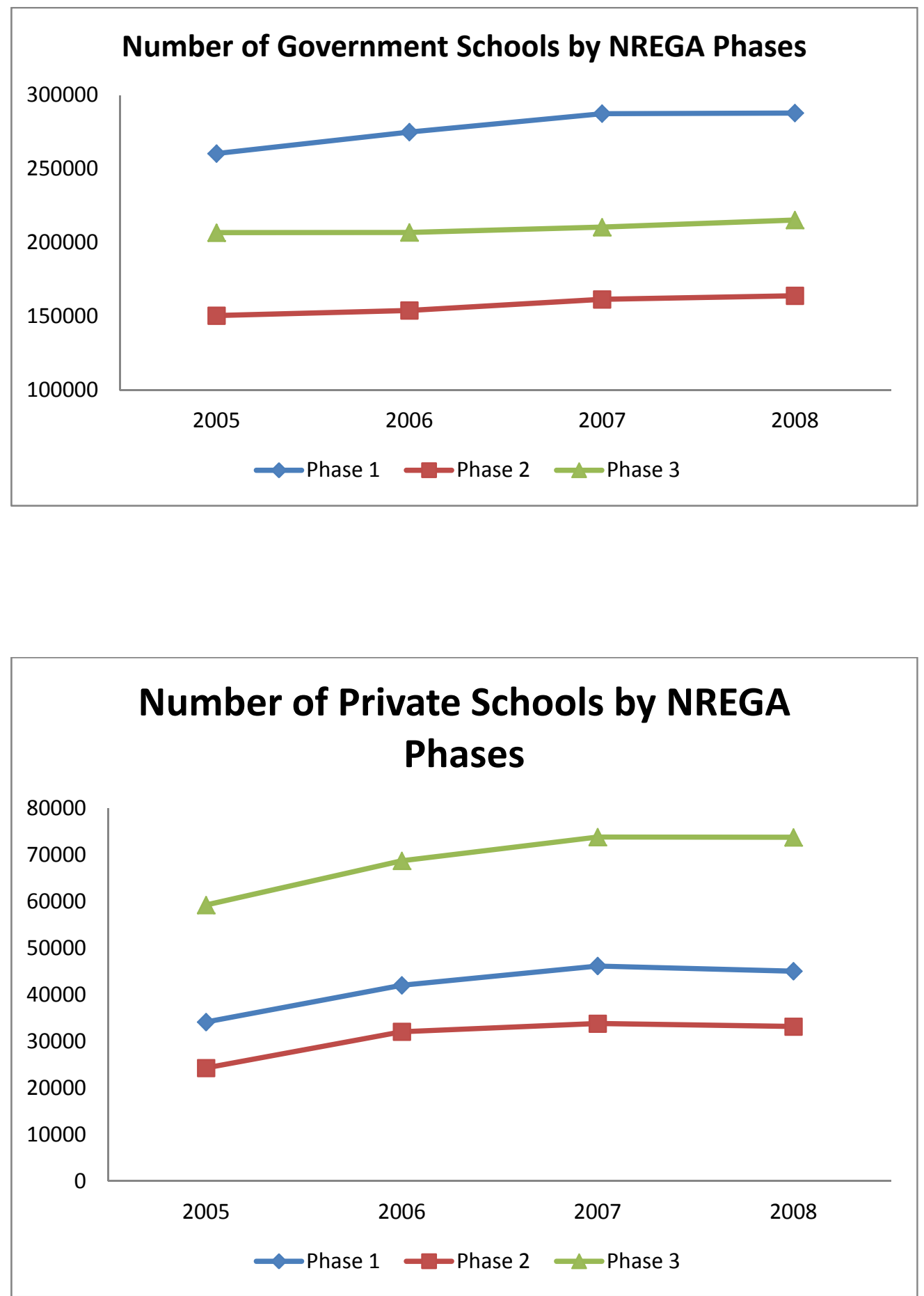


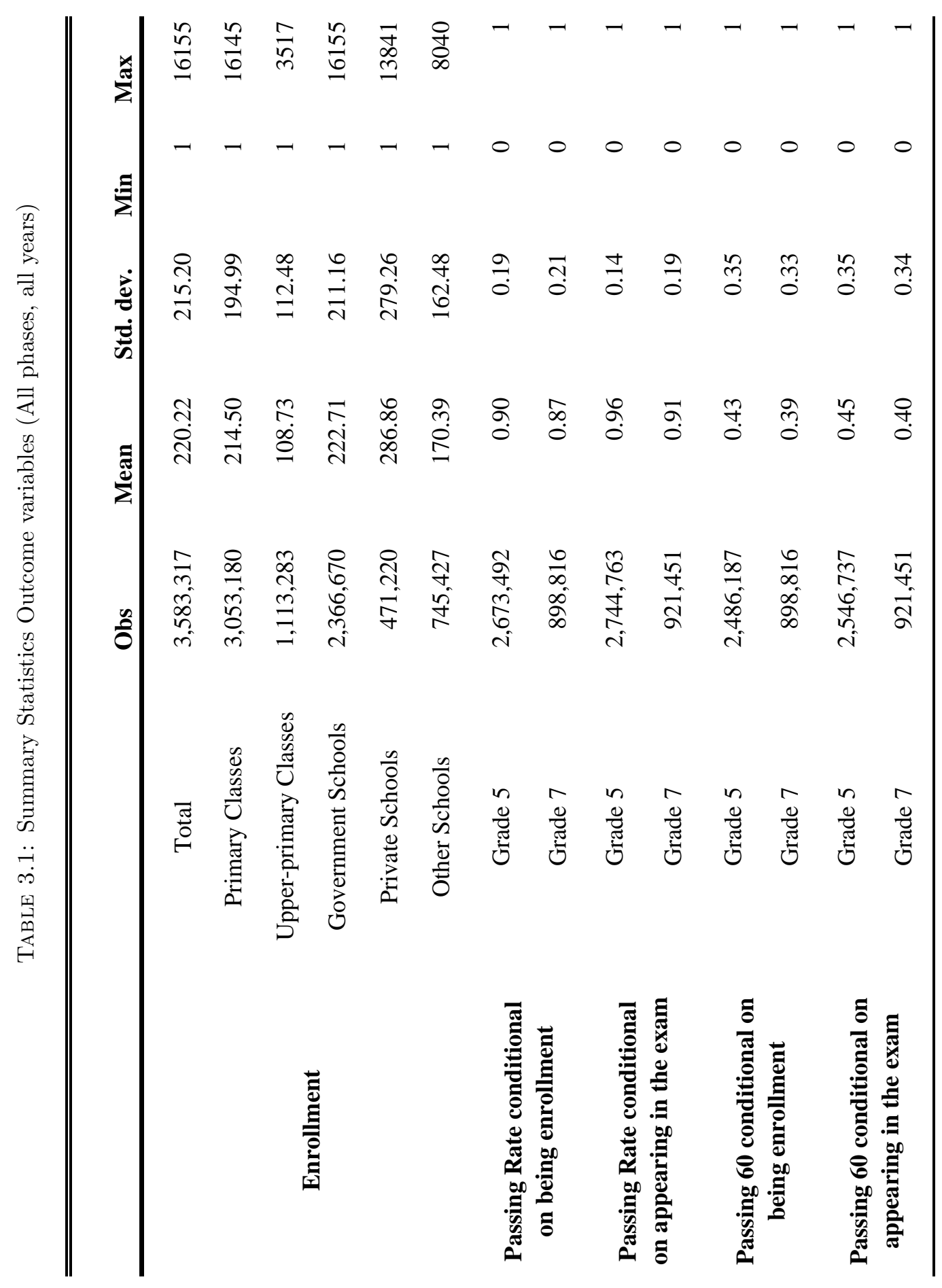




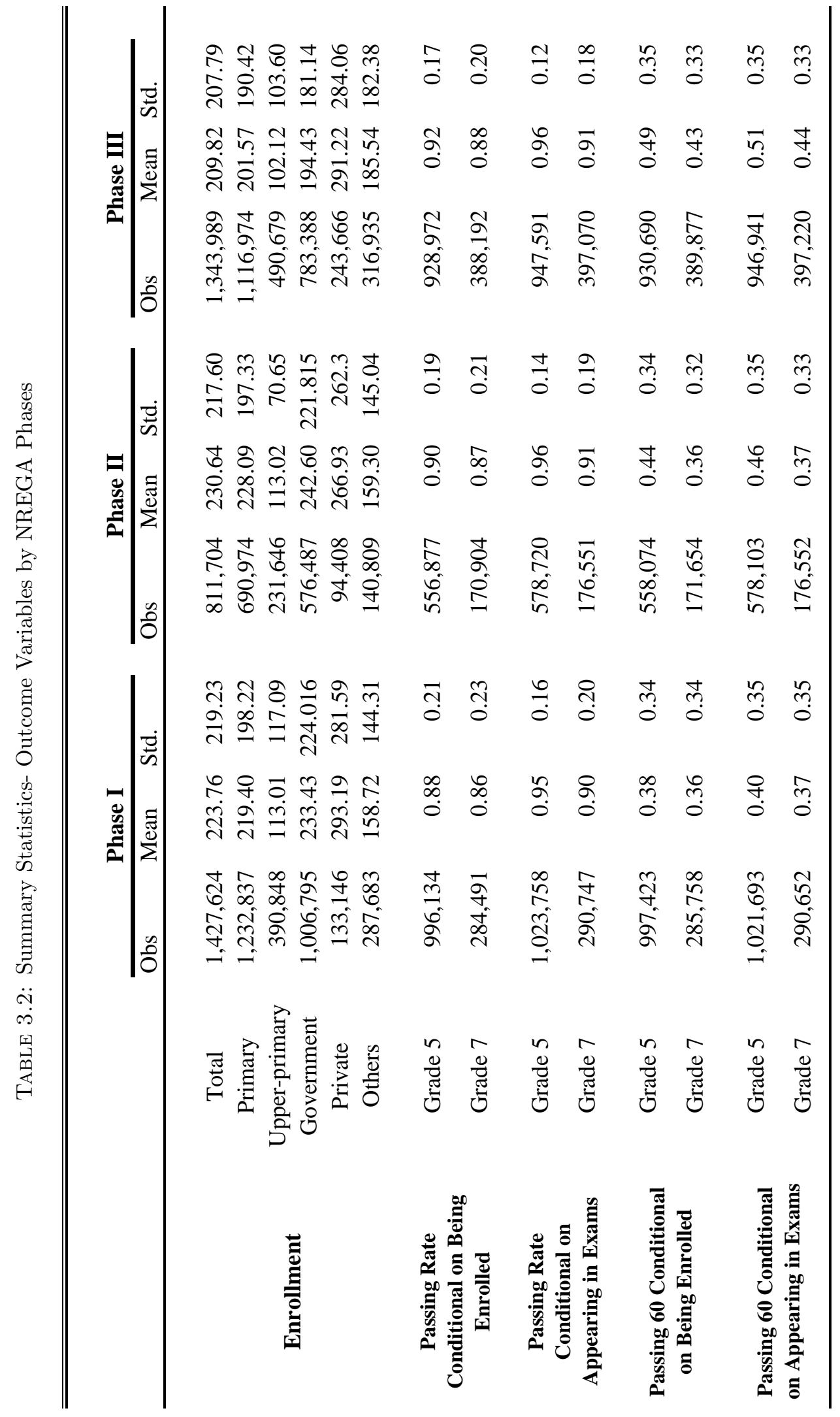




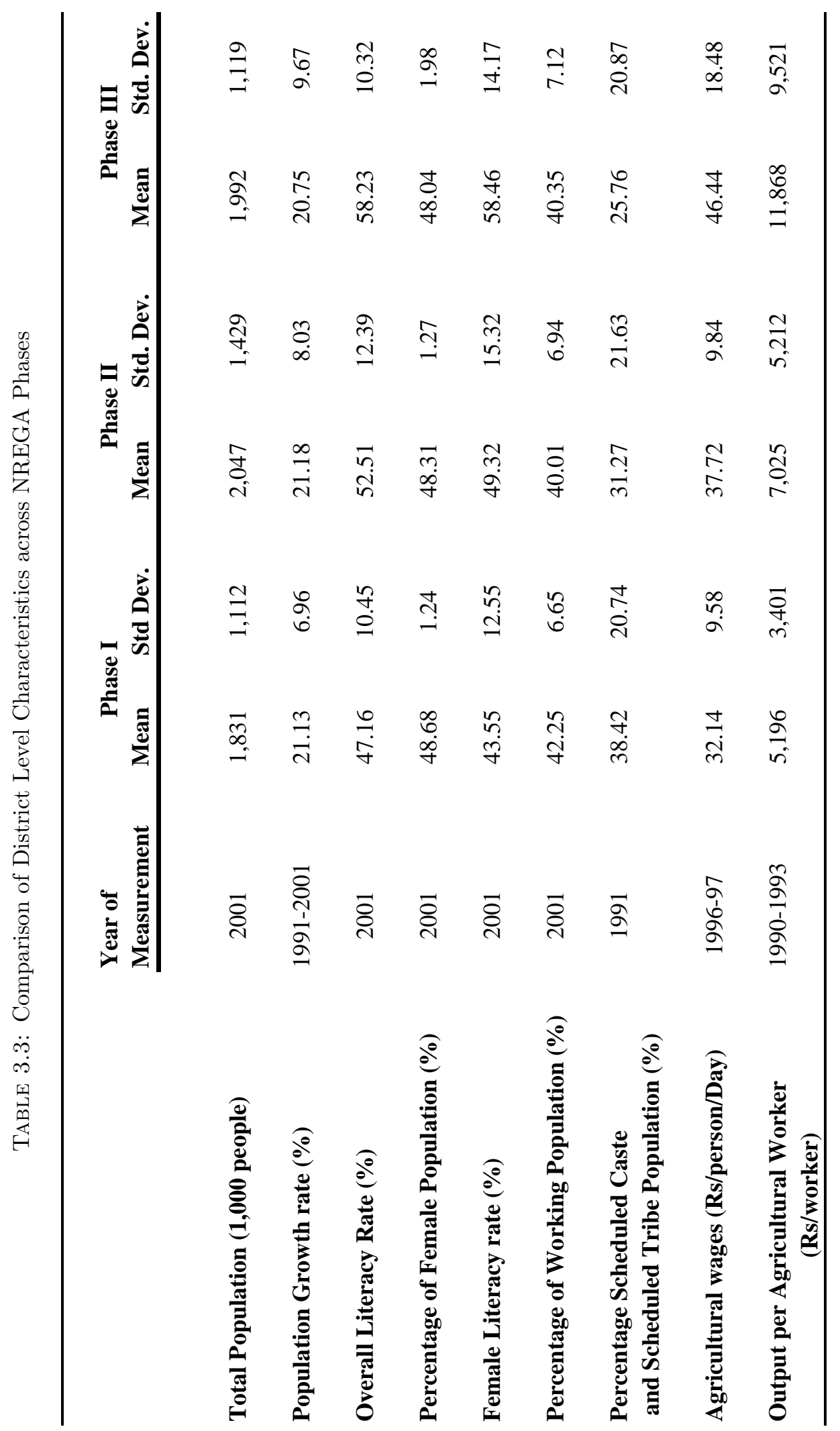




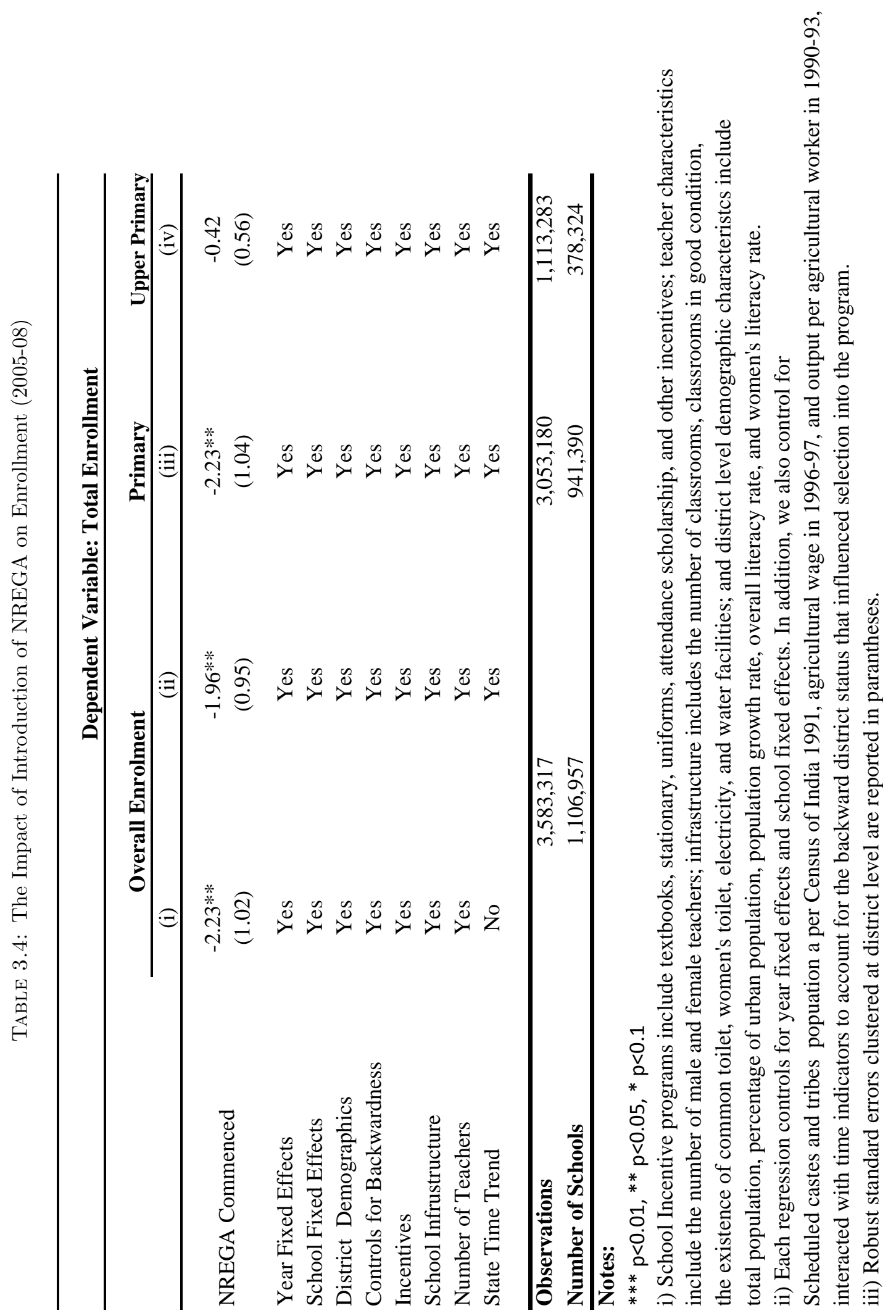




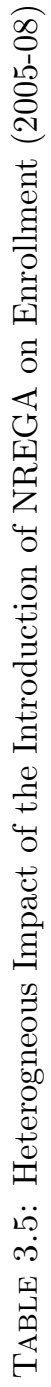

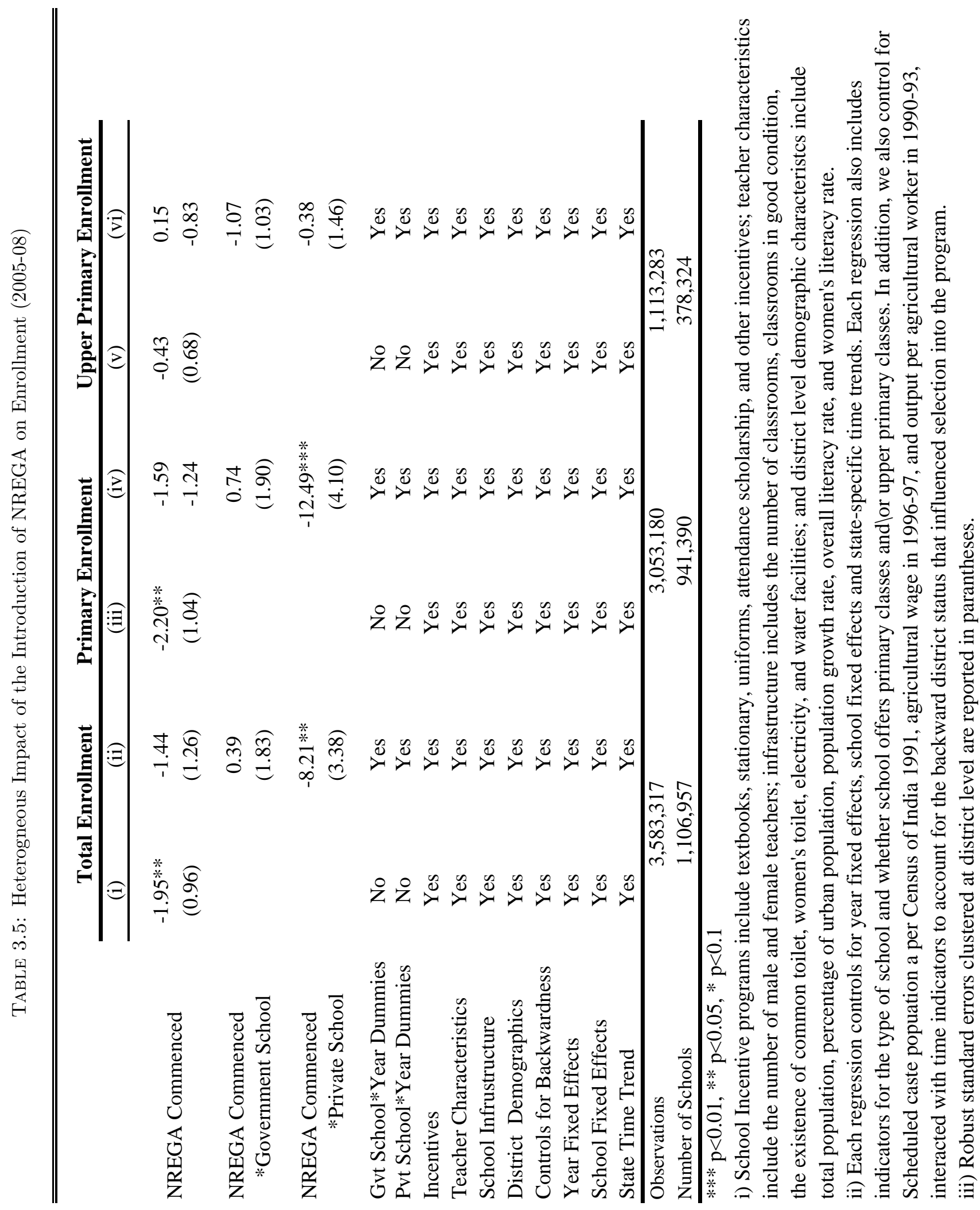


Chapter 3. The Unintended Consequences of Employment-Based Safety Net Programs (co-authored with Sheetal Sekhri)

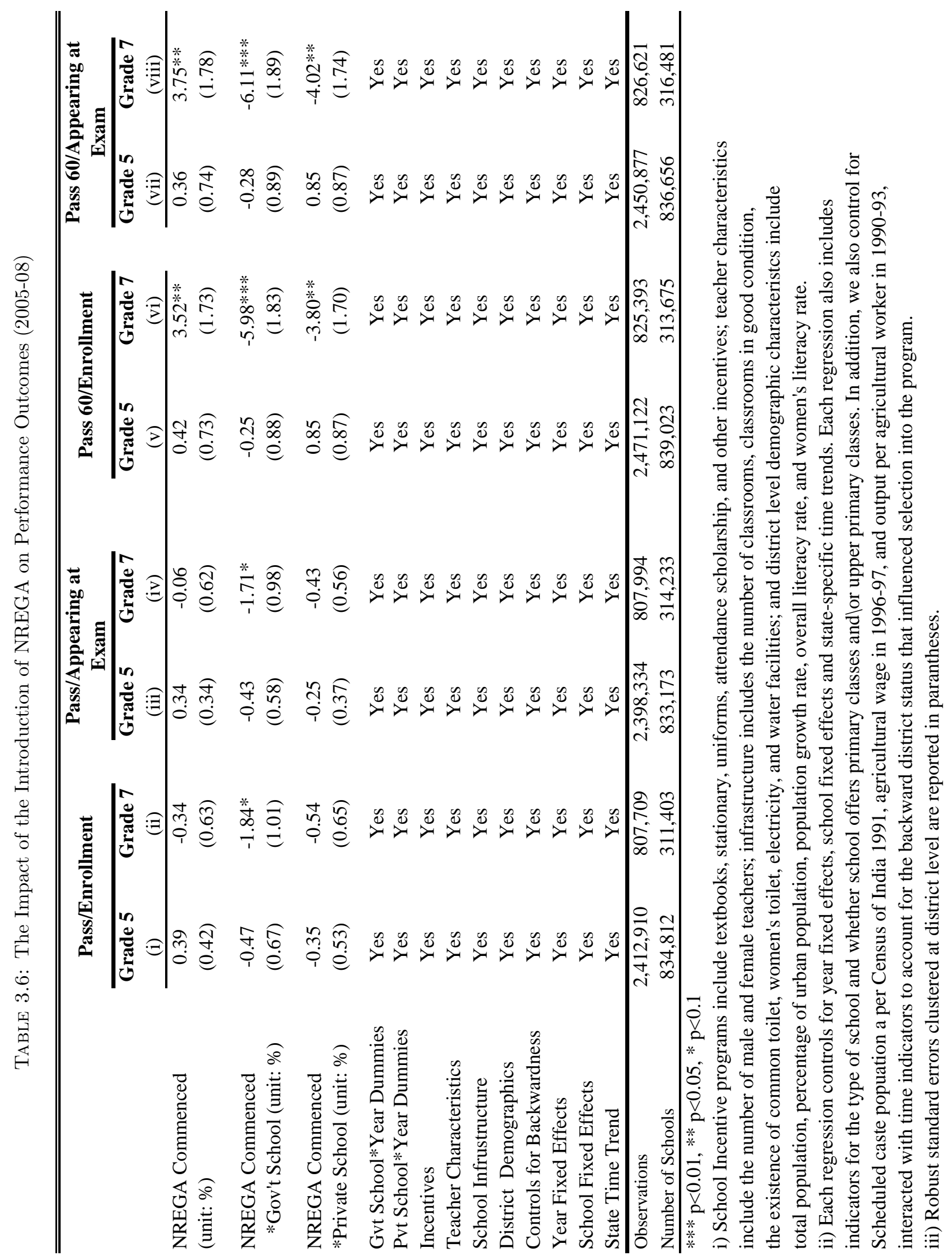




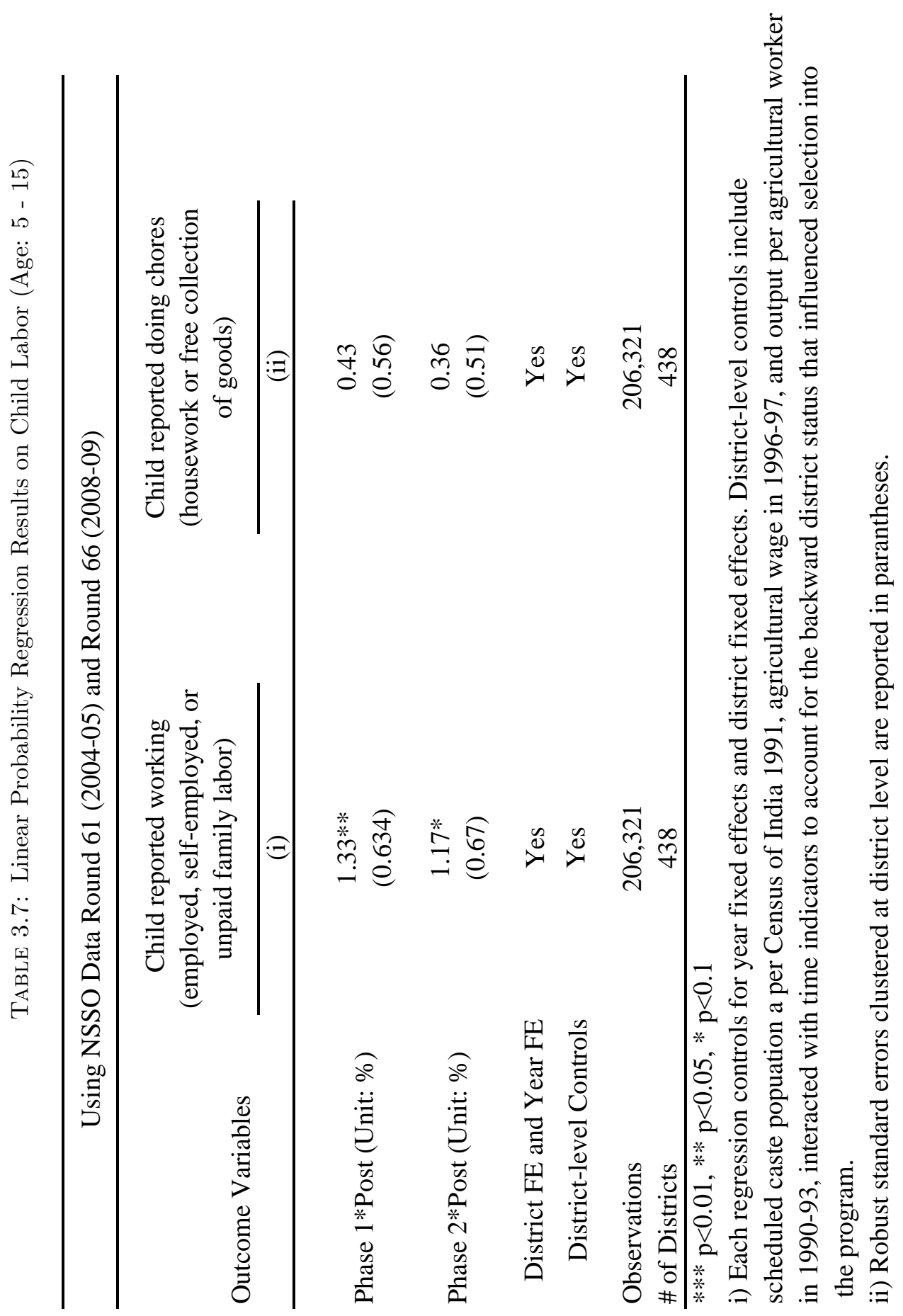




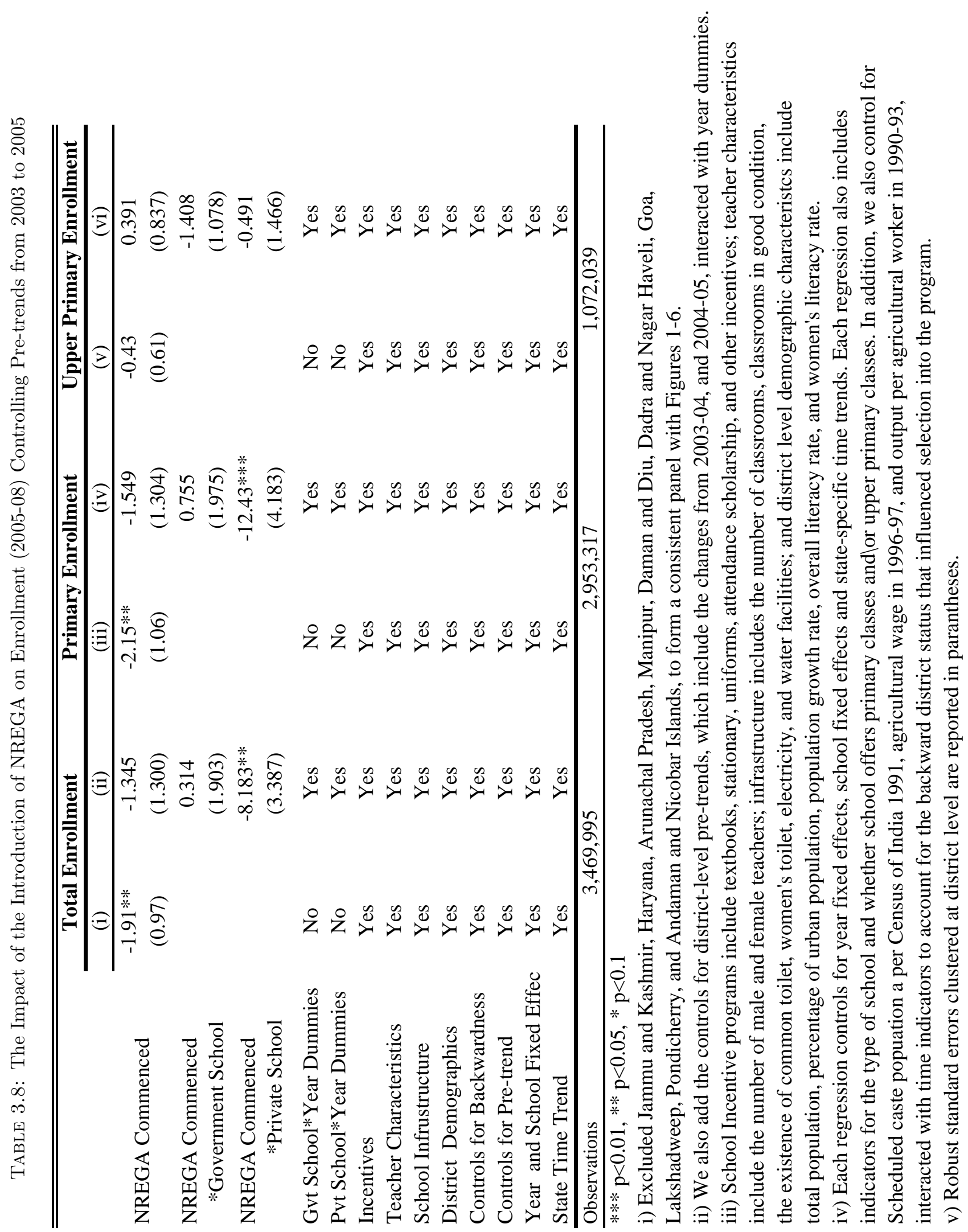




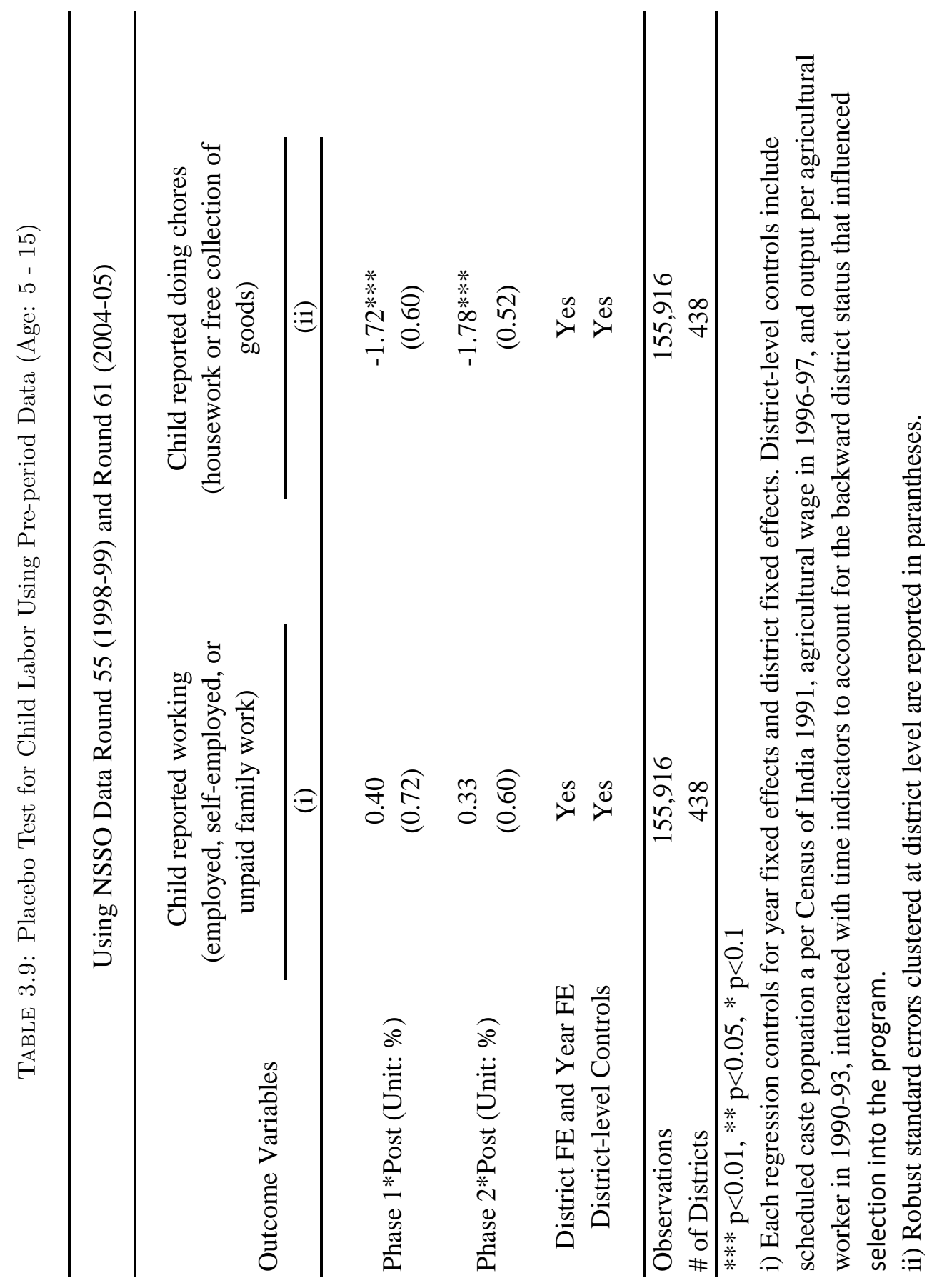




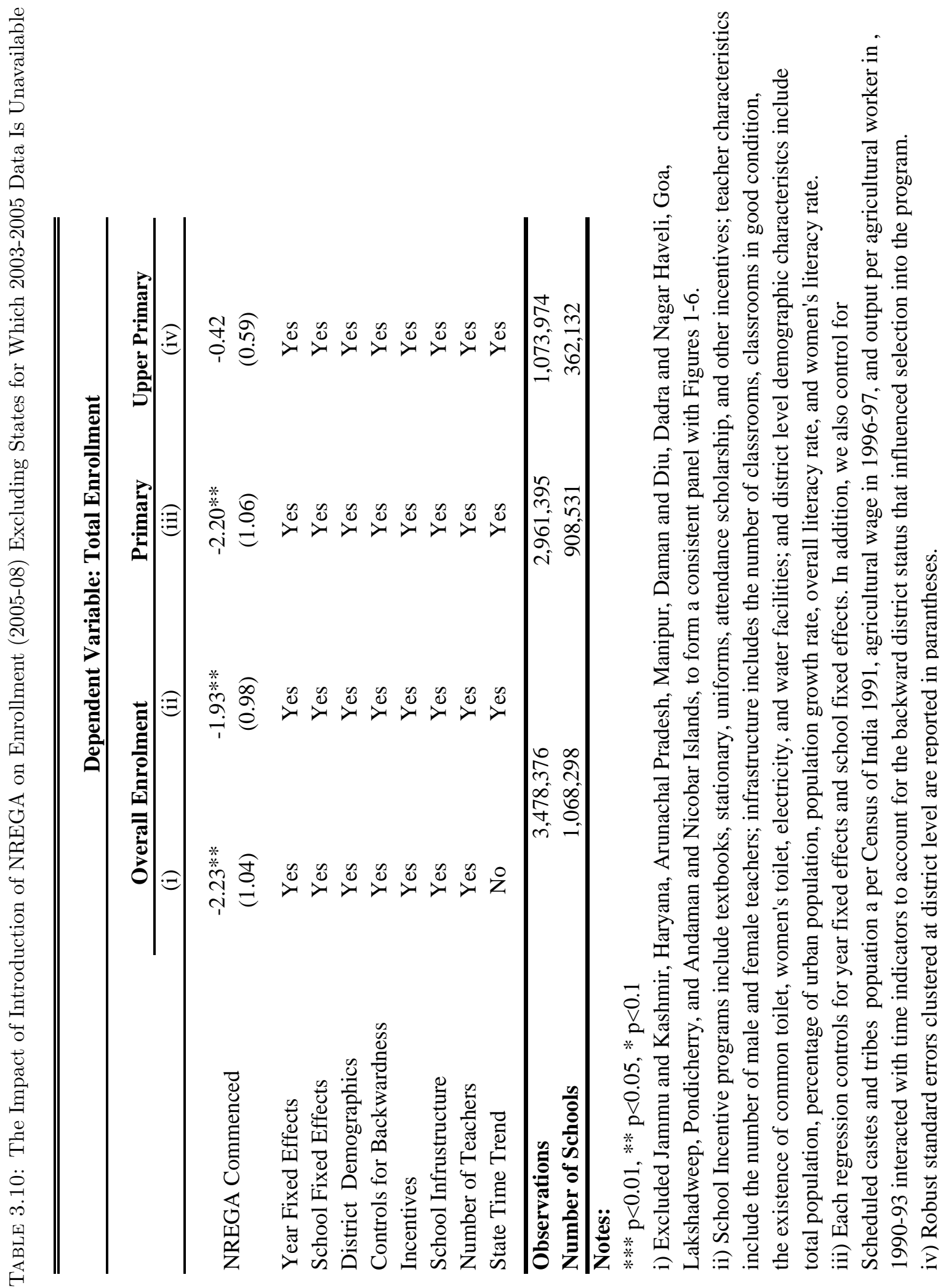




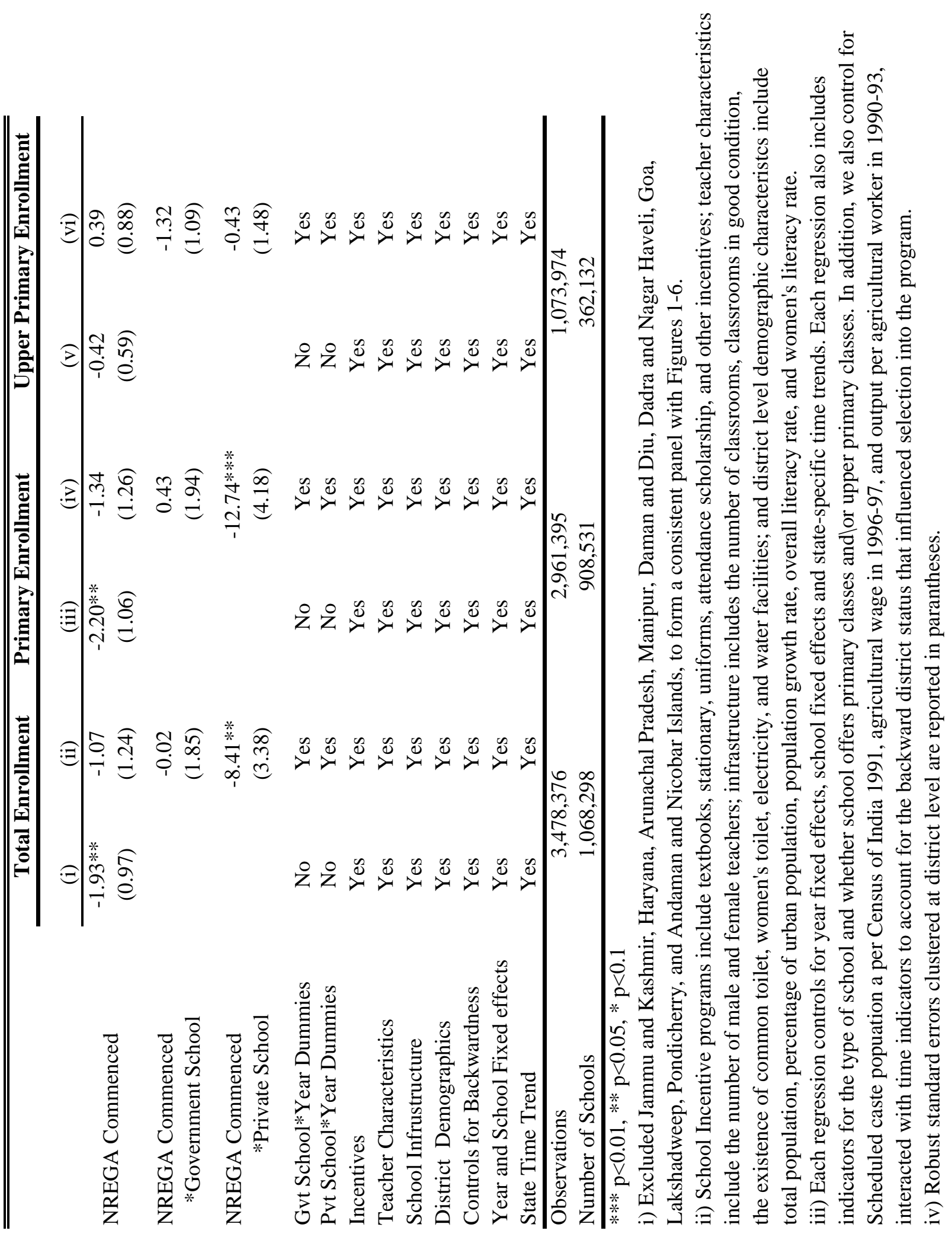




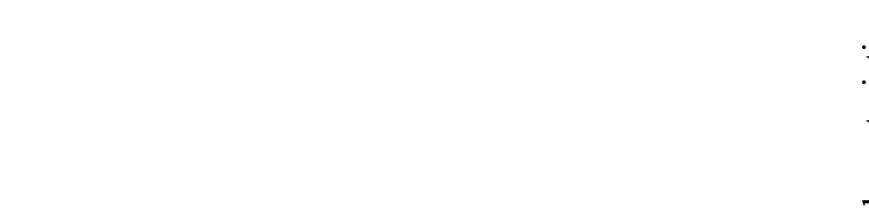

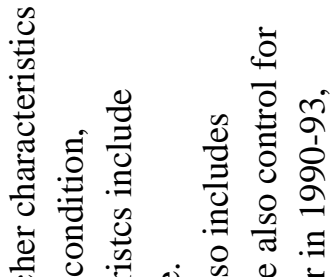

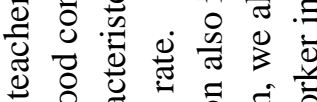
i d

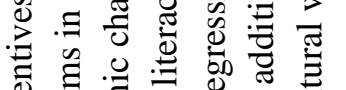

记

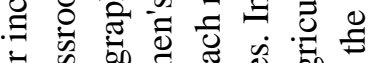
戈

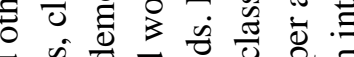

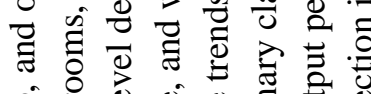

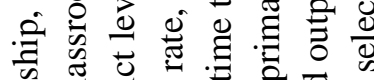

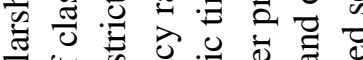

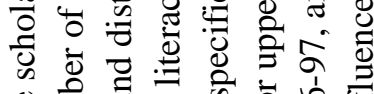

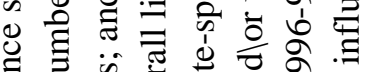

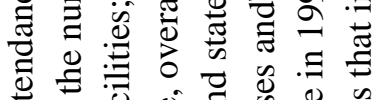
๘ ต

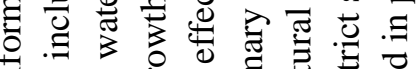

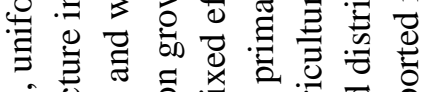

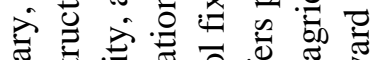

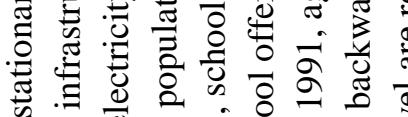

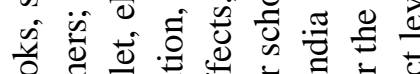

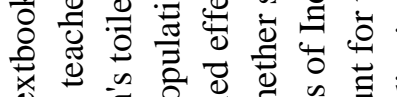

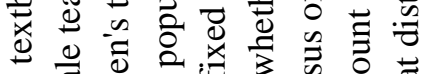

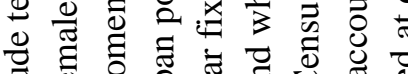
তี v.

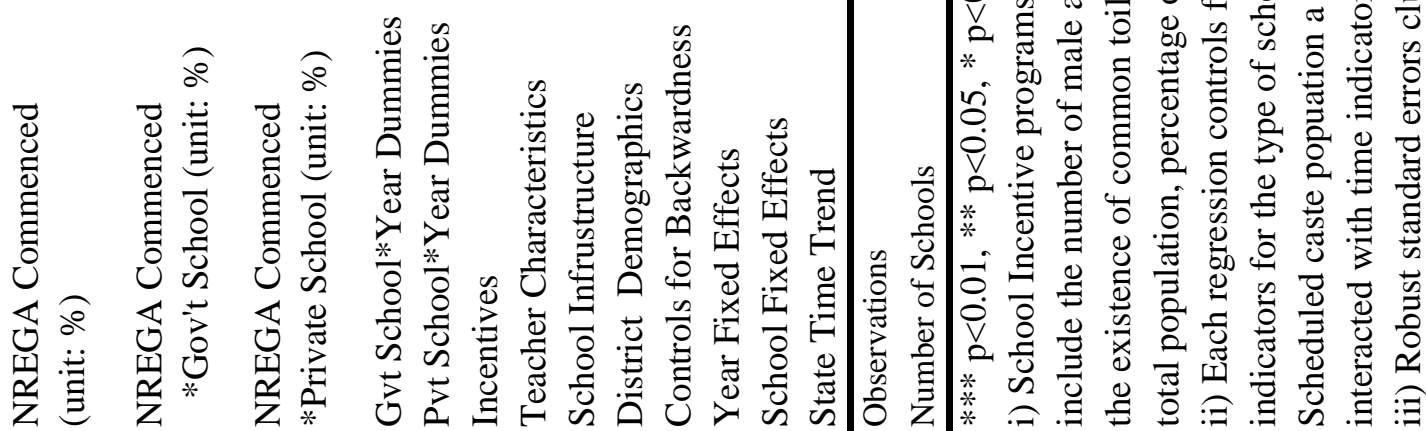

